\title{
Selected quantitative studies of patents in standards
}

\author{
Rudi Bekkers $^{*}, 1$, Justus Baron ${ }^{\ddagger}$, Arianna Martinelli ${ }^{\S}$, Yann Ménière ${ }^{\dagger}$, \\ Önder Nomaler ${ }^{*}$, Tim Pohlmann ${ }^{\dagger}$
}

* School of Innovation Sciences, Eindhoven University of Technology, The Netherlands

$\dagger$ Centre d'Economie Industrielle MINES ParisTech, France

* Searle Center on Law, Regulation, and Economic Growth, Northwestern University School of Law, Chicago, US

$\S$ Scuola Superiore Sant'Anna, Pisa, Italy

1 Corresponding author: r.n.a.bekkers@tue.nl

Hitotsubashi University (Tokyo), Institute of Innovation Research, PIE/CIS Working Paper 626

June 2014

The work published in the report was (partly) financed by the European Commission, Directorate-General for Enterprise and Industry (ENTR/90/PP/2011/FC). The information and views set out in this publication are those of the author(s) and do not necessarily reflect the opinion of the Commission. The Commission does not guarantee the accuracy of the data included in this publication. Neither the Commission nor any person acting on the Commission's behalf may be held responsible for the use which may be made of the information contained therein. 


\section{Preface}

This report contains a number of empirical studies on patents in standards that were executed as part of a larger study commissioned by the European Commission, Directorate-General for Enterprise and Industry. This larger study was published in April 2014 as:

Bekkers, R., Birkman, L., Canoy, M., de Bas, P. Lemstra, W. , Ménière, Y., Sainz, I., van Gorp, N. , Voogt, B., Zeldenrust, R., Nomaler, N., Baron, J., Pohlman, T., Martinelli, A. (2014). Patents and Standards: A modern framework for IPR-based standardisation. A study prepared for the European Commission Directorate-General for Enterprise and Industry. Brussels: European Commission. ISBN 978-92-79-35991-0. DOI: 10.2769/90861. Available at http://ec.europa.eu/enterprise/policies/industrial-competitiveness/industrialpolicy/intellectual-property-rights/patents-standards

Because we believe that these underlying studies may have merit in itself, we decided to publish them here as a separate report.

We would like to thank the EC for their funding, to thank our OEIDD database co-creators Timothy Simcoe (Boston University and NBER) and Christian Catalini (University of Toronto / MIT Sloan School of Management) for their willingness to make an early version of the database available for this study, and to thank Hitotsubashi University in Tokyo for providing time and facilities to finalize this report. 


\section{Table of contents}

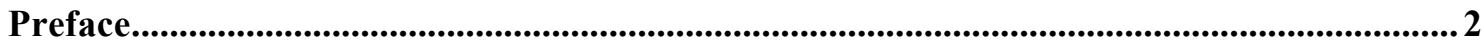

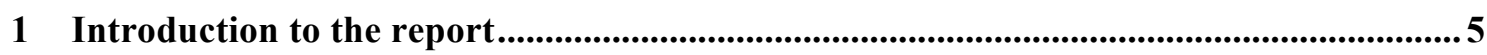

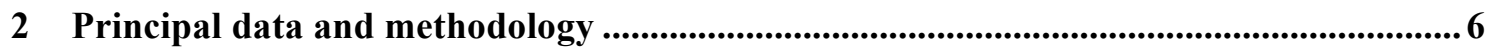

2.1 Data and methodology: the OEIDD database of SEP disclosures .................................. 6

2.2 Standards, industrial sectors, and the concept of technology areas ................................ 8

3 General findings on the occurrence of SEP disclosures.............................................. 12

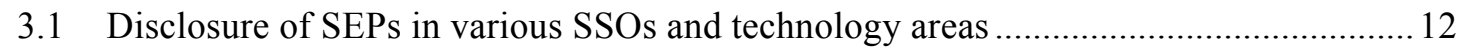

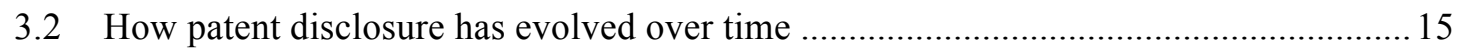

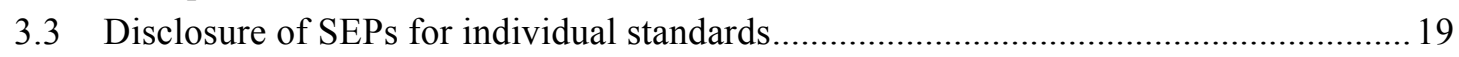

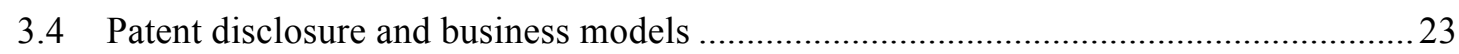

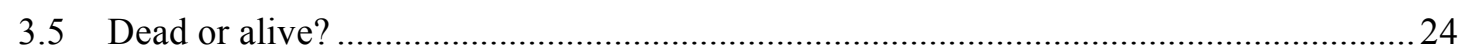

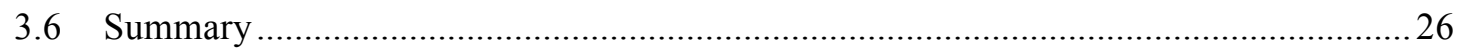

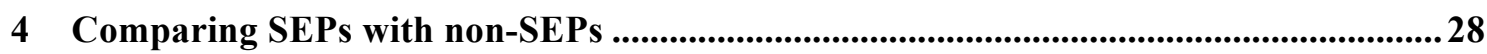

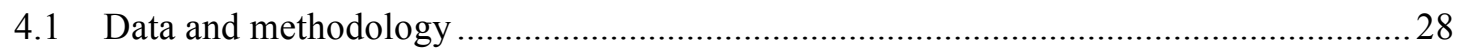

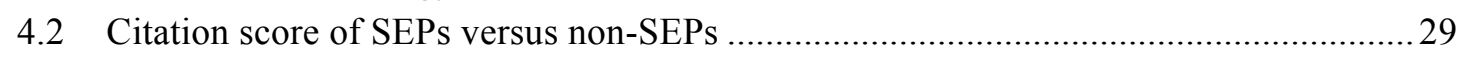

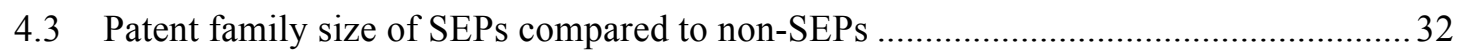

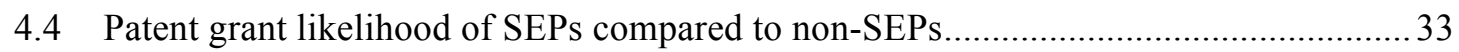

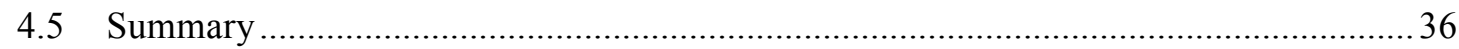

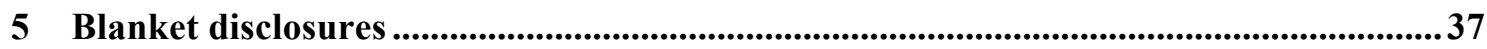

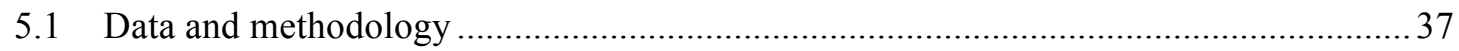

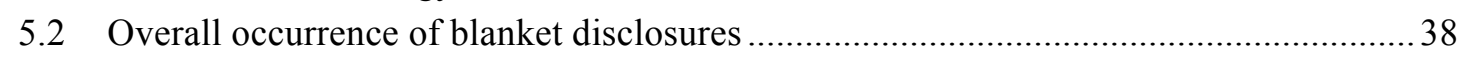

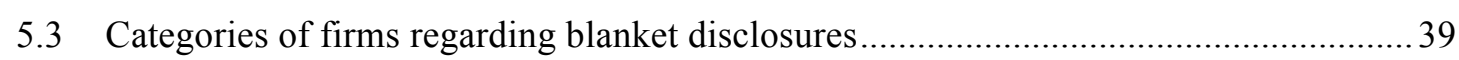

5.4 Blanket declaration occurrences for technology areas and individual standards ............40

5.5 Blanket declaration occurrence in relation to business models .......................................4 41

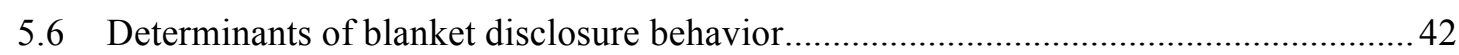

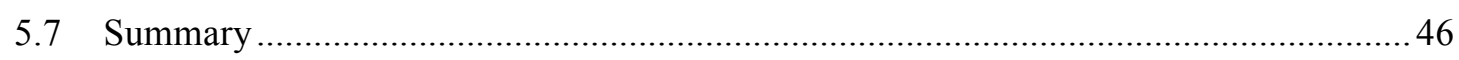

6 Transferring ownership of SEPs ............................................................................................. 47

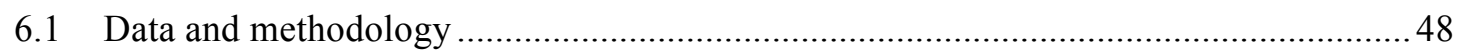

6.2 Distribution of SEP transfers over time, SSO and technology area ...............................49

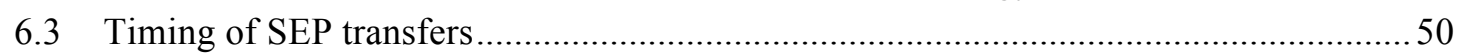

6.4 SEP transfers impact the distribution of SEP ownership at standard level ....................52

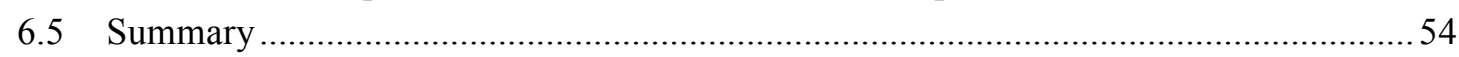

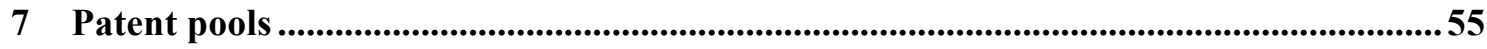

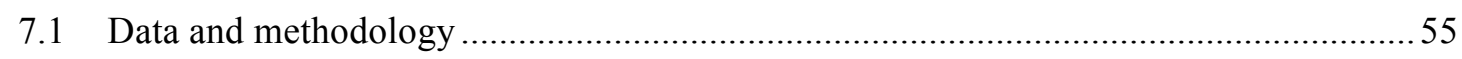

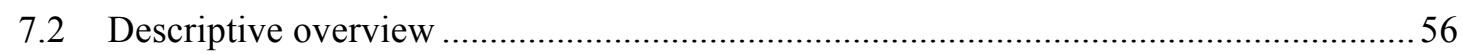

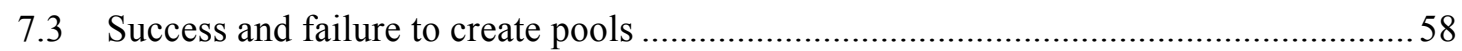

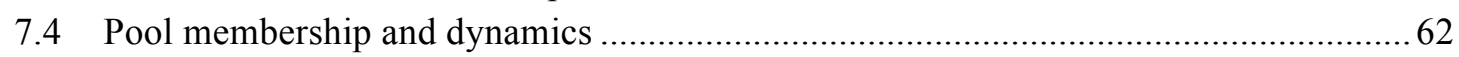

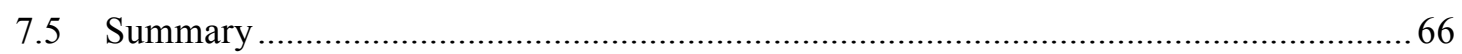




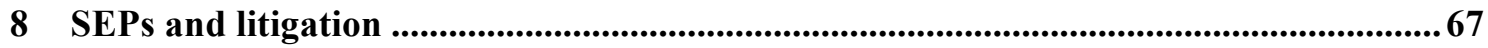

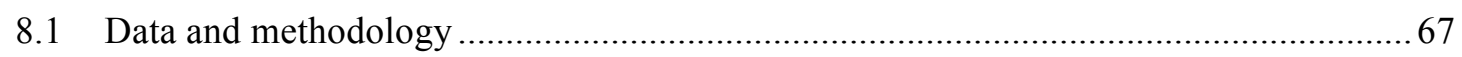

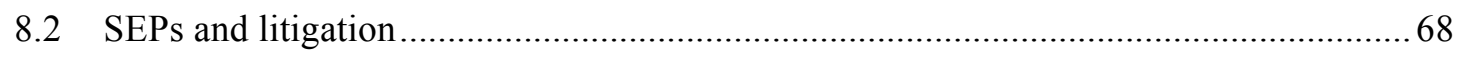

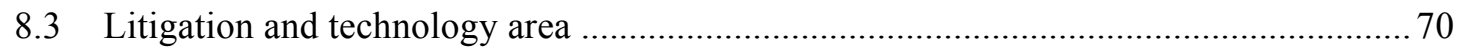

8.4 Relationship between litigation and the patent owner's business model........................ 72

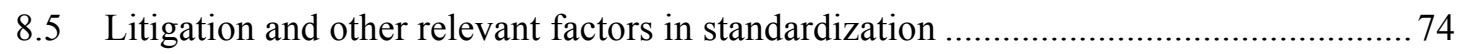

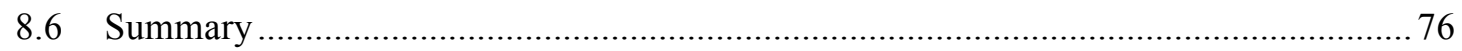




\section{Introduction to the report}

This report aims to provide a quantitative analysis of the phenomenon of patents in standards. In order to do so, it builds on the most tangible source of information on such 'essential' patents, namely the disclosures that companies make in the context of patent policies at standard setting organizations (SSOs). While this is not a perfect source for the existence of essential patents (in Section 2.1 we discuss this in more detail), in practice it is by far the best source for such information, and therefore widely used, both by companies and by academics.

This report is explorative in nature. It looks at essential patents from different perspectives, and provide analyses that allow for a better understanding of such patents. Because this study is meant to provide input into a wider process, we will not develop overall conclusions or recommendations, but just provide summaries of the findings at the end of each chapter.

Chapter 2 starts by providing information on the principal data and methodology used for this report. While we do not want to bore our readers with too many methodological details, we feel this information is necessary to understand the rest of the report. This chapter also considers the relationship between standards and industrial sectors or 'markets', which is important for understanding the relevance and consequences of our findings.

Chapter 3 presents general features of standard essential patents (also called SEPs). It considers the occurrence of essential patents, how their existence has developed over time, and how essential patents are distributed among SSOs, technology areas, standards, and owners (including their business models). It also considers the legal status of such patents, for example whether they are actually enforceable. Chapter 4 investigates in which sense SEPs differ from 'regular' patents. To make a fair comparison, a matched control set of patents was developed. We consider and compare the citation performance, the family size, and the patent grant likelihood.

The final four chapters focus on a set of topics that were chosen in consultation with the European Commission (see also the preface), as they may inform the policy discussion. These topics are 'blanket disclosures' (Chapter 5), essential patent transfer (Chapter 6), patent pools (Chapter 7), and litigation (Chapter 8). 


\title{
2 Principal data and methodology
}

\author{
This chapter was prepared by Rudi Bekkers
}

By almost any means, Standard Essential Patents (SEPs) have become a sizable phenomenon, attracting considerable attention among parties, academics and policy makers. While many standard setting bodies (SSOs) provide public information on the patents that members or other parties have disclosed as being essential to standards, it is not easy to use and interpret that information in a suitable way. Consequently this chapter opens with an extensive discussion on the main data source for our study, as well as the underlying methods and approach (Section 2.1). While not intending to divert the reader from the main content of this report, we feel this discussion is essential in order to gain a good understanding of the rest of the report. We have to appreciate that disclosure data on SEPs are fairly complex.

Preferably, we would like to relate the findings of this report to particular industries or sectors. Unfortunately, there is no one-to-one relationship between the standards on the one hand and industries, sectors or markets on the other. For that reason, Section 2.2 introduces a mapping based on the concept of 'technology areas'.

Some of the later sections in this report build on additional or different data than described in this chapter. Where that is the case, the chapter in question starts with an additional 'data and methodology' section.

\subsection{Data and methodology: the OEIDD database of SEP disclosures}

This chapter focuses mainly on the Open Essential IPR Disclosure Database (OEIDD), as do some of the later chapters. We will now provide a general introduction to this primary data source, whereas detailed aspects of this data and the additional work we carried out (such as defining technology fields and coding standards) are addressed in the specific sections where they are first used.

Developed from 2011 to 2013, OEIDD aims to provide the most comprehensive collection of disclosures of standard essential patents available, and was first introduced at an NBER conference in 2012. ${ }^{1}$ A preliminary version of this database was made available for our report. While OEIDD is based on disclosure records made publicly available by SSOs, very considerable efforts went into processing this information harmoniously. More specifically, the data was (1) cleaned, (2) harmonized, (3) matched, and (4) complemented with additional data. The cleaning entails information such as patent numbers, patent authorities, standards or standardization activities being examined, completed, corrected where necessary, and stored in a standardized format. Harmonization involves the consistent coding of information across

\footnotetext{
${ }^{1}$ Bekkers, R., Catalini, C., Martinelli, A., \& Simcoe, T. Intellectual Property Disclosure in Standards Development. Paper at the NBER conference on Standards, Patents \& Innovation, Tucson (AZ), January 20 and 21, 2012. Available at http://users.nber.org/ confer/2012/IPKE/Bekkers.pdf
} 
and within the data from the various SSOs, such as firm names and standardization activities. Matching means that each disclosed patent identity at either the US Patent and Trademark Office (USPTO) or the European Patent Office (EPO) is matched with data from a reference patent database, namely the OECD/EPO PATSTAT database, and complemented with relevant metadata. This metadata includes the date of the patent application, data on the first publication of the application, and information on the first publication of the patent, as well as the DOCDB and INPADOC family identities. The patent family information is particularly useful as it allows the user of the database to correct for the rather substantial degree of overlap that is present in the source data. Finally, we complemented the data with information about the patent owner, such as their home region (typically the world region in which the headquarters are located), and business model. The original disclosures on which OEIDD is based were those that were available in March 2011.

Despite being comprehensive, OEIDD by definition shares the same limitations as its source data. One of these limitations is that patent disclosures are on the basis of self-declaration. While many SSOs have rules on what has to be disclosed, these rules cannot and do not guarantee that all actual essential patents are on the list, and that all listed patents are actually essential. (A more detailed discussion of these rules can be found in a recent study commissioned by the US National Academies of Science - NAS. ${ }^{2}$ ) However, the SSOs' IPR disclosure databases still offer the best information on essential patents. Whenever we talk in this report about 'essential' patents (or SEPs), we are referring to patents or patent applications disclosed as being essential by their owner. Another limitation is that SSOs' source data differs both in availability and format. This inevitably has consequences for the compiled data as well, no matter how much effort is put into cleaning and harmonization.

In order to understand and interpret this data, it is useful to go back to the actual disclosure processes as they take place at SSOs. Here, companies or other organizations ${ }^{3}$ submit written declarations, sometimes using a (obligatory) template, sometimes just by sending a letter. We call these disclosure events. Some of these declarations concern one single patent; others list hundreds of patents that may or may not be for the same standard, and may or may not concern family members of the same invention (e.g. for different countries). Many SSOs allow the submission of a 'blanket disclosure', which is a statement declaring that the organization believes to own one or more essential patents for a specified standard, but does not provide the identity of these patents (or information on the countries where these patents have been applied for). In OEIDD terms, we break each disclosure into their smallest elements, which we call 'statements'. These statements are our smallest unit of observation and contain the identification of at most one single patent. Different statements could include patents that belong to the same patent family. Figure 1 shows the relationship between

\footnotetext{
${ }^{2}$ See: Bekkers, R., \& Updegrove, A. (2012). A study of IPR policies and practices of a representative group of Standards Setting Organizations worldwide. Washington, DC: National Academies of Science. Available from http://sites.nationalacademies.org/xpedio/groups/pgasite/documents/webpage/pga 072197.pdf.

${ }^{3}$ For the sake of simplicity, this report often refers to 'firms' or 'companies', even though we recognise that other organizations can also own IPRs and submit disclosures.
} 
disclosure events and statements, and also provides the total numbers for these events in the database. $^{4}$

Figure 1: Disclosure events and statements

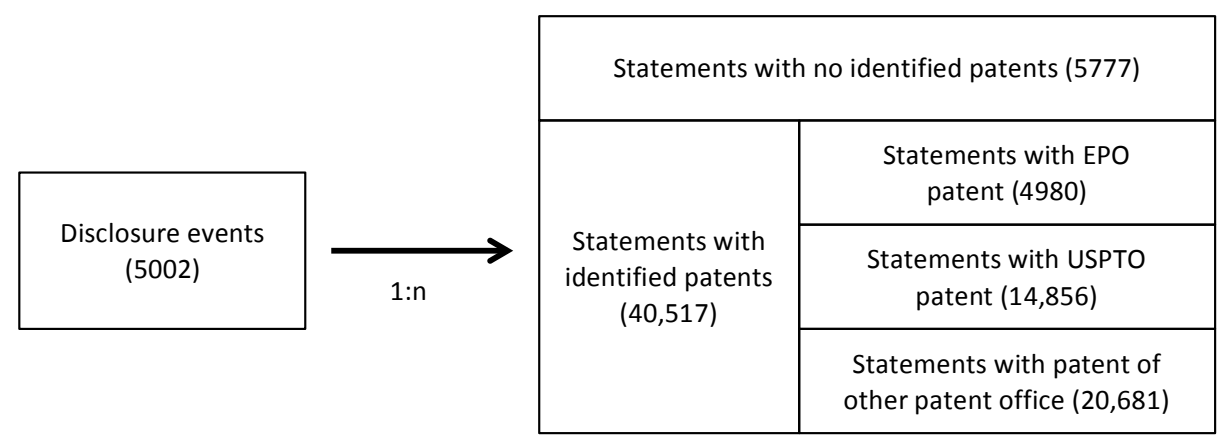

\subsection{Standards, industrial sectors, and the concept of technology areas}

One important aspect of this report is that we want to relate various observations of SEPs to 'industry sectors'. But first of all we should ask ourselves: what do industry sectors mean in this particular context, and what is their relationship to markets? In a simple world, there would be a standard for, say, the gauge of railway networks. The affected market sector would of course be the railway sector. In many modern technology areas, however, such relationships are often much more complicated, and this has to be appreciated in order to understand the effect of standards on markets.

Figure 2: Standards and sectors

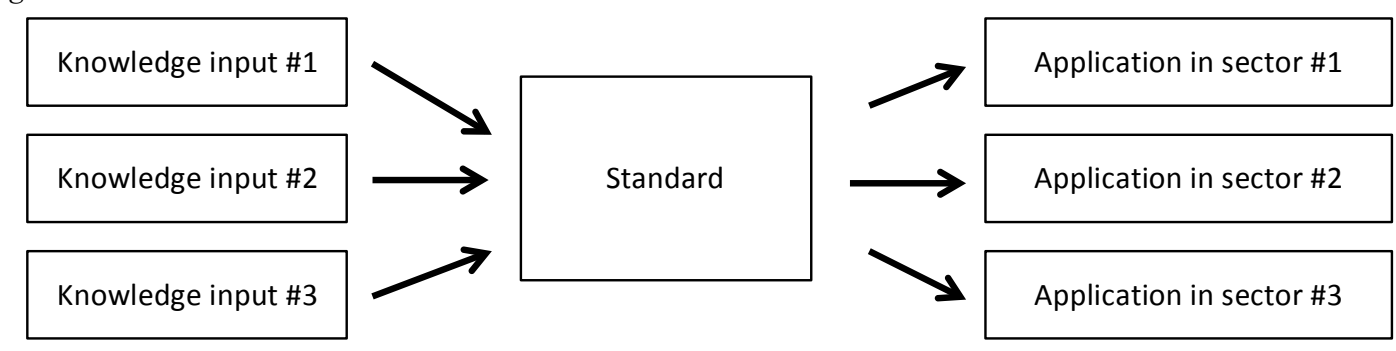

The relationship between knowledge, standards and application sectors is depicted in Figure 2. If we take the IEEE 802.11 series of standards ${ }^{5}$ as an example, we find a variety of knowledge inputs that might be patented or not. They could range from radio communications

\footnotetext{
${ }^{4}$ In some SSOs, these disclosure events can be examined for instance by retrieving a facsimile copy of the letter or filled-in template. In other SSOs, there is only a database with (often numerous) records, which are the result of disclosure events. As the OEIDD database strives for a harmonized representation of all data, disclosure events are 'recreated' by grouping all statements that are submitted by the same organization, on the same day, to the same SSO.

${ }^{5}$ Popularly known as 'Wi-Fi', although formally this term refers to the certification of certain categories of IEEE 802.11 based devices by the Wi-Fi Alliance, and thus is not exactly the same as the term IEEE 802.11.
} 
modulation technology, security and cyphering technology, to higher link packet technology and more. All this knowledge is combined in the technical standard. In this case, the initiative for the standard was taken by the company NCR, which had a very specific, narrow (niche) application area in mind, namely the wireless interconnection of cash registers in large retail stores, to avoid drilling and other cumbersome interventions when cash registers were moved or added. ${ }^{6}$ As we now know, this standard quickly gained traction in other application areas and became highly popular when Apple and later Dell Computers decided to equip laptop computers with IEEE 802.11 based wireless communications units. Later the technology was recognized as having potential for various applications in public telecommunications (local loop, public hotspots) and was integrated in many consumer devices ranging from smartphones, game consoles, to now even cameras. Moreover, it was increasingly recognized that this standard was suitable for enabling technology in entirely different markets. Hence, IEEE 802.11 is now listed as one of the standards relevant for smart grid networks by the EC Task Force for Smart Grids (TF), a group that was given a mandate by the European Commission to make an inventory of start grid related standards. ${ }^{7}$ Whether this standard will be actually relevant for future smart grids is dependent on the choices made by those who build these future smart grids. They might choose this technology for in-house communications related to the smart grid and perhaps for other purposes or opt for alternatives such as ZigBee, which is standardized as IEEE 802.15.5.

As illustrated by the above example, the relationship between knowledge, standards, and sectors in which these standards are applied is not always trivial. As shown, a single standard may impact multiple sectors - sometimes as 'core' technology (e.g. using IEEE 802.11 for connecting a laptop to an access point), sometimes as 'enabling technology' (such as using IEEE 802.11 for smart grids), or as a 'nice to have' addition (such as implementing IEEE 802.11 in still photography cameras). Moreover, this issue is also dynamic - in a few years, new sectors might be affected that we cannot yet identify. We do observe, however, both 'convergence' and the increasing role of ICT standards as 'enabling technologies' in other areas such as banking, public transport, logistics and intelligent transport systems, smart grids, e-health, biometrics and agricultural systems.

For the empirical analysis in this study, we sought to distinguish between different groups of standards. There are two guiding principles for selecting these groups: on the one hand, they had to be logically grouped in order to be able to map their impact on industrial sectors. On the other hand, the grouping had to take into consideration the extremely skewed nature of disclosed essential patents: it is known that the large majority of disclosures is concentrated in a very small number of technical areas, and a grouping whereby one category includes virtually all observations and all the other categories have almost none, is not very insightful. Obviously, we need to find a balance between these two principles.

\footnotetext{
${ }^{6}$ For an in-depth analysis of the origin and development of this standard, see Lemstra, W., Hayes, V., \& Groenewegen, J. (2010). The Innovation Journey of Wi-Fi: The Road To Global Success. Cambridge University Press.

${ }^{7}$ EU Commission Task Force for Smart Grids (2012). Expert Group 1: Functionalities of smart grids and smart meters, Final Deliverable.
} 
On the basis of the above principles, we can identify nine distinct categories of standards, as shown in Table 1. In addition, there is a small 'other' category, which is very broad, with disclosures for which no standard has been indicated, or information is otherwise missing.

Table 1. Standards' categories as defined for this empirical analysis

\begin{tabular}{|c|c|c|}
\hline Category & Technology area & $\begin{array}{l}\text { Examples of the most prominent standards in this category (in terms of } \\
\text { disclosed IPR) }\end{array}$ \\
\hline 1 Tele & $\begin{array}{l}\text { Telecommunications via public } \\
\text { networks }\end{array}$ & $\begin{array}{l}\text { GSM ( } 2 \text { G mobile telecommunications) } \\
\text { UMTS ( } 3 \text { G mobile telecommunications, aka 3GPP W-CDMA) } \\
\text { ISDN (Digital landline telephony) } \\
\text { ADSL (Internet services via standard telephone lines) } \\
\text { Various OMA standards for mobile applications }\end{array}$ \\
\hline 2 LAN & $\begin{array}{l}\text { LAN/PAN/BAN networks, wired and } \\
\text { wireless }\end{array}$ & $\begin{array}{l}\text { IEEE 802.11 (Wireless LAN - 'Wi-Fi') } \\
\text { IEEE 802.15.1 ('Bluetooth') } \\
\text { IEEE 802.15.4 ('ZigBee') } \\
\text { ETSI HIPERLAN (Wireless LAN) }\end{array}$ \\
\hline $3 \mathrm{IT}$ & Information technology and Internet & Various IETF standards for the internet \\
\hline $4 \mathrm{AV}$ & $\begin{array}{l}\text { Audio/video systems, coding and } \\
\text { compression, broadcasting, home } \\
\text { systems, home entertainment }\end{array}$ & $\begin{array}{l}\text { ITU H.262 ('MPEG-2 Video'), } \\
\text { ITU H.264', ISO } 10918 \text { ('JPG') } \\
\text { ETSI DBV (Digital television broadcast) }\end{array}$ \\
\hline $5 \mathrm{Secu}$ & $\begin{array}{l}\text { Security, identification, cryptography, } \\
\text { biometrics }\end{array}$ & $\begin{array}{l}\text { ISO/IEC } 18000 \text { ('RFID’) } \\
\text { JTC1 ISO/IEC } 14888 \text { (Techniques for digital signatures) } \\
\text { IEEE } 1363 \text { (Public Key Cryptography) }\end{array}$ \\
\hline 6 Trans & $\begin{array}{l}\text { Transport, logistics, aerospace, } \\
\text { intelligent transport systems (excl. areas } \\
\text { in the above categories) }\end{array}$ & $\begin{array}{l}\text { ISO } 17572 \text { (Intelligent Transport Systems) } \\
\text { ETSI project eCall (in-car emergency communication system) } \\
\text { ISO } 24099 \text { (Navigation data structures) }\end{array}$ \\
\hline 7 Energ & $\begin{array}{l}\text { Energy generation and distribution and } \\
\text { storage, fuel cells, power electronics }\end{array}$ & $\begin{array}{l}\text { IEC } 61850 \text { (Electrical substation automation in a power station), } \\
\text { IEC } 62026 \text { (Low-voltage switchgear and controlgear); } \\
\text { IEC } 62282 \text { (Fuel Cell technologies) }\end{array}$ \\
\hline 8 Ind & $\begin{array}{l}\text { Industrial equipment, manufacturing, } \\
\text { production }\end{array}$ & $\begin{array}{l}\text { ISO } 25239 \text { (Friction stir welding) } \\
\text { IEC } 61158 \text { ('Fieldbus' standard for industrial automation) } \\
\text { IEC } 61784 \text { ('openSAFETY' Digital data communications for measurement } \\
\text { and control) }\end{array}$ \\
\hline 9 MTS & $\begin{array}{l}\text { Measurement, testing, safety standards, } \\
\text { language standards }\end{array}$ & $\begin{array}{l}\text { IEC CISPR } 29 \text { (Electromagnetic compatibility in television broadcast) } \\
\text { IEEE } 1647 \text { (' } e \text { ' hardware verification language) } \\
\text { IEEE } 1364 \text { ('Verilog' hardware description language) }\end{array}$ \\
\hline Other & $\begin{array}{l}\text { [A wide variety of topics that do not fit } \\
\text { into the above categories] }\end{array}$ & N/A \\
\hline
\end{tabular}

The mapping of these standards categories to the industry sectors central to the ECSIP project is shown in Table 2 . We will elaborate briefly on this mapping:

- For the Communications Technologies (CT) sector, telecommunications standards (category 1) are obviously a core technology. While LAN technologies (category 2) - both wired and wireless - initially developed separately, they later often emerged as key technologies complementing or providing alternatives for classical telecommunications standards. Examples are Wi-Fi used for public hotspots, and Ethernet technologies replacing traditional SDH and PDH standards in operators' core networks. Similarly, IT standards (category 3)

\footnotetext{
${ }^{8}$ For the sake of readability, we sometimes provide the 'popular' terms used for these standards.

${ }^{9}$ The ITU H.264 standard is also known as the ISO/IEC - JTC1 IEC 14496 standard.
} 
play an increasingly important role, such as with Internet Protocol. Finally, AV standards such as video coding protocols became increasingly important to deliver TV, video and other media services over public telecommunications networks, and security standards became more and more important. In summary, the Communications Technologies rely heavily on a wide range of standards.

- For the Consumer Electronics (CE) sector, the initially most important group was that of the AV standards (category 4), including video coding standards specifically developed for digital television broadcasting, and for storing movies on DVD disks. In recent years, more and more CE devices also incorporate LAN standards (category 2), for example Wi-Fi in portable game consoles, or Ethernet ports on Blue Ray players. Similarly, IT standards (category 3) were added such as Internet Protocol and HTML markup languages. Finally, some categories of CE devices now also incorporate traditional telecom standards (category 1), like the Sony PlayStation VITA, boosting 3G capabilities in some versions.

- For the Energy sector, the traditional energy standards (Category 7) are crucial. However, a range of other categories is becoming important that enables technologies like cellular standards for smart metering, and telecom and LAN technologies for a range of other communication needs in networks.

- In the automotive sector, standards for transportation (Category 6) are obviously core. In recent years, developments such as eCall have made telecommunications standards (category 1) increasingly important. In consumer cars, LAN/PAN standards (including Bluetooth for hands-free telephony) are becoming more important, and likewise AV standards for in-car entertainment.

Table 2. Relevance of categories of standards to specific technology areas sectors

\begin{tabular}{lllll}
\hline Category & CT sector & CE sector & Energy sector & $\begin{array}{l}\text { Automotive } \\
\text { sector }\end{array}$ \\
\hline 1 Tele & $* * *$ & $*$ & $* *$ & $* *$ \\
\hline 2 LAN & $* * *$ & $* *$ & $* *$ & $*$ \\
\hline 3 IT & $* * *$ & $* *$ & $* *$ & $*$ \\
\hline 4 AV & $* *$ & $* * *$ & & $* *$ \\
\hline 5 Secu & $* *$ & $*$ & $* *$ & $* *$ \\
\hline 6 Trans & & & $* * *$ & $* *$ \\
\hline 7 Energ & $* *$ & $* *$ & $* *$ & \\
\hline 8 Ind & $* *$ & $* *$ & & \\
\hline 9 MTS & & & $* *$ \\
\hline Other & & & \\
\hline Legend: & & & $* *$ very relevant, $* *$ relevant, ${ }^{*}$ somewhat relevant. \\
\end{tabular}

Altogether, we conclude that different industrial sectors are increasingly dependent on the same categories of standards. 


\section{General findings on the occurrence of SEP disclosures}

This chapter was prepared by Rudi Bekkers and Önder Nomaler

This chapter presents the general features of standard essential patents (also called SEPs). It considers the occurrence of essential patents (Section 3.1), including the distribution over SSOs and technology areas. Section 3.2 shows how the phenomenon of essential patents has developed over time. We then look at SEP occurrence for individual - top - standards (Section 3.3) and at SEP owners' business model (Section 3.4). The last part of this chapter, Section 3.5, considers the legal status of SEPs and investigates to what extent these patents are actually enforceable.

\subsection{Disclosure of SEPs in various SSOs and technology areas}

We now turn to the data on SEP disclosure at specific SSOs and in specific technology areas, as defined in the previous paragraph. OEIDD provides data on disclosures at 13 SSOs.

However, the data for two of these bodies - ISO and IEC - is split into two distinct categories. The reason is that the so-called JTC1 standardization activities, which these two bodies jointly conduct on 'information technology' are so different in terms of patent disclosure statistics from the 'regular' activities of both SSOs, that just referring to the bodies as such would mask many underlying differences. Hence, ISO is divided into ISO-JTC1 and ISO (excluding JTC1). A similar situation applies for IEC. Therefore for the sake of simplicity, from now on we will speak of 15 SSOs.

Figure 3: Distribution of statements and disclosure events at the 15 Standard Setting Organizations

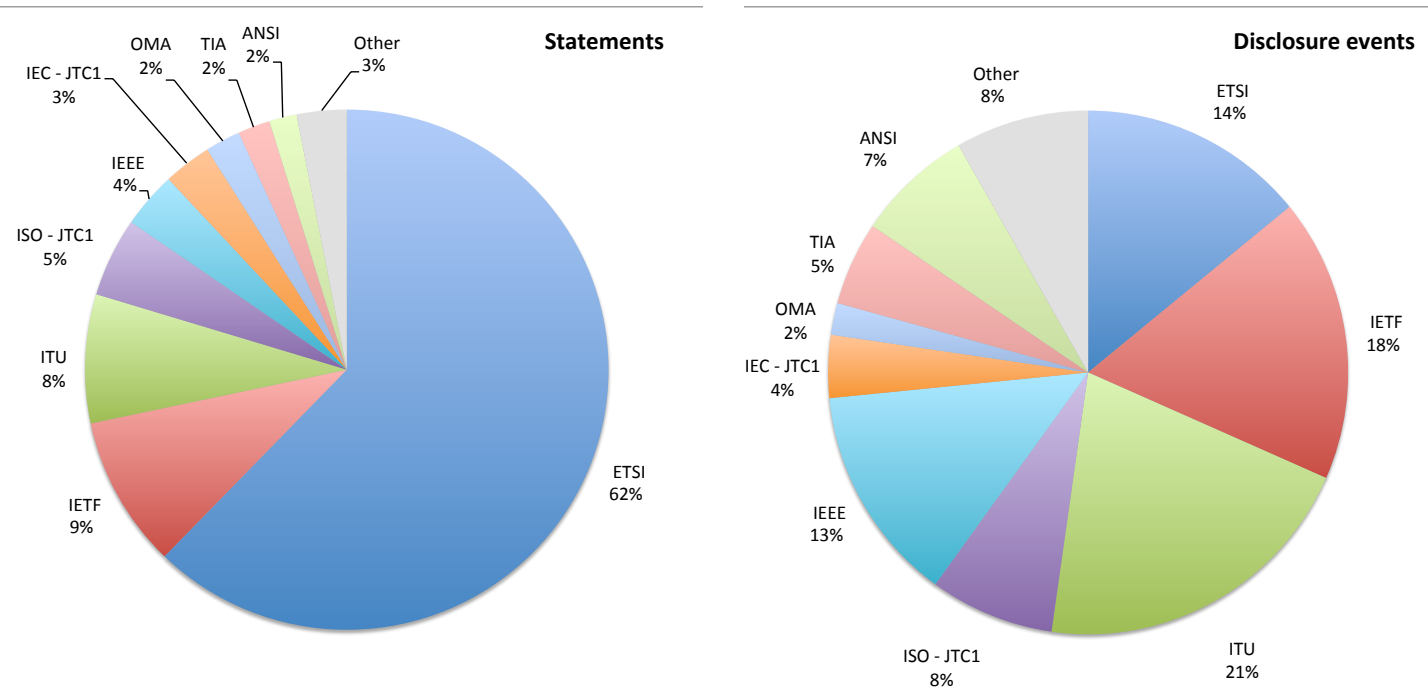


If we consider Figure 3, the first thing we note is a very strong skewness. Without a doubt, ETSI received more patent statements than any other SSO, alone being responsible for some 62 percent of all patent statements in the entire data set. Other large SSOs are IETF, ITU and ISO - JTC1. Although these bodies have more disclosure events than ETSI, the number of patent statements is lower. It is very important, however, to realize that these three bodies do allow for blanket statements, while ETSI does not. So it is highly likely that the actual number of essential patents for any of these three bodies is much larger than suggested here, but given the low level of transparency that blanket disclosures provide, there is simply no way to observe this.

Table 3. Disclosures at the various SSOs

\begin{tabular}{|c|c|c|c|c|c|}
\hline SSO & $\begin{array}{l}\text { Disclosure } \\
\text { events }\end{array}$ & $\begin{array}{l}\text { Statements (Total/ } \\
\text { Blankets/Specific) }\end{array}$ & $\begin{array}{l}\text { Specific at EPO } \\
\text { (total/identified) }\end{array}$ & $\begin{array}{l}\text { Specific at USPTO } \\
\text { (total/identified) }\end{array}$ & $\begin{array}{l}\text { Unique DocDB \&INPADOC } \\
\text { Patent Families }\end{array}$ \\
\hline ANSI & 366 & 784 / 381 / 403 & $10 / 4$ & $338 / 300$ & $224 / 190$ \\
\hline ATIS & 77 & 364 / 127 / 237 & $22 / 19$ & 212 / 193 & $178 / 118$ \\
\hline BBF & 23 & $142 / 9 / 133$ & $10 / 10$ & $77 / 64$ & $51 / 27$ \\
\hline CEN & 5 & $22 / 0 / 22$ & $21 / 21$ & $0 / 0$ & $5 / 4$ \\
\hline CENELEC & 11 & $17 / 13 / 4$ & $1 / 1$ & $3 / 3$ & $4 / 4$ \\
\hline ETSI & 699 & 28940 / 93 / 28847 & 3763 / 3691 & 7968 / 6735 & $4938 / 4131$ \\
\hline IEC & 166 & 367 / 94 / 273 & $58 / 56$ & $92 / 83$ & $94 / 79$ \\
\hline IEC - JTC1 & 196 & $1368 / 177 / 1191$ & $203 / 201$ & $458 / 418$ & $276 / 210$ \\
\hline IEEE & 655 & $1605 / 605 / 1000$ & 99 / 96 & $825 / 763$ & $563 / 447$ \\
\hline IETF & 890 & 4334 / 620 / 3714 & $269 / 257$ & $2546 / 2132$ & $609 / 475$ \\
\hline ISO & 134 & $503 / 289 / 214$ & $27 / 27$ & $104 / 102$ & $63 / 48$ \\
\hline ISO - JTC1 & 385 & $2256 / 1264$ / 992 & $166 / 165$ & $676 / 594$ & $267 / 213$ \\
\hline ITU & 1032 & 3679 / 1240 / 2439 & 249 / 209 & 965 / 911 & $718 / 571$ \\
\hline OMA & 100 & $1001 / 0$ / 1001 & $79 / 70$ & $557 / 506$ & 419 / 360 \\
\hline TIA & 263 & 912 / 865 / 47 & $3 / 3$ & $35 / 34$ & $28 / 23$ \\
\hline Total & 5002 & 46294 / 5777 / 40517 & 4980 / 4830 & 14856 / 12838 & $\begin{array}{l}8437 / 6900 \\
7988 / 6304\left(^{*}\right)\end{array}$ \\
\hline
\end{tabular}

$(*):$ The overlap of patent families between the categories has been removed.

The data underlying the two pie graphs is shown in more detail in Table 3. This table indicates that the total number of statements is composed of blanket statements and specific statements. It also shows the number of specific statements referring to patents filed at the EPO and at the USPTO, as well as the number of these patents we managed to successfully identify in the OECD/EPO PATSTAT database, which is 97 percent of all EPO patents, 86 percent of all USPTO patents (and 90 percent combined). ${ }^{10}$ Recognizing the majority of these patents in PATSTAT is important for a number of later analyses, where we will use specific patent data from that database. Using PATSTAT, we were also able to analyze the actual number of

\footnotetext{
${ }^{10}$ There is a variety or reasons why patents might not be recognised in PATSTAT. These include erroneous patent numbers, references to serial application numbers (which cannot be tracked, nor can publications of patent applications, or publications of granted patents), references to provisional applications (in the US), or the mere fact that a patent application had not yet been made public at the time of the publication of the PATSTAT database we used.
} 
unique patent families (in both the DocDB and INPADOC definition). ${ }^{11}$ Bringing together patent family members both within and between countries, these measurements provide a much more realist insight into patented essential 'inventions' than patent counting itself, which is prone to considerable double-counting.

A similar skewness exists when we consider the technology areas, see Figure 4. After the previous graphs, this should not come as a surprise because many SSOs are linked to specific technology areas. At the statement level, we observe a higher concentration than at disclosure events, and again we stress the fact that the SSOs that are dominant in categories such as LAN, IT and AV allow for blanket disclosure and could actually have more SEPs than the category Tele. As explained, these blankets do not allow us to observe this. Table 4 illustrates the same data as the previous pie graphs, but in more detail.

Figure 4: Distribution of statements and disclosure events for the different technology areas

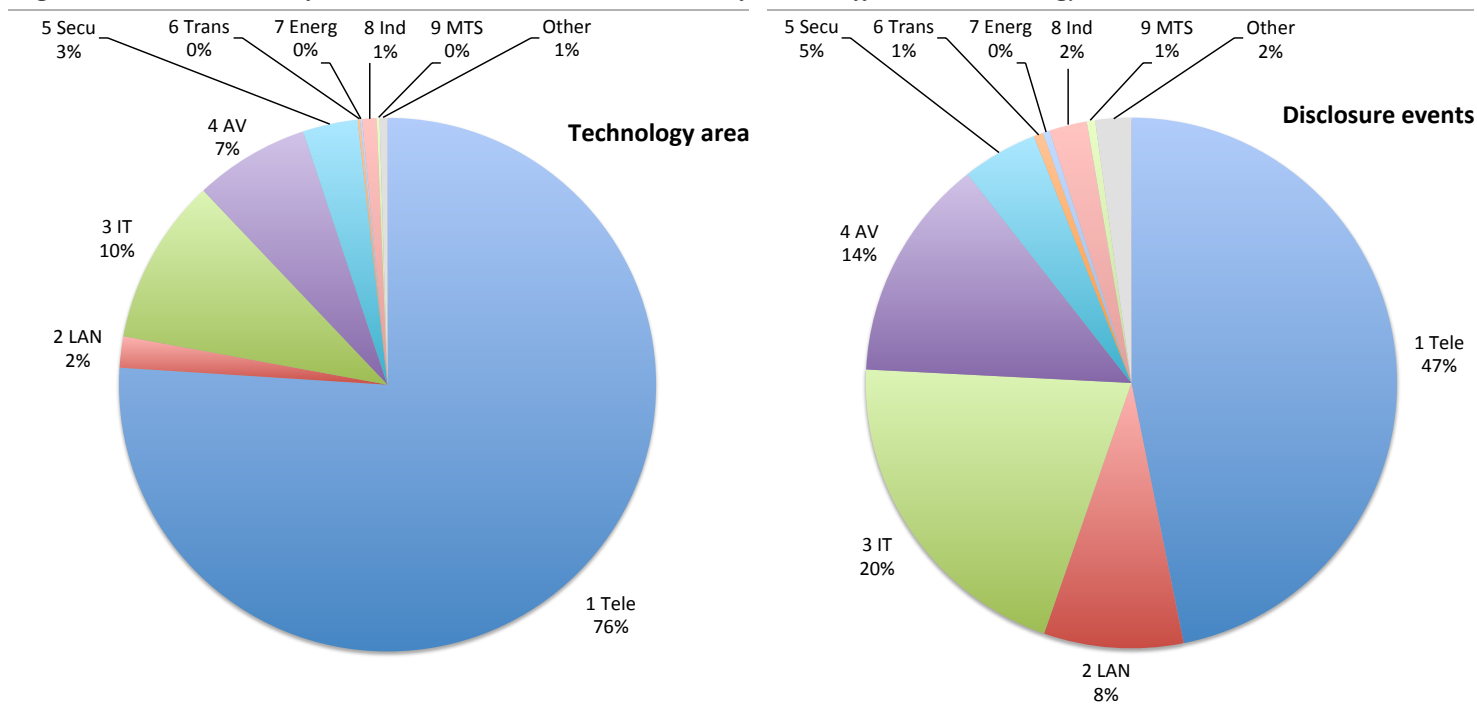

Note: Uncoded disclosures and disclosures where the standard is missing are excluded from these graphs. See Table 4 for more details.

\footnotetext{
${ }^{11}$ See Section 4 for a further explanation of patent families.
} 
Table 4. Disclosure for the various technology areas

\begin{tabular}{llllll}
\hline $\begin{array}{l}\text { Technology } \\
\text { area }\end{array}$ & $\begin{array}{l}\text { Disclosure } \\
\text { events }\end{array}$ & $\begin{array}{l}\text { Statements } \\
\text { (Total/ Blankets/Specific) }\end{array}$ & $\begin{array}{l}\text { Specific at EPO } \\
\text { (total/identified) }\end{array}$ & $\begin{array}{l}\text { Specific at USPTO } \\
\text { (total/identified) }\end{array}$ & $\begin{array}{l}\text { Unique DocDB \& INPADOC } \\
\text { Patent Families }\end{array}$ \\
\hline $\begin{array}{l}\text { 1 Tele } \\
\text { 2 LAN }\end{array}$ & 2208 & $34606 / 2249 / 32357$ & $4076 / 3959$ & $9808 / 8443$ & $6283 / 5039$ \\
3 IT & 400 & $859 / 397 / 462$ & $48 / 46$ & $375 / 347$ & $267 / 214$ \\
4 AV & 965 & $4573 / 669 / 3904$ & $277 / 265$ & $2705 / 2287$ & $707 / 556$ \\
5 Secu & 641 & $3150 / 1637 / 1513$ & $188 / 181$ & $722 / 601$ & $387 / 267$ \\
6 Trans & 217 & $1505 / 144 / 1361$ & $284 / 281$ & $678 / 648$ & $255 / 192$ \\
7 Energ & 20 & $68 / 21 / 47$ & $4 / 4$ & $25 / 19$ & $18 / 9$ \\
8 Ind & 108 & $396 / 189 / 207$ & $7 / 6$ & $9 / 8$ & $11 / 10$ \\
9 MTS & 24 & $77 / 7 / 70$ & $35 / 35$ & $88 / 80$ & $72 / 59$ \\
Other & 103 & $215 / 65 / 150$ & $7 / 6$ & $32 / 31$ & $24 / 16$ \\
Uncoded & 325 & $708 / 355 / 353$ & $44 / 43$ & $76 / 74$ & $63 / 55$ \\
Missing & 51 & $83 / 33 / 50$ & $8 / 2$ & $296 / 259$ & $198 / 172$ \\
\hline Grand Total & 5089 & $46294 / 5777 / 40517$ & $4980 / 4830$ & $14856 / 12838$ & $8326 / 6620$ \\
\hline
\end{tabular}

Notes: 'Other' refers to a technology area that is different from those in categories 1-9. 'Missing' means that this information was missing in the original disclosure. 'Uncoded' means we could not determine the technology area (all these cases are within ANSI, where it is sometimes very difficult to identify the actual content of the standard on the basis of the data provided in the original disclosure). $\left({ }^{*}\right)$ : Here, the overlap of patent families between the categories has been removed.

\subsection{How patent disclosure has evolved over time}

Nowadays, it is widely understood that SEP disclosure is a phenomenon of considerable proportions. Yet, the first patents in standards were discussed in the 1930 s already, ${ }^{12}$ while the first patent policies that prescribed disclosure of SEPs were introduced in the 1980s and 1990s. So how did disclosure develop over time? Has it grown considerably in the past few years?

In order to understand the time-scales, it is important to distinguish at least two different elements. The first element is the timing of the disclosure as such to the SSO. This is typically data recorded by the SSO itself and can usually be found alongside each disclosure in their patent database. The second element is the timing of the underlying patent or patents (if it can actually be identified). There are a number of dates associated with a typical patent, most importantly: (1) the priority date, (2) the filing date, (3) the first publication of the application and (4) the first publication of the granted patent. In the context of this study, the priority date is the most interesting because this is the date that comes closest to the actual invention being made.

Focusing initially on the first element, we see that the phenomenon of patent disclosure has clearly grown over time. This growth is apparent if you look at the total number of disclosures and statements (Figure 5). When considering the individual annual totals, however, we see that the growth rate is far from smooth (Figure 6), demonstrating ups and downs. This is probably due to the cyclic nature of the standardization process: in some years, SSOs are

\footnotetext{
${ }^{12}$ See the report referenced in Footnote 2.
} 
working on 'big' standards that attract a peak of disclosures, while in other years, it is quieter. But at any rate, the amount is increasing.

Figure 5: Number of events and statements over time (cumulative)

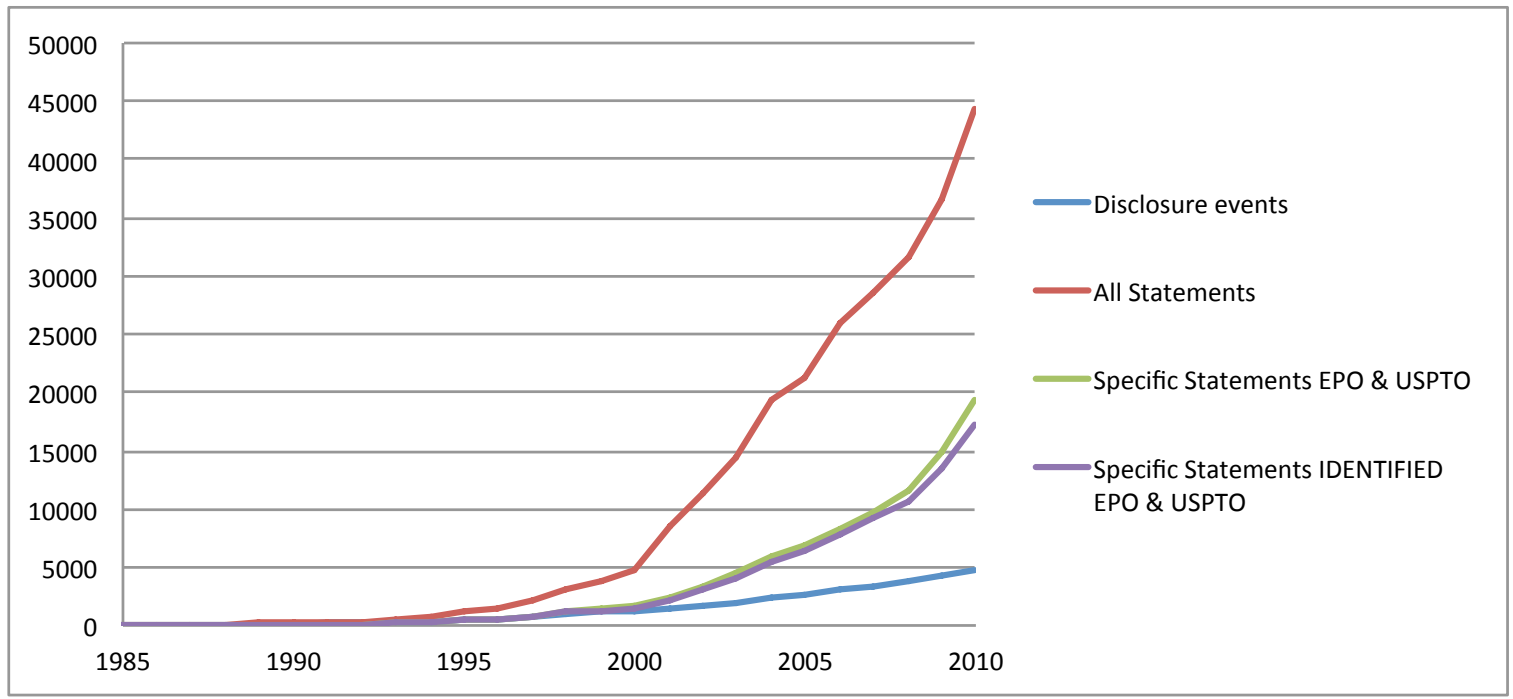

Figure 6: Number of events and statements over time (annual)

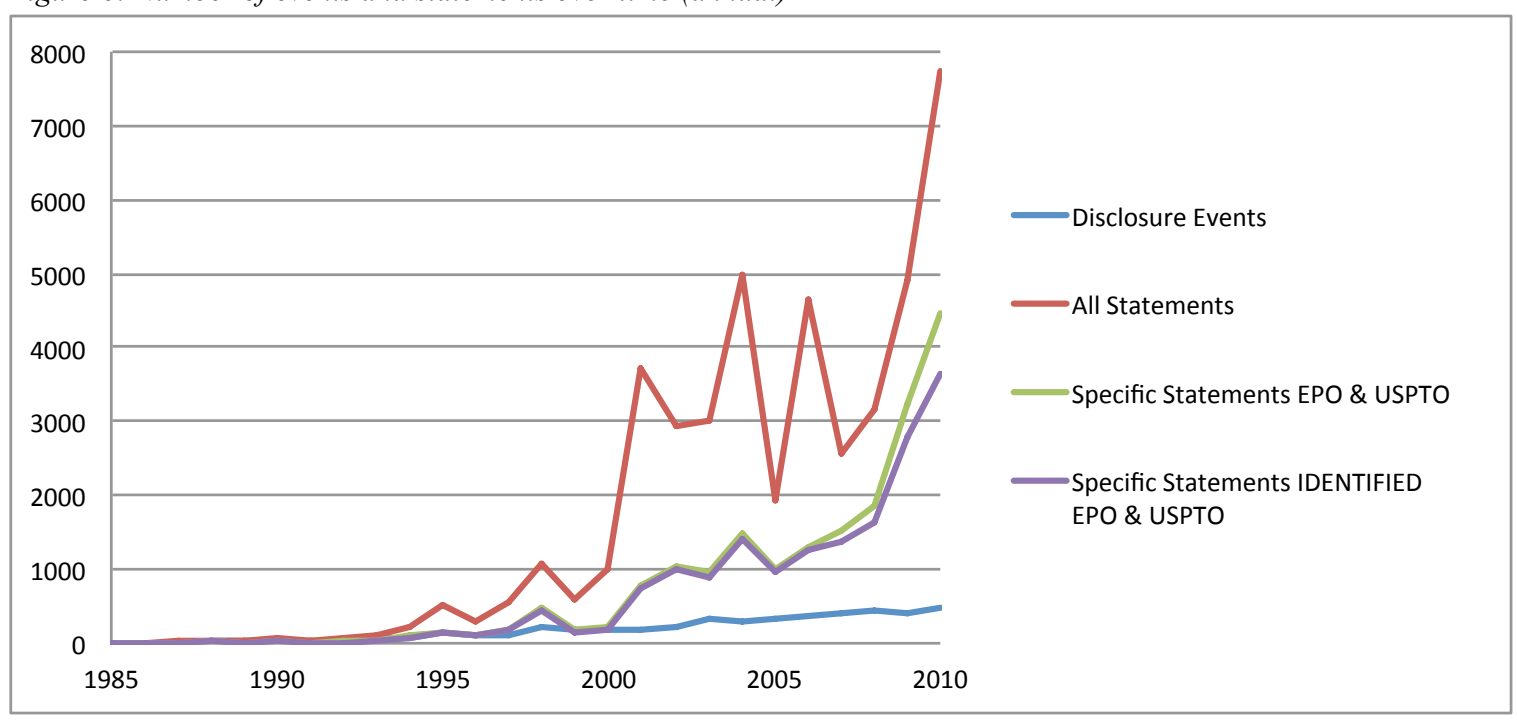

The two figures also reveal that the number of statements is growing faster than the number of disclosures. This can be attributed to the increasing number of statements / patents per disclosure events, as we can see in Figure 7. 


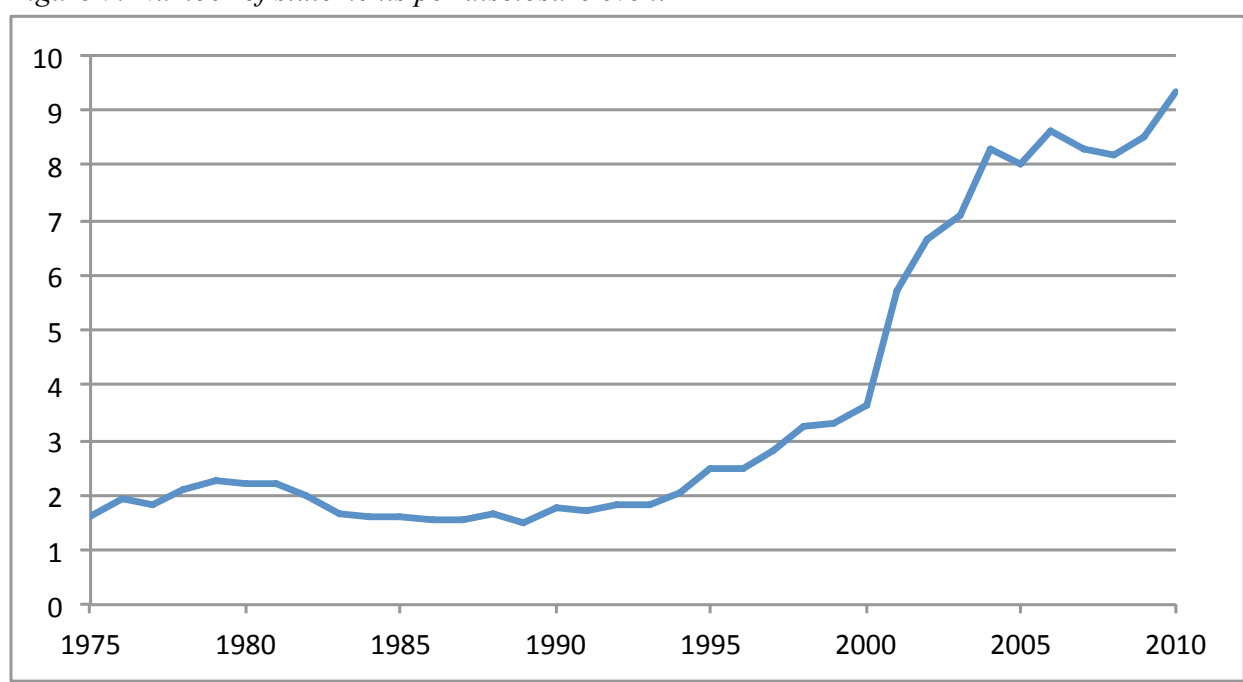

It is important to realize, that although we see disclosure growth in nearly every SSO, the overall data is dominated by the large SSOs. This is clearly visible in Figure 8, where we only focus on identified EPO or USPTO statements, to isolate the possible effect of firms disclosing more and more similar patents in different countries.

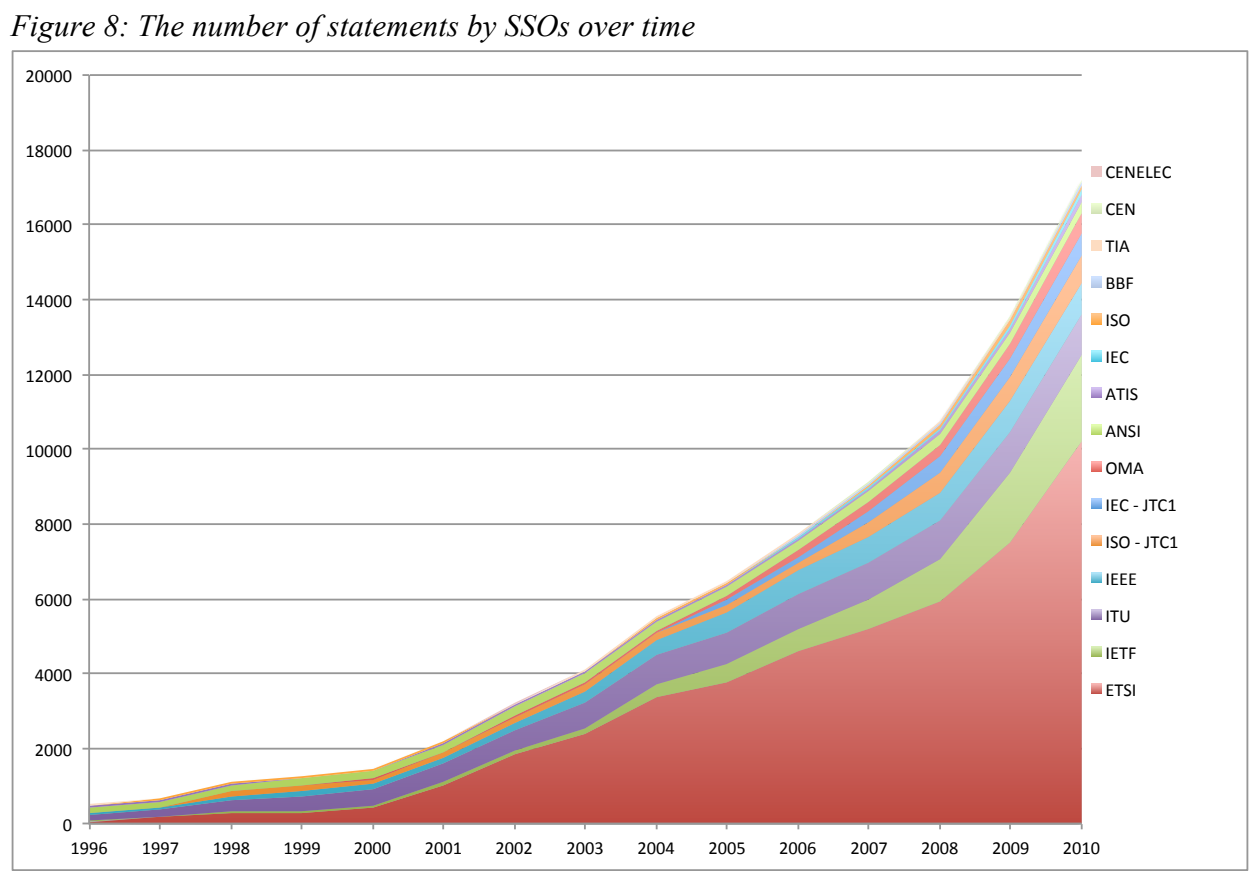

Moving to the second element, we now considered the timing of the underlying patents (if known). ${ }^{13} \mathrm{We}$ did this by comparing their dates with the disclosure data. In other words, we considered how 'old' patents are when they are disclosed as being essential to a standard.

\footnotetext{
${ }^{13}$ If a statement failed to identify a patent, or if it provided erroneous information, or the patent in question was not (yet) available in PATSTAT, we could not complement the required patent information.
} 
Patents that are disclosed may differ widely in age. Some patents have already been applied for more than 10 years before they are disclosed as essential to a given standards; other patents are applied for at the same time. ${ }^{14}$

A significant caveat applies here. It is important to realize that there might be different reasons for a certain (high) age. While it would be appealing to see these as late disclosures, this is not necessarily the case. In fact, a patented technology might have already been around for, say, ten years before a standardization effort is established that implements this technology. Even if the owner is very prompt in disclosing their patent (supposing they do so directly after they become aware their patent would be essential to the standard), the measured age would still be considerable. A high age, however, can also be the result of a relatively reluctant patent owner who discloses their patent only long after they are actually aware of essentiality to a standard.

In fact, it is impossible to say anything about 'late disclosure' without very detailed information on the moment when a patent owner could reasonably have been aware of essentiality (assuming also detailed information on the exact technical development of the draft standard and different versions of the standard over time are available); and without a deep understanding of the disclosure rules at the SSO in question (which are often ambiguous about the required timing, as they understand early disclosure has both benefits and costs). This data is almost never available, not even for a single case (apart from an extremely 'simple' standard perhaps).

Figure 9 shows the average age of the patent by the time it is disclosed as being essential. Since a given patent might be applied for at a certain date in the specified country, but be equal to another patent being applied for earlier on in another country, we also measured both the time lag from the application date and from the priority date of the patents. Table 5 provides the same information, but then expressed as average years, and broken down by SSO as well as by technology area. On average, a patent is disclosed as being essential 7 years after its application date, and 8 years after its priority date.

Figure 9 Distribution of the lags between patent application and SEP disclosure to SSO (in years)

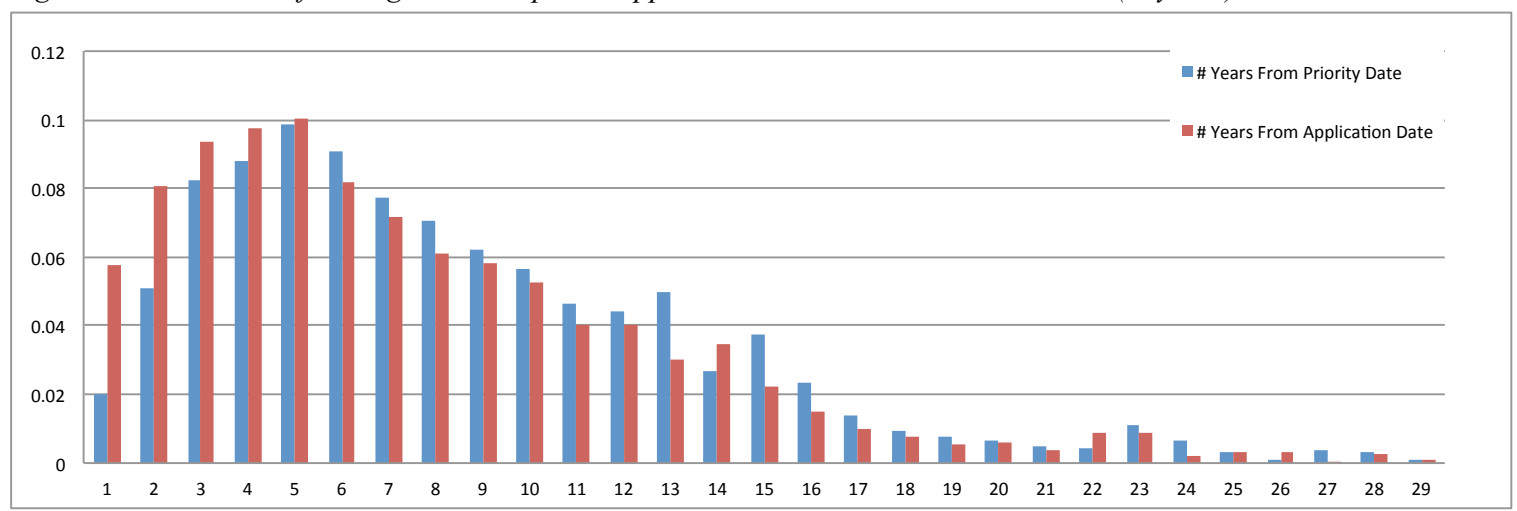

\footnotetext{
${ }^{14}$ If we consider the priority date of a patent, we can assume that the 'age' of a disclosed patent is never below zero, because firms will not disclose a patent that is not even applied for anywhere in the world. If we would have considered the filing date or any of the publication dates, the age value could have become negative.
} 
Table 5: Distribution of the lags between patent application and SEP disclosure to SSO

\begin{tabular}{|c|c|c|c|c|c|c|c|}
\hline & \multirow{2}{*}{$\begin{array}{l}\text { Number of } \\
\text { considered } \\
\text { statements }\end{array}$} & \multicolumn{2}{|c|}{$\begin{array}{l}\text { Lag from application to } \\
\text { disclosure (years) }\end{array}$} & \multicolumn{2}{|c|}{$\begin{array}{l}\text { Lag from priority date to } \\
\text { disclosure (years) }\end{array}$} & \multicolumn{2}{|c|}{$\begin{array}{c}\text { Lag from priority date to } \\
\text { application (years) }\end{array}$} \\
\hline & & Average & Std Dev & Average & Std Dev & Average & Std Dev \\
\hline ETSI & 10243 & 7.07 & 5.70 & 8.00 & 5.70 & 0.93 & 1.27 \\
\hline IETF & 2336 & 7.13 & 4.30 & 8.21 & 4.54 & 1.08 & 1.99 \\
\hline ITU & 1083 & 7.10 & 5.56 & 8.12 & 5.75 & 1.02 & 1.65 \\
\hline IEEE & 839 & 7.04 & 4.73 & 7.93 & 4.99 & 0.89 & 1.59 \\
\hline ISO - JTC1 & 759 & 9.39 & 4.78 & 10.43 & 4.71 & 1.04 & 1.40 \\
\hline IEC - JTC1 & 619 & 7.80 & 4.77 & 9.12 & 4.72 & 1.33 & 1.70 \\
\hline OMA & 576 & 4.93 & 3.31 & 5.75 & 3.34 & 0.82 & 1.23 \\
\hline ANSI & 300 & 6.46 & 5.51 & 6.93 & 5.51 & 0.47 & 1.12 \\
\hline ATIS & 206 & 5.10 & 4.55 & 6.25 & 4.63 & 1.16 & 1.66 \\
\hline IEC & 139 & 6.23 & 4.55 & 7.27 & 4.62 & 1.05 & 0.85 \\
\hline ISO & 129 & 8.67 & 4.18 & 9.41 & 4.44 & 0.82 & 1.30 \\
\hline BBF & 74 & 4.76 & 3.36 & 6.34 & 3.75 & 1.58 & 2.13 \\
\hline TIA & 37 & 5.47 & 3.12 & 5.92 & 3.44 & 0.45 & 0.74 \\
\hline CEN & 21 & 8.16 & 3.10 & 8.61 & 2.70 & 0.45 & 0.44 \\
\hline CENELEC & 4 & 4.13 & 0.60 & 4.63 & 0.72 & 0.50 & 0.58 \\
\hline 1 Tele & 12177 & 6.91 & 5.57 & 7.86 & 5.60 & 0.95 & 1.35 \\
\hline $3 \mathrm{IT}$ & 2498 & 7.31 & 4.49 & 8.34 & 4.68 & 1.03 & 1.94 \\
\hline $5 \mathrm{Secu}$ & 927 & 8.43 & 4.42 & 9.76 & 4.41 & 1.33 & 1.72 \\
\hline $4 \mathrm{AV}$ & 776 & 7.75 & 5.11 & 8.57 & 5.11 & 0.82 & 1.04 \\
\hline 2 LAN & 381 & 7.65 & 5.30 & 8.47 & 5.43 & 0.83 & 1.35 \\
\hline 8 Ind & 115 & 5.62 & 4.11 & 6.51 & 4.23 & 0.89 & 0.89 \\
\hline 9 MTS & 37 & 4.82 & 3.96 & 5.90 & 4.02 & 1.08 & 1.55 \\
\hline 6 Trans & 23 & 5.95 & 3.81 & 7.34 & 4.32 & 1.39 & 1.80 \\
\hline 7 Energ & 14 & 6.31 & 4.89 & 7.10 & 4.90 & 1.02 & 0.88 \\
\hline Missing $\left({ }^{*}\right)$ & 43 & 6.11 & 4.07 & 6.95 & 4.39 & 0.84 & 1.91 \\
\hline Other & 117 & 8.12 & 4.39 & 8.92 & 4.50 & 0.86 & 1.13 \\
\hline Uncoded & 257 & 6.51 & 5.72 & 6.92 & 5.69 & 0.41 & 0.92 \\
\hline Total & 17365 & 7.08 & 5.34 & 8.05 & 5.39 & 0.97 & 1.46 \\
\hline
\end{tabular}

\subsection{Disclosure of SEPs for individual standards}

To most insiders it will come as no surprise that disclosed SEPs are strongly skewed to a relatively small set of standards. A few standards attract hundreds or even thousands of disclosed SEPs, whereas most standards (that do have disclosed SEPs) only have a few. Before we can report on this distribution, however, the information on standards in the patent disclosures needs to be cleaned and harmonized. This is not an easy task, which is further explained in Box 1. 
Box 1: The cleaning and harmonization of references to standards

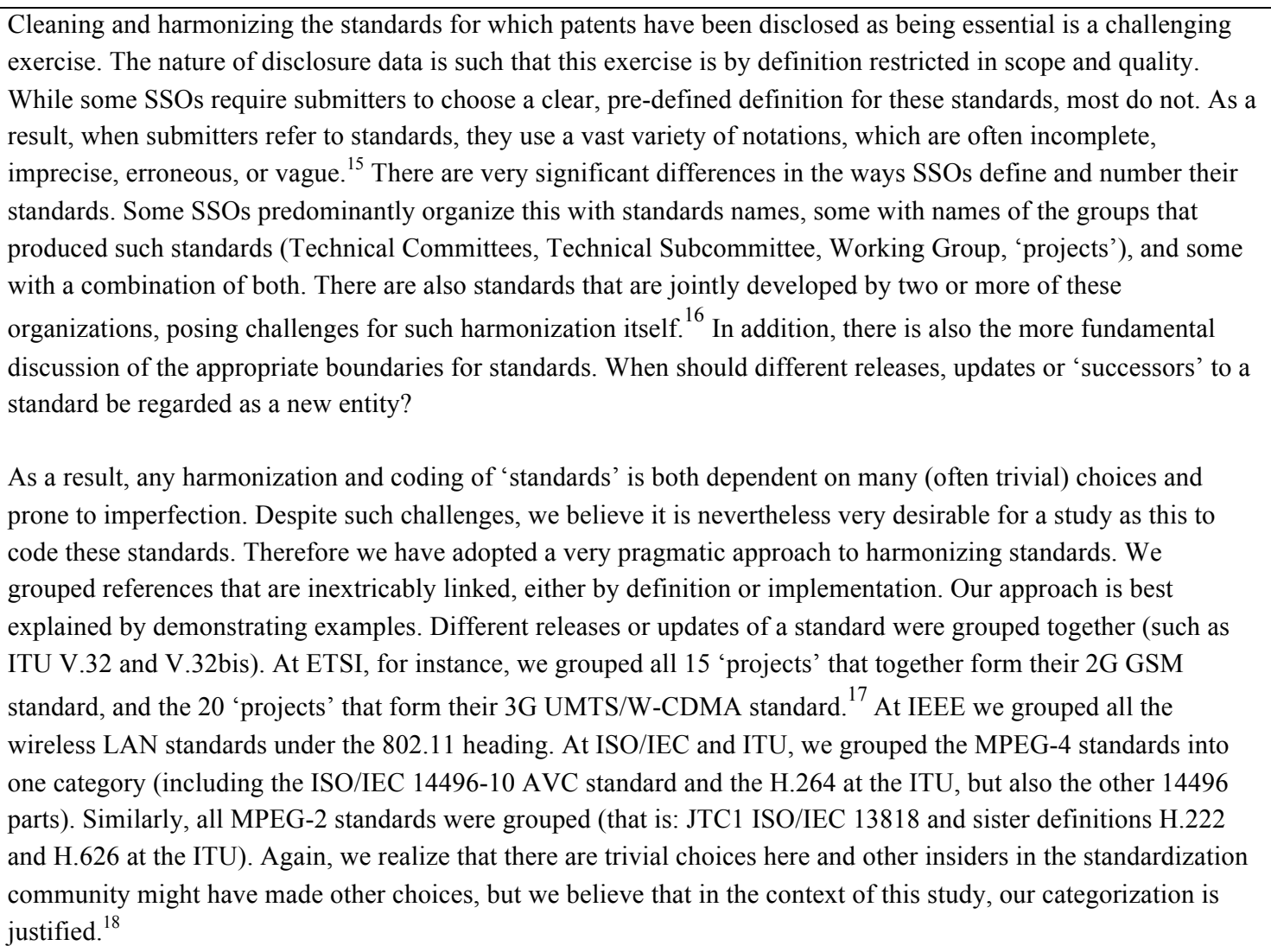

Table 6 shows some of the distributional characteristics of the 1486 different standards we distinguished among the patent disclosures. There is a group of just 7 standards that have more than 100 disclosure events. These 7 standards are 'large' in every respect: they attracted an average of approximately 4,500 statements, of which 22 per cent are blanket statements. They represent almost 31,000 of all 43,000 statements. Put differently: just 7 of the 1486 standards represent 72 percent of all patent statements, illustrating the extreme skewness of the distribution. On the other side of the spectrum, there is a group of no fewer than 886 standards that have just one disclosure event, with an average of 2.7 statements, half of which are blanket statements.

\footnotetext{
${ }^{15}$ It is hard to identify the referred standards when the only reference a disclosure includes is like 'draft-brusilovsky-pak-11', 'rim-ipr-draft-allen-dispatch-imei-urn-as-instanceid-00' or 'juniper-ipr-draft-kuarsingh-v6ops-6to4-provider-managed-tunnel00'. There are also many typos such as 'TIA J-SDT-009' (which presumably should be 'TIA J-STD-009'), which challenge automated cleaning.

${ }^{16}$ For instance the popular H.264/AVC standard for video coding was developed jointly by ISO, IEC and ITU. At the first two organizations, this is known as JTC1 ISO/IEC 14496-10 - being part 10 of the broader MPEG-4 standard, while at ITU, it is known as H.264 standard, a 'stand alone standard'.

${ }^{17}$ For the exact groups, see the footnotes 19, 20 and 21, below.

${ }^{18}$ We would also like to point out, that for the purpose of our analysis, it is preferable to have a slightly more encompassing than too narrow a definition of standards.
} 
Table 6. Size of groups based on disclosure events and their features

\begin{tabular}{|c|c|c|c|c|c|c|}
\hline $\begin{array}{l}\text { Size of groups/No. of } \\
\text { disclosure events }\end{array}$ & $\begin{array}{l}\text { No. of } \\
\text { standards }\end{array}$ & $\begin{array}{l}\text { Aver. No. of } \\
\text { statements }\end{array}$ & $\begin{array}{l}\text { Min. No. of } \\
\text { statements }\end{array}$ & $\begin{array}{l}\text { Max. No. of } \\
\text { statements }\end{array}$ & $\begin{array}{l}\text { Total No. of } \\
\text { statements }\end{array}$ & $\begin{array}{l}\text { Aver. blanket } \\
\text { statements }\end{array}$ \\
\hline$>100$ disclosure events & 7 & 4422.9 & 381 & 16007 & 30960 & $22 \%$ \\
\hline 51-100 disclosure events & 6 & 173.7 & 92 & 335 & 1042 & $43 \%$ \\
\hline 11-20 disclosure events & 45 & 45.4 & 12 & 169 & 2043 & $40 \%$ \\
\hline 21-50 disclosure events & 25 & 87.5 & 22 & 270 & 2187 & $61 \%$ \\
\hline 6-10 disclosure events & 80 & 19.2 & 6 & 111 & 1537 & $46 \%$ \\
\hline 3-5 disclosure events & 200 & 10.9 & 3 & 61 & 2173 & $47 \%$ \\
\hline 2 disclosure events & 237 & 5.3 & 2 & 59 & 1247 & $47 \%$ \\
\hline 1 disclosure event & 886 & 2.7 & 1 & 57 & 2421 & $50 \%$ \\
\hline Grand Total & 1486 & 29.3 & 1 & 16007 & 43610 & $49 \%$ \\
\hline
\end{tabular}

Then we further investigated the 'large' standards. Table 7 lists all 24 standards that have 100 or more patent statements. We see quite a few usual suspects in this list, but also some standards that may come as a surprise, such as a standard on friction stir welding, illustrating that essential standards are by no means restricted to ICT or compatibility standards. 
Table 7. The 24 standards that have 100 or more patent statements

\begin{tabular}{|c|c|c|c|c|}
\hline Standard & Description & $\begin{array}{l}\text { Total } \\
\text { disclosure } \\
\text { events }\end{array}$ & $\begin{array}{c}\text { Total } \\
\text { statements }\end{array}$ & $\begin{array}{l}\text { Identified unique } \\
\text { DOCDB families }\end{array}$ \\
\hline ETSI grouping $3 \mathrm{G}$ & $\begin{array}{l}\text { Standard for } 3 \mathrm{G} \text { mobile telecommunications, a.k.a. UMTS, W-CDMA and } \\
3 \mathrm{GPP}^{19}\end{array}$ & 343 & 16007 & 2784 \\
\hline ETSI grouping $2 \mathrm{G}$ & Standard for $2 \mathrm{G}$ mobile telecommunications, a.k.a. GSM and DCS- $1800^{20}$ & 170 & 7458 & 1114 \\
\hline ETSI project LTE & Standard for $4 \mathrm{G}$ mobile telecommunications & 125 & 3876 & 1588 \\
\hline $\begin{array}{l}\text { JTC1 ISO/IEC } 14496 \\
\text { incl. ITU H.264 }\end{array}$ & $\begin{array}{l}\text { Standard for video compression, aka MPEG-4 Part 10, Advanced Video } \\
\text { Coding. Developed as collaboration between ISO/IEC JTC1 and ITU. Used } \\
\text { in many devices including Blu-ray players, game consoles, computer } \\
\text { software, etc. }\end{array}$ & 265 & $1682(*)$ & $146(*)$ \\
\hline JTC1 ISO/IEC 18000 & Standard for RFID technologies & 104 & $1107(*)$ & $161(*)$ \\
\hline IEEE 802.11 & Standard for wireless Local Area Networks, popularly known as 'Wi-Fi' & 167 & $449(*)$ & $136(*)$ \\
\hline $\begin{array}{l}\text { JTC1 ISO/IEC } 13818 \\
\text { and H.222 and H.626 }\end{array}$ & $\begin{array}{l}\text { Standard for video compression, aka MPEG-2. Parts } 1 \text { and } 2 \text { of MPEG-2 } \\
\text { were developed in collaboration with ITU-T. Used in many devices } \\
\text { including DVD players, computer software, etc. }\end{array}$ & 121 & $381(*)$ & $46\left(^{*}\right)$ \\
\hline IEEE 802.16 & $\begin{array}{l}\text { Standard for wireless Metropolitan Area Networks., popularly known as } \\
\text { 'WiMax' }\end{array}$ & 90 & $335(*)$ & $196(*)$ \\
\hline ETSI grouping DVB & Standard for digital television broadcast ${ }^{21}$ & 40 & 270 & 106 \\
\hline ITU G.992 & $\begin{array}{l}\text { Standard for ADSL, for delivering internet services to residential homes } \\
\text { via telephone cables }\end{array}$ & 65 & $229(*)$ & $38(*)$ \\
\hline ITU M.1225 & $\begin{array}{l}\text { Not a product standard in itself, but guidelines for the various } 3 \mathrm{G} \text { mobile } \\
\text { technologies were going to be evaluated by ITU (the so-called process for } \\
\text { IMT-2000) }\end{array}$ & 43 & $204(*)$ & $64(*)$ \\
\hline ISO 25239 & $\begin{array}{l}\text { Standard for friction stir welding, a technique that is applied in } \\
\text { shipbuilding, aerospace, automotive and railway sectors, among others }\end{array}$ & 35 & $191(*)$ & $0(*)$ \\
\hline $\begin{array}{l}\text { ETSI group BRAN } \\
\text { HIPERLAN/2 } \\
\text { HIPERMAN }\end{array}$ & $\begin{array}{l}\text { ETSI activities for Broadband Radio Access Networks (BRAN), including } \\
\text { HiperLan/2, HiperAccess, HiperMan }\end{array}$ & 17 & 169 & 74 \\
\hline JTC1 ISO/IEC 15938 & Standard for multimedia content description, also known as MPEG-7 & 42 & $167(*)$ & $1(*)$ \\
\hline IEEE 802.3 & Wired LAN standard known as Ethernet & 99 & $149\left(^{*}\right)$ & $53(*)$ \\
\hline ETSI project TETRA & $\begin{array}{l}\text { Standard for professional mobile radio applications for policy, ambulance } \\
\text { and fire brigade applications, as well as commercial use }\end{array}$ & 21 & 144 & 42 \\
\hline ITU G.729 & $\begin{array}{l}\text { Voice compression technology used in Voice over Internet Protocol } \\
\text { (VoIP) application, among others }\end{array}$ & 57 & $132(*)$ & $37\left(^{*}\right)$ \\
\hline TIA 136 & $\begin{array}{l}\text { Second generation (2G) mobile telecommunication standard developed } \\
\text { in the US, known as D-AMPS. Now considered end-of-life and replaced by } \\
\text { GSM or } 3 \text { G technologies }\end{array}$ & 31 & $124(*)$ & $0(*)$ \\
\hline ITU G.993 & $\begin{array}{l}\text { Standard for VDSL, for delivering internet services to residential homes } \\
\text { via telephone cables. Faster than ADSL }\end{array}$ & 43 & $117(*)$ & $35(*)$ \\
\hline OMA WAP & $\begin{array}{l}\text { Wireless Application Protocol (WAP), for interactive data services on } \\
\text { mobile phones. Now considered end-of-life }\end{array}$ & 17 & 117 & 34 \\
\hline ITU M.1457 & $\begin{array}{l}\text { Again not a product standard in itself, but detailed specifications of the } \\
\text { terrestrial radio interfaces of International Mobile Telecommunications- } \\
2000 \text { (IMT-2000) }\end{array}$ & 14 & $113(*)$ & $22(*)$ \\
\hline JTC1 ISO/IEC 14888 & Techniques for digital signatures & 8 & $111(*)$ & $7(*)$ \\
\hline IEEE 802.1 & $\begin{array}{l}\text { Standard for architecture, interworking, overall network management } \\
\text { and several other general elements of LAN and MAN networks }\end{array}$ & 9 & $105\left(^{*}\right)$ & $36(*)$ \\
\hline JTC1 ISO/IEC 11172 & $\begin{array}{l}\text { MPEG-1 is a standard for compression of video and audio. Used for digital } \\
\text { radio and video CD, but best known for the MP3 audio format it } \\
\text { introduced (which is officially called MPEG-1 Part } 3)^{22}\end{array}$ & 41 & $100(*)$ & $0(*)$ \\
\hline
\end{tabular}

$\left.{ }^{*}\right)$ Blanket disclosures are allowed in these bodies. As a result, the number of identified unique DOCDB families may be a gross undercount of actual SEP ownership.

${ }^{19}$ This group includes the following ETSI projects: 3GPP, 3GPP / AMR-WB, 3GPP / AMR-WB+, 3GPP / EMS, 3GPP Release 7, 3 GPP Release 99, HSPA+, HSUPA, UMTS, UMTS / CDMA, UMTS FDD, UMTS Release 4, UMTS Release 5, UMTS Release 6, UMTS Release 7, UMTS Release 8, UMTS Release 9, UMTS Release 99, WCDMA, SAE.

${ }^{20}$ This group includes the following ETSI projects: DCS 1800, GPRS, GSM, GSM / AMR-NB, GSM / TDMA, GSM Release 6, GSM Release 7, GSM Release 98, GSM Release 99, GERAN, GERAN Release 6, GERAN Release 7, GERAN Release 8, GERAN Release 98, GERAN Release 99.

${ }^{21}$ This group includes the following ETSI projects: DVB, DVB-C2, DVB-H, DVB-S2, DVB-SH, DVB-T2.

${ }^{22}$ Later, an audio layer was introduced in MPEG-2 that provides backward compatibility with MPEG-1 Part 3 . As such, the common term 'MP3' typically refers to both MPEG-1 Part 3 (Audio Layer III) and MPEG-2 Part 3 (Audio Layer III). 


\subsection{Patent disclosure and business models}

What type of companies or organizations own essential patents? For this study, we examined the business model of parties that disclosed having standard essential patents. We determined the business model for 334 organizations, which included all organizations with 7 or more statements in the database, as well as firms with 6 or fewer statements but with a well-known firm name (to ensure that we did not miss any very significant firm that nevertheless only made one very broad blanket claim). This sub-sample accounts for just over 80 percent of all declared essential IPR. The remaining tail of firms is long (981 organizations) but mostly made up of small firms, and also includes numerous inventor names. Each of the investigated organizations was assigned to one of eleven business model categories. While any such classification is inherently subjective, we found that it was often (though not always) relatively easy to assign organizations to a particular category. Categories A, B, C and D can be considered 'upstream' business models: these organizations serve parties downstream in the business chain, either by supplying knowledge or products. Categories E and F can be considered 'downstream' business models: these companies provide products or services to end users.

Table 8 shows the presence of the various types of business models. Regarding both the number of declarations and the number of statements, equipment suppliers are clearly the largest category. Note that all of these are by definition vertically integrated companies as they can only feature in this table if they are (also) a patent owner.

Table 8: Business models of organizations that disclose essential IPR (for the 334 'largest' firms, see text)

\begin{tabular}{|c|c|c|c|c|}
\hline Business model & Declarations & $\begin{array}{c}\text { Share of } \\
\text { declarations }\end{array}$ & Statements & $\begin{array}{c}\text { Share of } \\
\text { statements }\end{array}$ \\
\hline $\begin{array}{l}\text { A. Pure upstream knowledge developer or } \\
\text { patent holding company (excl. universities) }\end{array}$ & 147 & $3.6 \%$ & 5,598 & $12.5 \%$ \\
\hline $\begin{array}{l}\text { B. Universities / public research institutes / } \\
\text { states }\end{array}$ & 162 & $4.0 \%$ & 499 & $1.1 \%$ \\
\hline C. Components (incl. semiconductors) & 518 & $12.8 \%$ & 8,889 & $19.9 \%$ \\
\hline D. Software and software-based services & 232 & $5.7 \%$ & 975 & $2.2 \%$ \\
\hline $\begin{array}{l}\text { E. Equipment suppliers, product vendors, system } \\
\text { integrators }\end{array}$ & 2,435 & $60.0 \%$ & 25,075 & $56.1 \%$ \\
\hline $\begin{array}{l}\text { F. Service providers (telecommunications, radio, } \\
\text { television, etc.) }\end{array}$ & 454 & $11.2 \%$ & 3,291 & $7.4 \%$ \\
\hline $\begin{array}{l}\text { G. SSOs, fora and consortia, technology } \\
\text { promoters }\end{array}$ & 13 & $0.3 \%$ & 60 & $0.1 \%$ \\
\hline H. Other & 26 & $0.6 \%$ & 56 & $0.1 \%$ \\
\hline I. Too diverse to categorize & 30 & $1 \%$ & 116 & $0.3 \%$ \\
\hline J. Individual patent owner & 33 & $1 \%$ & 94 & $0.2 \%$ \\
\hline K. Measurement and instrument, test systems & 9 & $0 \%$ & 39 & $0.1 \%$ \\
\hline Total & 4,059 & $100 \%$ & 44,692 & $100 \%$ \\
\hline
\end{tabular}


It is quite conceivable that there are differences between SSOs in this respect. Such differences are shown in Table 9. The highlighted cells denote shares that differ considerably (either in a positive or negative sense) from the average.

Table 9. Share of statements by business models and by SSO (for 334 'largest' firms, see text)

\begin{tabular}{|c|c|c|c|c|c|c|c|c|c|c|c|c|c|c|c|c|}
\hline Row Labels & $\bar{n}$ & $\stackrel{n}{\frac{1}{\varepsilon}}$ & 岕 & 总 & 总 & $\overline{\bar{n}}$ & $\stackrel{\underline{\underline{u}}}{2}$ & 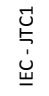 & 㞧 & 密 & $\stackrel{\circ}{\circ}$ & 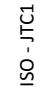 & $\stackrel{?}{\mathrm{E}}$ & $\sum_{0}^{\nwarrow}$ & $\overleftrightarrow{\leftrightarrows}$ & $\begin{array}{l}\bar{\pi} \\
\stackrel{5}{\circ}\end{array}$ \\
\hline $\begin{array}{l}\text { A. Pure upstream knowledge developer or } \\
\text { patent holding company (excl. universities) }\end{array}$ & $4 \%$ & $6 \%$ & $0 \%$ & $0 \%$ & $0 \%$ & $15 \%$ & $2 \%$ & $6 \%$ & $7 \%$ & $22 \%$ & $0 \%$ & $5 \%$ & $3 \%$ & $1 \%$ & $1 \%$ & $13 \%$ \\
\hline $\begin{array}{l}\text { B. Universities / public research institutes / } \\
\text { states }\end{array}$ & $0 \%$ & $1 \%$ & $0 \%$ & $0 \%$ & $0 \%$ & $0 \%$ & $1 \%$ & $1 \%$ & $4 \%$ & $1 \%$ & $13 \%$ & $7 \%$ & $3 \%$ & $0 \%$ & $0 \%$ & $1 \%$ \\
\hline C. Components (incl. semiconductors) & $8 \%$ & $34 \%$ & $60 \%$ & $100 \%$ & $0 \%$ & $24 \%$ & $10 \%$ & $10 \%$ & $12 \%$ & $11 \%$ & $13 \%$ & $6 \%$ & $7 \%$ & $27 \%$ & $23 \%$ & $20 \%$ \\
\hline D. Software and software-based services & $20 \%$ & $19 \%$ & $5 \%$ & $0 \%$ & $0 \%$ & $0 \%$ & $0 \%$ & $3 \%$ & $4 \%$ & $6 \%$ & $8 \%$ & $4 \%$ & $5 \%$ & $4 \%$ & $0 \%$ & $2 \%$ \\
\hline $\begin{array}{l}\text { E. Equipment suppliers, product vendors, } \\
\text { system integrators }\end{array}$ & $52 \%$ & $29 \%$ & $17 \%$ & $0 \%$ & $33 \%$ & $57 \%$ & $55 \%$ & $62 \%$ & $54 \%$ & $43 \%$ & $57 \%$ & $59 \%$ & $57 \%$ & $65 \%$ & $67 \%$ & $56 \%$ \\
\hline $\begin{array}{l}\text { F. Service providers (telecommunications, } \\
\text { radio, television, etc.) }\end{array}$ & $8 \%$ & $11 \%$ & $18 \%$ & $0 \%$ & $0 \%$ & $3 \%$ & $13 \%$ & $15 \%$ & $18 \%$ & $15 \%$ & $0 \%$ & $16 \%$ & $21 \%$ & $3 \%$ & $7 \%$ & $7 \%$ \\
\hline $\begin{array}{l}\text { G. SSOs, fora and consortia, technology } \\
\text { promoters }\end{array}$ & $0 \%$ & $0 \%$ & $0 \%$ & $0 \%$ & $67 \%$ & $0 \%$ & $13 \%$ & $0 \%$ & $0 \%$ & $0 \%$ & $0 \%$ & $0 \%$ & $0 \%$ & $0 \%$ & $1 \%$ & $0 \%$ \\
\hline H. Other & $4 \%$ & $0 \%$ & $0 \%$ & $0 \%$ & $0 \%$ & $0 \%$ & $2 \%$ & $0 \%$ & $0 \%$ & $1 \%$ & $2 \%$ & $0 \%$ & $0 \%$ & $0 \%$ & $0 \%$ & $0 \%$ \\
\hline I. Too diverse to categorize & $2 \%$ & $0 \%$ & $0 \%$ & $0 \%$ & $0 \%$ & $0 \%$ & $1 \%$ & $2 \%$ & $0 \%$ & $0 \%$ & $7 \%$ & $1 \%$ & $1 \%$ & $0 \%$ & $0 \%$ & $0 \%$ \\
\hline J. Individual patent owner & $1 \%$ & $0 \%$ & $0 \%$ & $0 \%$ & $0 \%$ & $0 \%$ & $2 \%$ & $0 \%$ & $1 \%$ & $2 \%$ & $0 \%$ & $0 \%$ & $0 \%$ & $0 \%$ & $0 \%$ & $0 \%$ \\
\hline K. Measurement and instrument, test systems & $0 \%$ & $0 \%$ & $0 \%$ & $0 \%$ & $0 \%$ & $0 \%$ & $2 \%$ & $0 \%$ & $0 \%$ & $0 \%$ & $0 \%$ & $0 \%$ & $1 \%$ & $0 \%$ & $0 \%$ & $0 \%$ \\
\hline Grand Total & $\hat{\emptyset}$ & 品 & $\stackrel{\mathscr{m}}{\rightarrow}$ & $\stackrel{\infty}{\sim}$ & $\approx$ & $\begin{array}{c}\text { 岁 } \\
\infty \\
\infty \\
\infty\end{array}$ & $\underset{N}{\mathscr{N}}$ & $\underset{\substack{m \\
-i}}{\stackrel{m}{i}}$ & $\underset{\substack{n \\
r}}{i}$ & 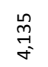 & $\vec{m}$ & $\underset{\substack{0 \\
i}}{a}$ & 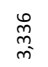 & న̆ & Oి & 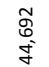 \\
\hline
\end{tabular}

Note: Orange shading indicates that the total numbers for the $\mathrm{SSO}$ are too small to make these individual numbers representative

\subsection{Dead or alive?}

Apart from the question whether a disclosed patent is actually essential or not, the mere fact that a party disclosed a patent does not necessarily mean that patent is actually granted and enforceable. Using the so-called INPADOC Legal Data for all the disclosed patents we identified at the EPO and the USPTO, we categorized each patent into one of the following, mutually exclusive categories:

'Alive' The patent has been granted and is enforceable

'Pending $<20$ yrs.' There has been a patent filing but no patent grand yet

'Pending $>20$ yrs.' There has been a patent filing, but 20 years have passed so a future grand is impossible

'Lapsed' The patent was granted, but the owner failed to pay the fees, rendering the patent unenforceable ${ }^{23}$

'Expired' As the name implies, the patent has reached its maximum lifetime and is no longer enforceable

\footnotetext{
${ }^{23}$ For the EPO, the situation is somehow more complex, as lapsing occurs nationally. We consider a patent lapsed if it was applied for in Germany and/or France and/or the UK and subsequently lapsed in at least one of these countries.
} 
The results for the EPO patents are shown in Figure 10. We found that almost half of all disclosed EPO patents are not enforceable as of early 2013 when we performed the analysis (Figure 10, right hand side bar). Around a third of the disclosed patents are pending. While the relatively young ones (applied for in 2005 or later) might still have a fair chance of being granted, the older applications have a lower chance. The group of lapsed patents is still 15 percent, which could be found remarkable given the specific value that SEPs represent. The overall share of expired patents is around 5 percent; the time-scale shows the obvious fact that these are mostly old patents. ${ }^{24}$

Figure 10. Legal status of disclosed EPO patents, based on a total of 2351 patents. The horizontal axis is the year of application.

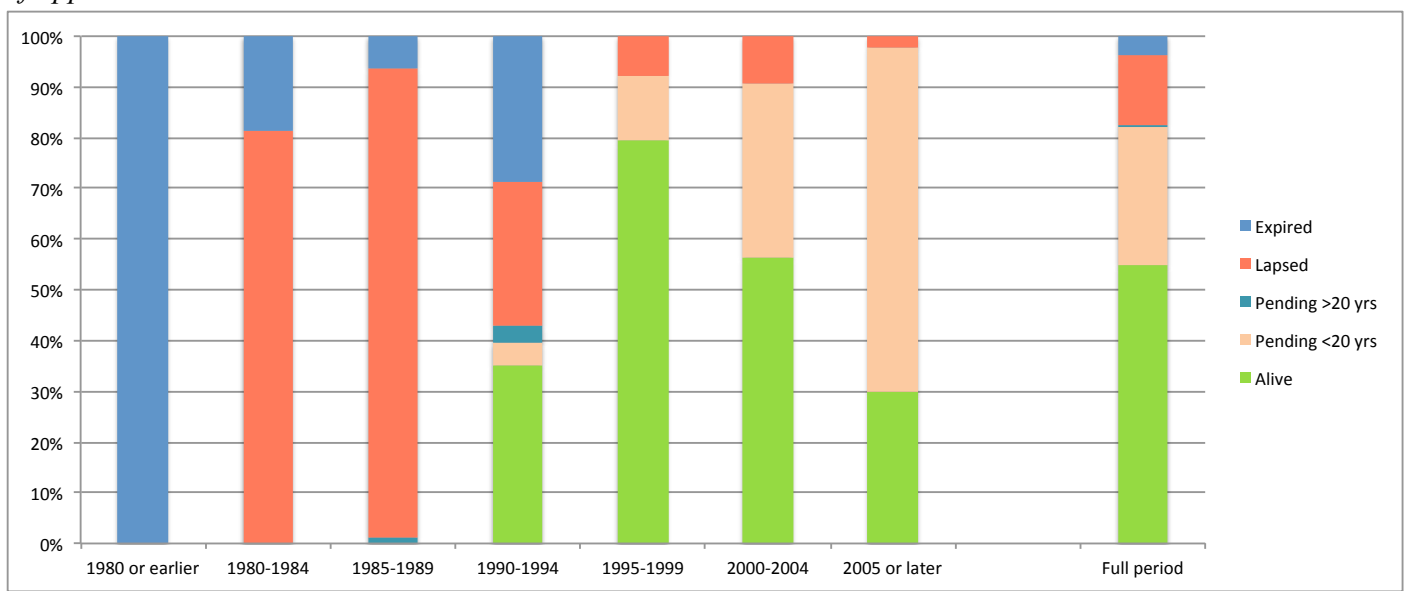

A similar analysis on the (larger) group of disclosed USPTO patents shows a similar pattern (Figure 11). The most remarkable difference is the higher grant rate of patents, due to patent owners failing less often to pay the patent fee.

Figure 11. Legal status of disclosed USPTO patents, based on a total of 7014 patents. The horizontal axis is the year of application.

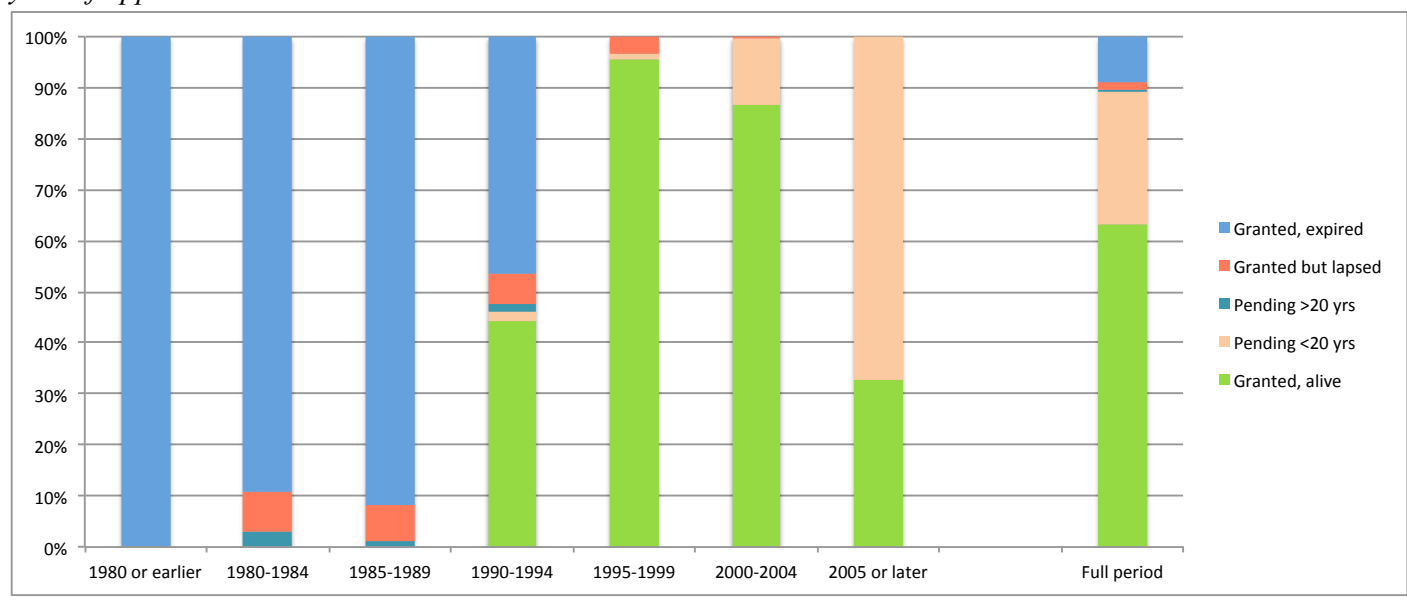

Finally, we note that this section focused on the legal status of patents as determined on the basis of information available at patent offices. We did not investigate to what extent patents

\footnotetext{
${ }^{24}$ The reason the $100 \%$ blue bar on the left results in only a small blue bar for the overall data, is that the number of patents in that category is relatively low.
} 
that are eventually litigated and challenged in court are actually found to be invalid. Anecdotal evidence seems to indicate that invalidation of SEPs is quite common, ${ }^{25}$ but one can only observe this for the patents that are actually challenged (and even then there might be differences between jurisdictions).

\subsection{Summary}

We can summarize the main findings of this section as follows:

We estimate that approximately 12,000 to 18,000 unique SEP patent families underlie the disclosures at the thirteen large SSOs we examined. The number of patents that are essential for standards is very substantial. For the 13 selected, large standard setting bodies, we found 5,000 disclosure events, with 46,294 statements (either a specific patent or a blanket). However, there can be considerable (geographic and non-geographic) overlap in this data. We identified around 20,000 USPTO or EPO patents, relating to 7988 unique innovations (DOCDB patent families). It is known that the disclosure databases used for this analysis are far from perfect and subject to both under and over disclosure. The fact that many standards bodies allow 'blanket disclosures' (see also Section 5) also means that a significant group of essential IPR is not identified. While it is hard to estimate the actual amount of SEPs, we believe these may well be in the range of 1.5 to 2 times the number of patents identified for the selected standard setting bodies. Then there are of course also many other standard setting bodies. The well-known live inventory of SSOs by Andrew Updegrove ${ }^{26}$ includes over 800 organizations, of which the lion's share is best characterized as consortia. Given the typically much narrower size and scope of these bodies, and the fact that many are in areas that do not 'attract' a great deal of standard essential patents, we believe these organizations altogether have fewer SEPs than the 13 organizations we reviewed.

On average, the number of SEPs is doubling every five years. While there are clear peaks (and lows) for certain years, which can probably be contributed to a 'big' standard being developed, the long-term growth is relatively stable.

On average, patents are already 8 years old once they are declared essential. But it is not possible to determine whether these are 'late disclosures' or whether the standard has simply been developed much later than the patent application was submitted.

In almost any dimension, SEP occurrence is highly skewed. Number-wise, it is very much concentrated in:

- a few SSOs (ETSI, and then at a considerable distance IETF, ITU, and JTC-1 (at ISO and IEC);

- a few technology areas (telecommunications, and at some distance, audiovisual, IT, and LAN technologies);

\footnotetext{
${ }^{25}$ See the detailed discussion of recent SEP litigation cases at www.fosspatents.com, a high quality blog created by Florian Mueller.

${ }^{26} \mathrm{See} \mathrm{http://www.consortiuminfo.org/links.}$
} 
- a few standards (just 7 of the 1486 standards represent 72 percent of all patent statements).

However, we should stress that numbers do not say everything. A standard with a single SEP owner demanding 15 percent of running royalties affects implementers more than a standard with hundreds of owners that together only demand, say, 5 percent.

\section{Equipment suppliers are responsible for the largest share of SEP declarations and}

statements. This share is around 60 percent. Component and software suppliers together have another 22 percent, while Non Practicing Entities (NPEs) including universities and research institutes account for around 14 percent.

Many SEPs are not enforceable. Of all the identified SEPs at the EPO, only about half are actually 'live' patents. The remaining patents are either pending (especially recent applications), expired, or have simply lapsed (because the owner failed to pay the patent fee). 


\title{
4 Comparing SEPs with non-SEPs
}

\author{
This chapter was prepared by Rudi Bekkers and Önder Nomaler
}

In this chapter we assess the 'value' of SEPs on the basis of the established scientific literature on "patent value" which draws on various bibliometric indicators. In terms of three such indicators, we compare the SEPs' performance against a larger set of randomly selected patents that are 'similar' to the actual SEPs.

In Section 4.2 we compare the citation score of SEPs with non-SEPs, in Section 4.3 the family size differences, and in Section 4.4 the likelihood to be granted.

\subsection{Data and methodology}

This analysis builds on the OEIDD database, as introduced earlier. In order to do any comparison with non-SEPs, a crucial task is to create a control (or: reference) database of non-SEPs comparable to the essential patents we have. If this task is not done properly, any observed differences could simply stem from a different distribution, instead of actual differences between SEPs and non-SEPs.

Given the practical concerns, our initial aim was to select randomly 20 similar patents (with replacement) for each of the 9408 SEPs identified in the OEIDD database. We imposed three different similarity criteria, one on technology category (i.e. the IPC codes), one on application year, and one on application authority. The latter two criteria are straightforward: for a given 'focal' SEP, each matching (randomly selected) non-SEP should have the same application authority (i.e. EPO and/or USPTO) and the application year should be within the limit of plus or minus two years of the focal patent.

The definition of the former similarity criterion is more complex, mainly because patents may be assigned to any number of different IPC codes. For this discussion, we will call the part of the IPC code before the forward slash ' 5 digit' (e.g. H04L 12) and the entire code ' 6 digit' (e.g. H04L 12/56).

Our strong criteria define similarity on the basis of 6 digit IPC similarity as follows:

1) For a focal patent with one IPC code, each matching patent should have at most two IPC codes, one being identical to that of the focal patent ;

2) For a focal patent with two IPC codes, each matching patent should have at most four IPC codes, two being identical to that of the focal patent;

3) For a focal patent with three IPC codes, each matching patent should have at most eight IPC codes, three being identical to that of the focal patent; 
4) For a focal patent with more than three IPC codes, each matching patent can have any number of IPCs greater than three as long as the IPC code list includes at least three IPC codes of the matching patent.

For focal patents with up to three IPC classes, the sampling procedure prioritizes matching patents with the lower number of IPC classes; for focal patents with more than three IPC codes, priority goes to matching patents with the higher number of IPC code matches.

Eventually, this 'strong criteria' turned out to be too strong. For about half of the SEPs, the number of patents in the entire PATSTAT database was less than 20. Therefore we had to relax our 6-digit-based criterion to 5 digits, while conforming to all the remaining restrictions. However, throughout the (otherwise random) sampling procedure, 6-digit matches took priority over 5-digit matches whenever they existed. In order to reduce the polarity between the SEPs with a low number and a high number of matches, we also relaxed the "20 matching patents" criteria and made the maximum size of the matching set (for each focal patent) a random number between 10 and 20 .

Consequently we compiled a control set of 121,971 matching patents. No appropriate matching patents could be found for only 166 of the 9408 SEPs. For another 164 SEPs, the IPC codes were unknown (i.e. not present in PATSTAT), thus we could not find matching patents for these either. Taking into account the remainder of 9078 patents, 121,971 matching patents implies that we found an average of 13 non-SEP matches per SEP.

\subsection{Citation score of SEPs versus non-SEPs}

Economists of innovation have attempted to assess the value of patents using a number of characteristics such as citations received, renewals, family size, opposition, etc. ${ }^{27}$ So far, the number of forward citations (i.e. received by a patent) is certainly the most popular indicator of patent value. Following the pioneering contributions of Carpenter et al. ${ }^{28}$ and Trajtenberg, ${ }^{29}$ various studies have consistently established that forward citations are systematically correlated with the economic value or the industrial importance of patents. ${ }^{30}$ The idea behind the use of forward citations as indicator of a patent's value is relatively straightforward: if a patent receives many citations, this means that the technological solution outlined in the patent serves as a basis for a large number of subsequent technological developments. Another related argument is that if a patent receives many citations, this may also mean that it has been frequently used by patent examiners to reduce the scope of protection claimed by

\footnotetext{
${ }^{27}$ A detailed survey of this literature is provided in Van Zeebroeck, N., 2011. The Puzzle of Patent Value Indicators. Economics of Innovation and New Technology 20, 33-62.

${ }^{28}$ Carpenter, M.P., Narin, F. \& Woolf, P., 1981. 'Citation rates to technologically important patents'. World Patent Information 3, 160-163.

${ }^{29}$ Trajtenberg, M., 1990. A Penny for your Quotes: Patent Citations and the Value of Innovations. RAND Journal of Economics 21, 172-187.

${ }^{30}$ See for example Albert, M.B. et al., 1991. Direct validation of citation counts as indicators of industrially important patents. Research Policy 20, 251-259, and Sampat, B.N. \& Ziedonis, A.A. (2004). 'Patent citations and the economic value of patents', in: Moed, H.F., Glanzel, W. \& Schmoch, U. (Eds), Handbook of Quantitative Science and Technology Research. Kluwer, Dordrecht, the Netherlands, 277-299.
} 
subsequent patents; this again points to the significance of the technological solution contained in the original patent. ${ }^{31}$ For all these reasons, it seems acceptable to presume that the technological value of a patent will be captured by the number of forward citations.

When considering the citation performance of essential patents, it is important to realize that there may be an endogeneity effect: patents may receive citations because they are disclosed as being essential. ${ }^{32}$ This effect is studied in a paper by Rysman and Simcoe ${ }^{33}$ among others. Therefore, any comparison of the performance between SEPs and non-SEPs should bear in mind this possibility.

We compared the citation performance of the SEPs in our database with the control set of non-SEPs. Since the latter is based on a matching process, and therefore has identical distributional features in terms of application years and technology class, we had already satisfied the standard corrections as suggested by Jaffe and Trajtenberg. ${ }^{34}$

In terms of the average number of citations received (not shown), SEPs perform significantly worse than non-SEPs in the first 5 years, whereas the situation is dramatically reversed thereafter. Since citation results may be easily influenced by extreme outliers in the observations, instead of looking merely at averages, we present here the (cumulative) distributions, which, nevertheless fully correspond with the average figures. Figure 12 shows the citations results for 1, 2, 3 and 4 years after the date of the publications (if any) that receive any citations. The vertical scale shows the share of patents that has a certain number of citations or less. We see that in the first 4 years, SEPs have a lower citation performance than non-SEPs. For instance, the fourth graph shows that 4 years after patent application, around 90 percent of the SEPs received three or more citations, whereas around 90 percent of the non-SEPs received six or more citations. In earlier years, the situation is even worse. For example, within the first year after the related publication, more than 99 percent of the SEPs receive no citations at all, while about 12 percent of the non-SEPs receive at least one citation.

\footnotetext{
${ }^{31}$ Van Zeebroeck, 2011, see Note 27 above.

${ }^{32}$ Firstly, SEPs are more 'visible'. Secondly, companies may direct their follow-up research towards existing SEPs, hoping that new research is valuable for products relating to (popular) standards, and perhaps even become SEPs for newer releases of the standard themselves.

${ }^{33}$ Rysman, M., \& Simcoe, T. (2008). Patents and the Performance of Voluntary Standard-Setting Organizations. Management Science, 54(11), 1920-1934.

${ }^{34}$ Jaffe, A. B., \& Trajtenberg, M. (Eds.). (2002). Citations \& Innovations: A Window on the Knowledge Economy. MIT Press.
} 
Figure 12. SEP vs. non-SEP citation performance for 1, 2, 3 and 4 years after patent publication
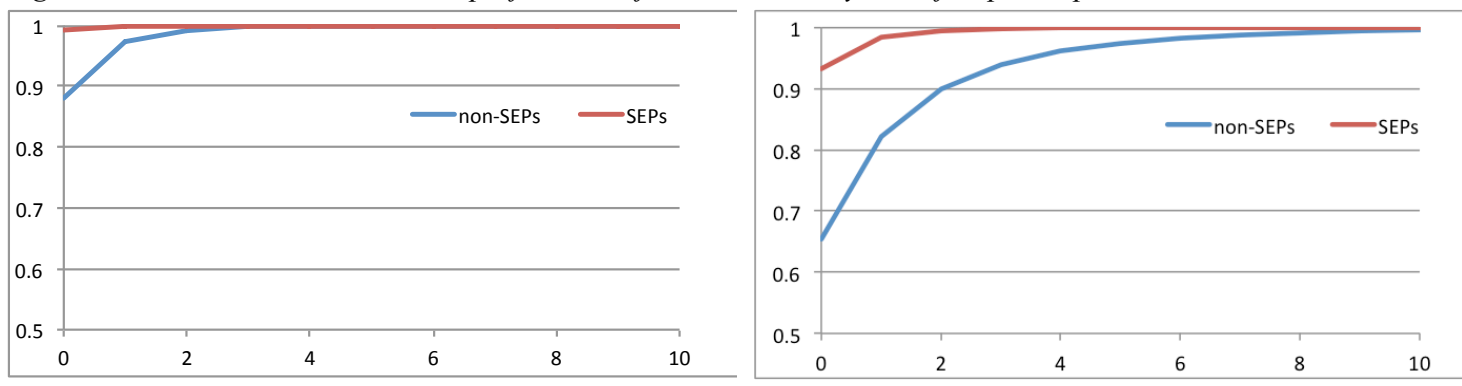

1 year after patent publication

2 years after patent publication
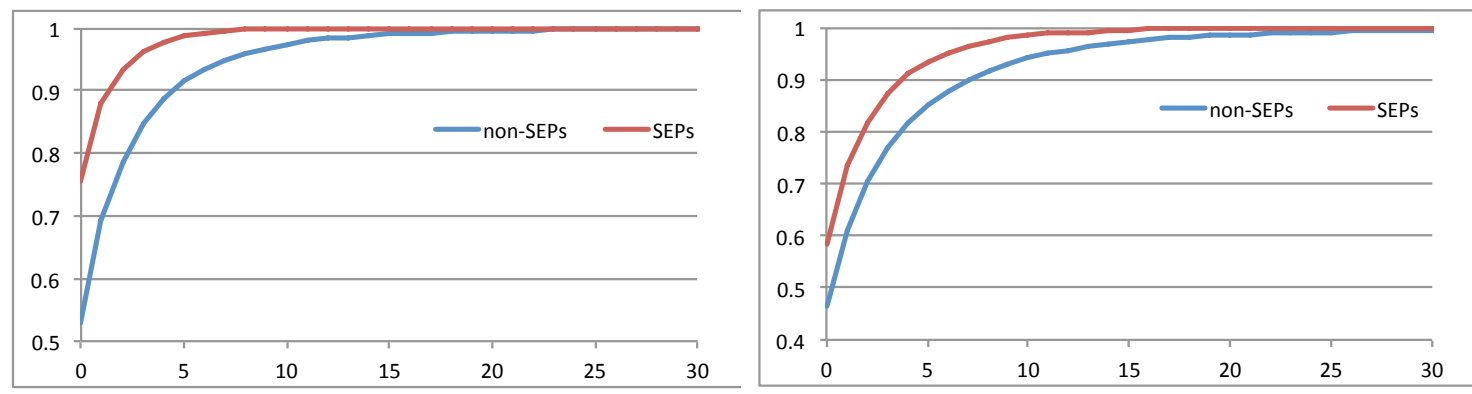

3 years after patent publication

4 years after patent publication

In Figure 14 we see the results for 5, 10 and 15 years after the related patent publication, respectively. At 5 years, SEPs are getting close to the citation performance of non-SEPs, and for 10 and 15 years after their application, SEPs have a clearly superior citing performance compared to non-SEPs.

Figure 13. SEP vs. non-SEP citation performance for 5, 10, and 15 years after publication

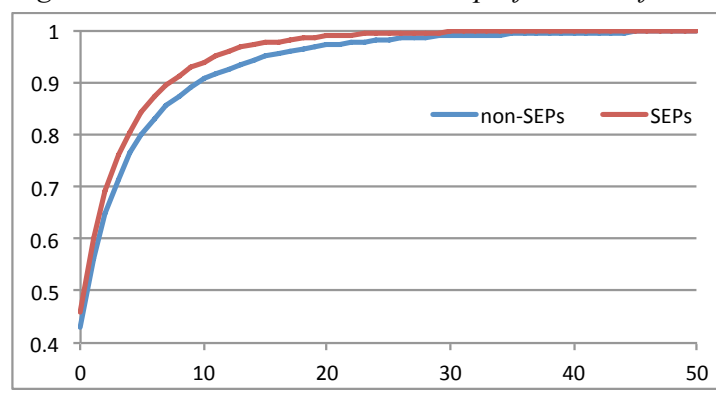

Citation performance 5 years after patent publication

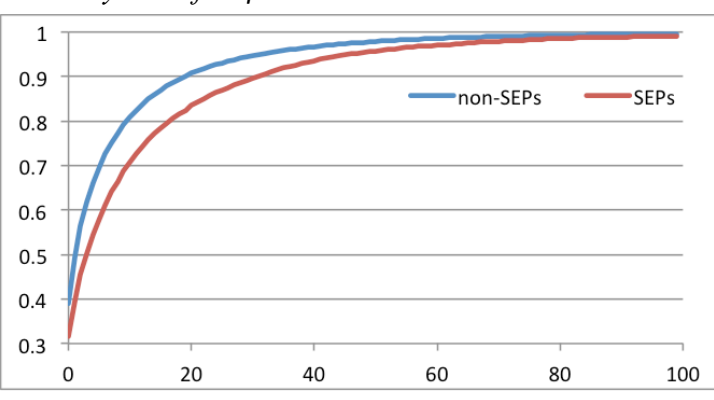

Citation performance 10 years after patent publication

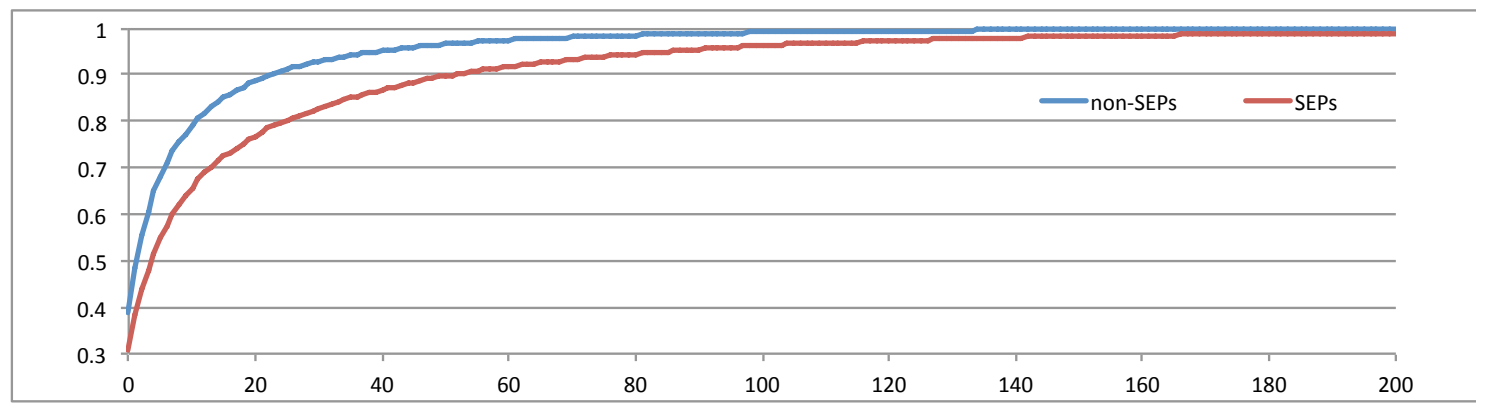

Citation performance 15 years after patent publication 
The superior performance of SEPs at a higher age is expected (assuming that standards attract valuable technologies) and is consistent with earlier findings in the literature, particularly those of Rysman and Simcoe ${ }^{35}$ and those of Bekkers, Bongard and Nuvolari ${ }^{36}$. To some extent, however, these higher scores are probably also the result of endogeneity (patents get cited because they are disclosed as SEPs). As discussed in Section 3.2, the average time lag between patent application and SEP disclosure to SSO is about seven years, which appears to be close to the time it takes for an average SEP to catch up with the citation performance of an average non-SEP.

The poor citation performances of SEPs at an earlier age has not been reported before, however these are intriguing, because they are 'pure' measurements, not yet influenced by the knowledge that these patents become essential patents later on. We are not sure which explanation is correct. A plausible and positive explanation is that these patents are quite unique and advance of their time, and it takes a while before follow-up research catches up. A pessimist explanation would be that SEPs are actually not that valuable at all (and their later higher scores are only because of endogeneity).

\subsection{Patent family size of SEPs compared to non-SEPs}

Many patents do not come alone: they are part of patent families. A patent family, putting it simply, is a set of patents on the same invention. These might be applications in different countries, or applications in one and the same country (continuation patents, continuations-inparts, divisionals, re-issued patents) $)^{37}$. The latter is usually done to extend the scope or the protection period of the patent, and is more of a strategic behavior. There are different definitions of patent families, ${ }^{38}$ of which the DOCDB family and the INPADOC family are the best known.

A larger patent family indicates that the patent owner is willing to spend more resources on protecting that invention, most likely because it represents greater value for the company (whatever way this value emerges: excluding, revenue-generating, cross-licensing, defensive, blocking competitors' technology routes, etc.).

We investigated whether essential patents have larger families. Here, we aim to disentangle the family size in terms of multiple countries on the one hand, and the family size within individual countries on the other.

\footnotetext{
${ }^{35}$ Rysman, M., \& Simcoe, T. (2008). Patents and the Performance of Voluntary Standard-Setting Organizations. Management Science, 54(11), 1920-1934.

${ }^{36}$ Bekkers, R., Bongard, R., \& Nuvolari, A. (2011). An empirical study on the determinants of essential patent claims in compatibility standards. Research Policy, 40, 1001-1015.

${ }^{37}$ For a discussion on such patent types, see Hegde, D., Mowery, D. C., \& Graham, S. J. H. (2007). Pioneers, Submariners, or Thicket-Builders: Which Firms Use Continuations in Patenting? NBER working paper No. 13153.

${ }^{38}$ A widely adopted, 'broad' family definition is one in which patents are grouped that share at least one priority document (examples are INPADOC by the EPO/OECD, and Derwent DII by Thomson Reuters). A narrower definition is one in which all family members have to share exactly the same set of priority documents (e.g. DOCDB, also by the EPO/OECD).
} 
As shown in Figure 14, almost 50 percent of the SEPs have family members in 6 or more countries. For non-SEPs, this is only 22 percent. We also examined the differences for each SSO and for each technology area (not shown), and did not see many differences; it is a rather universal pattern. ${ }^{39} \mathrm{We}$ conclude that SEPs enjoy better geographic protection than non-SEPs.

Figure 14. Number of countries where family members exist

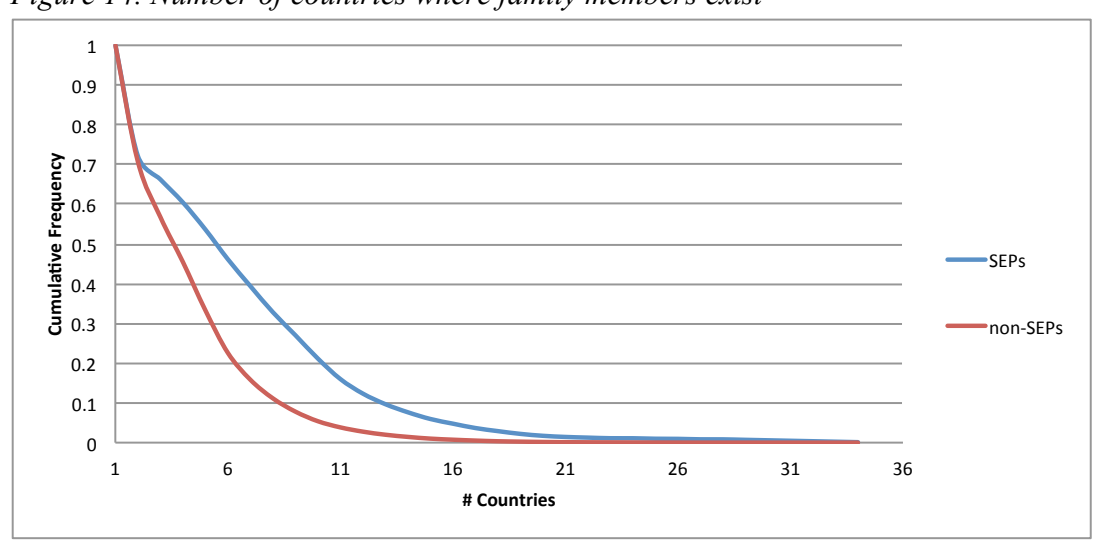

Turning now to family size within a single country, we looked at the number of applications that are part of the same DOCDB patent family both for the EPO and the USPTO. While the average USPTO family sizes are larger than EPO family sizes, we observe few differences between SEPs and non-SEPs.

Table 10. Patent family sizes within the EPO and the USPTO
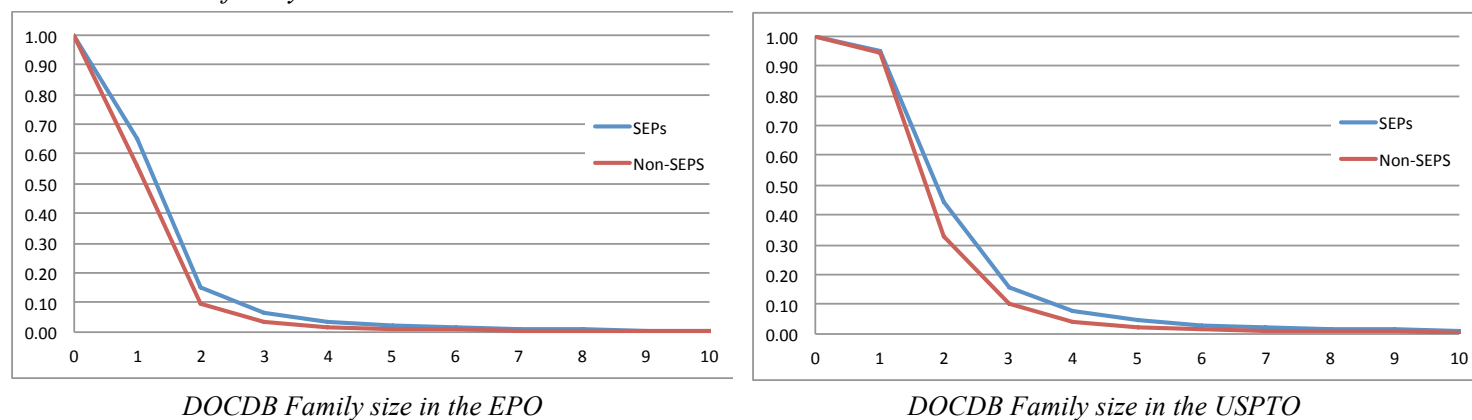

\subsection{Patent grant likelihood of SEPs compared to non-SEPs}

Are SEPs more likely to be granted than non-SEPs? If so, does this indicate that SEPs are higher 'quality' patents? These are the questions addressed in this section. Overall, Figure 15 shows that SEPs have a significantly higher likelihood to be granted than non-SEPs. Note again that our control sample of non-SEPs mirrors the SEP patents exactly in terms of age and technology areas, so these results are not biased regarding those dimensions.

\footnotetext{
${ }^{39}$ Exceptions are ANSI, where we see almost no difference, and ATIS, where the non-SEPs actually have larger international families. It is perhaps due to these organizations focusing more on American standards, and the patent holders caring less about international protection.
} 
Figure 15. Grant rates of SEPS vs. non-SEPS

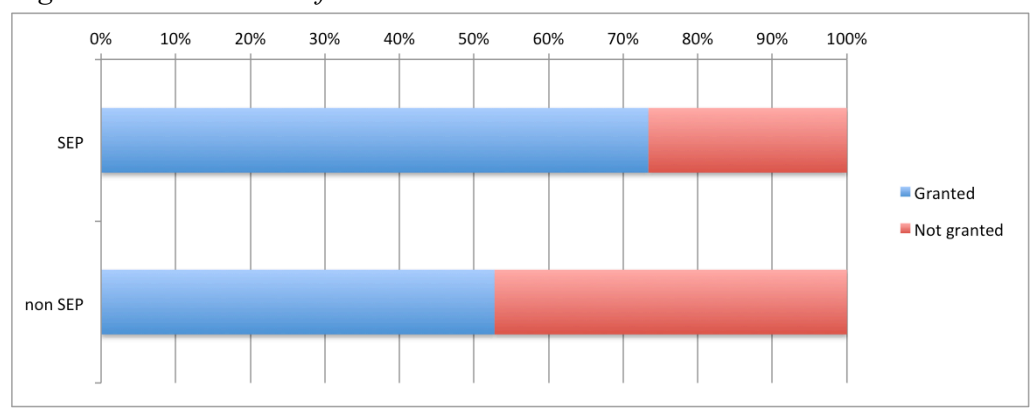

Table 11 confirms that this phenomenon is universal, so not associated with just one of a few (dominant) SSOs or technology areas. For almost all SSOs, the grant rate of SEPs is higher than that of non-SEPs in the matched control sample. The only exception is CENELEC, but the number of observations at this organization is so low that this is not a reliable sample.

Table 11: Grant rates of SEPS vs. non-SEPS by SSO and by technical area

\begin{tabular}{|c|c|c|c|c|c|c|}
\hline & \multicolumn{3}{|c|}{ SEPS } & \multicolumn{3}{|c|}{ Non-SEPs } \\
\hline & Total & Granted & Grant Rate & Total & Granted & Grant Rate \\
\hline ANSI & 229 & 219 & $95.63 \%$ & 3279 & 2753 & $83.96 \%$ \\
\hline ATIS & 186 & 130 & $69.89 \%$ & 2818 & 1622 & $57.56 \%$ \\
\hline BBF & 72 & 50 & $69.44 \%$ & 1227 & 721 & $58.76 \%$ \\
\hline CEN & 5 & 5 & $(100.00 \%)$ & 59 & 33 & $55.93 \%$ \\
\hline CENELEC & 4 & 3 & (75.00\%) & 61 & 50 & $81.97 \%$ \\
\hline ETSI & 6331 & 4440 & $70.13 \%$ & 94543 & 46444 & $49.12 \%$ \\
\hline IEC & 127 & 84 & $66.14 \%$ & 2319 & 1157 & $49.89 \%$ \\
\hline IEC - JTC1 & 394 & 299 & $75.89 \%$ & 6499 & 3767 & $57.96 \%$ \\
\hline IEEE & 580 & 531 & $91.55 \%$ & 8814 & 6479 & $73.51 \%$ \\
\hline IETF & 631 & 469 & $74.33 \%$ & 11087 & 6338 & $57.17 \%$ \\
\hline ISO & 75 & 70 & $93.33 \%$ & 952 & 714 & $75.00 \%$ \\
\hline ISO - JTC1 & 345 & 282 & $81.74 \%$ & 5529 & 3510 & $63.48 \%$ \\
\hline ITU & 726 & 648 & $89.26 \%$ & 11371 & 8654 & $76.11 \%$ \\
\hline OMA & 514 & 325 & $63.23 \%$ & 8628 & 3997 & $46.33 \%$ \\
\hline TIA & 28 & 26 & $92.86 \%$ & 372 & 277 & $74.46 \%$ \\
\hline 1 Tele & 7541 & 5331 & $70.69 \%$ & 114848 & 59080 & $51.44 \%$ \\
\hline 2 LAN & 255 & 232 & $90.98 \%$ & 4182 & 3111 & $74.39 \%$ \\
\hline 3 IT & 736 & 564 & $76.63 \%$ & 12809 & 7742 & $60.44 \%$ \\
\hline $4 \mathrm{AV}$ & 382 & 281 & $73.56 \%$ & 6389 & 3783 & $59.21 \%$ \\
\hline $5 \mathrm{Secu}$ & 335 & 279 & $83.28 \%$ & 5225 & 3389 & $64.86 \%$ \\
\hline 6 Trans & 21 & 14 & $66.67 \%$ & 245 & 124 & $50.61 \%$ \\
\hline 7 Energ & 14 & 9 & $64.29 \%$ & 232 & 103 & $44.40 \%$ \\
\hline $8 \mathrm{Ind}$ & 95 & 65 & $68.42 \%$ & 1656 & 877 & $52.96 \%$ \\
\hline 9 MTS & 27 & 24 & $88.89 \%$ & 447 & 314 & $70.25 \%$ \\
\hline Totals & 9378 & 6882 & $73.38 \%$ & 121971 & 64350 & $52.76 \%$ \\
\hline
\end{tabular}

Note 1: Figures in brackets indicate that the number of observations is too low to make reliable comparisons.

Note 2: We have also performed separate analyses for the EPO and USPTO patent sets. While the USPTO has a higher overall grant rate, the patterns in SSOs and technology areas are similar. 
At first glance, these results seem to indicate that SEPs have a higher 'quality" ${ }^{40}$ than nonSEPs. After all, they are more likely to pass the test of novelty, non-obviousness and industrial applicability that patent examiners apply. Some might see this as an indication that these patents represent more significant inventions.

Unfortunately, it is not that simple. While patent grants may be assumed to be purely dependent on the features of the patent as they were when filed ${ }^{41}$ (opposed to forward citations, which may be the result of events later in time), we still might be facing a selection bias. More precisely, this selection is at the patent owner: around 53 percent of all SEPs are disclosed (for whatever reason) ${ }^{42}$ only after they are already granted (Table 12). We might have a concern that patent owners disclose only - or mainly - those patents of which they already know are granted. In conclusion, we cannot make strong claims about a higher 'patent quality' of SEPs because it is not possible to correct for selection bias.

Table 12. Degree to which patents are already granted by the time they are disclosed as being an SEP

\begin{tabular}{lcccc}
\hline $\begin{array}{l}\text { SSO or } \\
\text { technology area }\end{array}$ & $\begin{array}{c}\text { No. of patents in } \\
\text { this analysis }\end{array}$ & $\begin{array}{c}\text { SEP disclosure after 1st } \\
\text { publication of patent } \\
\text { grand }\end{array}$ & $\begin{array}{c}\text { SEP disclosure before 1st } \\
\text { publication of patent grand }\end{array}$ & $\begin{array}{c}\text { Patent not yet } \\
\text { granted }\end{array}$ \\
\hline ANSI & 229 & $87.07 \%$ & $8.56 \%$ & $4.37 \%$ \\
ATIS & 186 & $56.43 \%$ & $13.46 \%$ & $30.11 \%$ \\
BBF & 72 & $42.21 \%$ & $27.23 \%$ & $30.56 \%$ \\
CEN & 5 & $83.33 \%$ & $16.67 \%$ & $0.00 \%$ \\
CENELEC & 4 & $75.00 \%$ & $0.00 \%$ & $25.00 \%$ \\
ETSI & 6331 & $46.14 \%$ & $23.99 \%$ & $29.87 \%$ \\
IEC & 127 & $53.92 \%$ & $12.22 \%$ & $33.86 \%$ \\
IEC - JTC1 & 394 & $62.21 \%$ & $13.68 \%$ & $24.11 \%$ \\
IEEE & 580 & $77.79 \%$ & $13.76 \%$ & $8.45 \%$ \\
IETF & 631 & $54.58 \%$ & $19.75 \%$ & $25.67 \%$ \\
ISO & 75 & $85.10 \%$ & $8.24 \%$ & $6.67 \%$ \\
ISO - JTC1 & 345 & $74.10 \%$ & $7.64 \%$ & $18.26 \%$ \\
ITU & 726 & $71.26 \%$ & $18.00 \%$ & $10.74 \%$ \\
OMA & 514 & $42.54 \%$ & $20.69 \%$ & $36.77 \%$ \\
TIA & 28 & $85.98 \%$ & $6.88 \%$ & $7.14 \%$ \\
\hline 1 Tele & 7541 & $47.96 \%$ & $22.73 \%$ & $29.31 \%$ \\
2 LAN & 255 & $78.93 \%$ & $12.05 \%$ & $9.02 \%$ \\
3 IT & 736 & $58.08 \%$ & $18.55 \%$ & $23.37 \%$ \\
4 AV & 382 & $62.06 \%$ & $11.50 \%$ & $26.44 \%$ \\
5 Secu & 335 & $71.48 \%$ & $11.81 \%$ & $16.72 \%$ \\
6 Trans & 21 & $61.90 \%$ & $4.76 \%$ & $33.33 \%$ \\
7 Energ & 14 & $45.92 \%$ & $18.37 \%$ & $35.71 \%$ \\
8 Ind & 95 & $53.22 \%$ & $15.20 \%$ & $31.58 \%$ \\
9 MTS & 27 & $73.20 \%$ & $15.69 \%$ & $11.11 \%$ \\
\hline Total & 5378 & $52.85 \%$ & $20.53 \%$ & $26.62 \%$ \\
\hline & & & &
\end{tabular}

\footnotetext{
${ }^{40}$ Here, the word 'quality' is used in the narrowest sense, i.e. the likelihood that a patent is granted. This relates to the 'legal quality' of patents, where scholars consider the grant rate and whether a patent holds in court when challenged.

${ }^{41}$ We ignore here that patent owners might put more effort into the prosecution phase if they realized their patent might be an SEP.

${ }^{42}$ This may be a 'late disclosure' (where the patent owner does not disclose until long after they are already aware this patent is an essential one) or merely because the technology was only incorporated in the standard long after the patent was applied for.
} 


\subsection{Summary}

This chapter investigated the differences between SEPs and a comparable control set of nonSEPs. We can summarize the main findings of this section as follows:

The citations performance, often considered an indicator of patent value, differs between SEPs and non-SEPs. In later years, SEPs show a higher score. This is consistent with earlier literature but may be due to an endogeneity effect (that patents get cited because they are disclosed as essential). In earlier years, SEPs had a poorer citation performance. This result has not been previously reported in the literature and is difficult to interpret. A positive explanation is that these patents are quite unique and advanced for their time, and it takes a while before follow-up research catches up. A pessimistic explanation is that SEPs are actually not that valuable at all (and their later higher scores are only due to endogeneity).

On average, SEPs are applied for in many more countries than non-SEPs. Almost 50 percent of the SEPs have family members in 6 or more countries. For non-SEPs, this is only 22 percent. Regarding family size within a given country (as a result of continuation patents, continuations-in-parts, divisionals, re-issued patents), we see little difference between SEPs and non-SEPs.

SEPs are more often granted than comparable non-SEPs. However, since there is no way to rule out selection bias by the patent owner themselves (when deciding what to disclose), we cannot argue whether or not this indicates a higher patent 'quality' of SEPs. 


\title{
5 Blanket disclosures
}

\author{
This chapter was prepared by Arianna Martinelli and Rudi Bekkers
}

Whereas most SSO IPR policies have disclosure requirements, the exact scope of these requirements and the specification of the exact information that has to be disclosed, vary. This charter looks into a quite specific but common phenomenon, known as 'blanket disclosures'. These are declarations whereby a party indicates it believes to own one or more patents for a given standard, but does not reveal the identity of these patents. Consequently, the level of transparency of the disclosed information is much lower than with 'specific disclosures', that is, disclosures where these identities are indeed provided.

Of the fifteen SSOs we considered (see Section 3.1 on how we dealt with JTC1), nine have an IPR policy that allows firms to file blanket disclosures: ${ }^{43}$ ATIS, IEC, IEC-JTC1, IEEE, IETF $^{44}$, ISO, ISO-JTC1, ITU and TIA. Yet all these organizations can also opt to provide specific disclosures. Another five SSOs have policies that - formally - do not allow blanket disclosures: BBF, CEN, CENELEC, ETSI, and OMA. Nevertheless, having investigated their IPR databases (see Table 3 in Chapter 3), we did observe some blanket disclosures. These are cases where a firm submits such a blanket regardless of the actual rules, and apparently this submission is 'tolerated'. For the fifteenth SSO, ANSI, we cannot state whether blankets are allowed or not, as ANSI is actually an accreditation body and its underlying SSOs might have different rules on blankets.

This chapter investigates in detail the occurrence of blanket disclosures, and aims to provide an understanding of whether this phenomenon is associated with particular sectors or particular types of actors. The final section presents an analysis of the determinants of blanket disclosures: is it true that high search costs prevent companies from doing specific disclosures, as is often argued?

\subsection{Data and methodology}

The empirical analysis in this section uses the OEIDD dataset, which has been introduced earlier. In principle, we limit our data to those eight SSOs where blanket disclosures are allowed. We also collected additional firm-level data in order to learn more about the determinants of blankets, such as firms' overall patent portfolios including those in knowledge areas relevant to specific standards for which they make disclosures. This data will be introduced in more detail in Section 5.6.

\footnotetext{
${ }^{43}$ See the report referenced in Footnote 2 for an in-depth discussion on the SSO IPR policies and the rules on blankets in particular.

${ }^{44}$ At IETF, blanket disclosures are only allowed insofar the patent owner commits to a Royalty Free (RF) license. For royalty bearing FRAND commitments, patent owners must make specific declarations.
} 
The total dataset of the eight selected SSOs encompasses 2,908 disclosure events and 11,054 statements. However, in several of our specific analyses we sometimes had fewer observations. There are various reasons for this: (a) for some observations, the disclosure date (day-month-year) is missing on the original disclosure; (b) for some observations, the name of the claimant (!) is missing on the original disclosure; (c) for some observations, the identification of the standard is missing on the original disclosure; (d) for some observations, we could not determine the business model of the claimant (see Section 3.4). In the most restrictive cases, the total number of disclosure events can drop to 2,358 (i.e. 81 percent of the full set) but often the drop is more modest, depending of course on the specific variables required for a given analysis.

\subsection{Overall occurrence of blanket disclosures}

Blanket disclosures are a frequent phenomenon. The eight SSOs we reviewed that do allow such disclosures represent about one third of all disclosure statements made (Figure 16a). Looking at it this way might be a bit misrepresentative, though. A single blanket statement may represent many distinct patents.

Therefore it might be better to do this comparison at the disclosure event level. After all, this is where a company can choose: either to submit a disclosure with a single blanket statement, or to make a disclosure with (one or multiple) specific patent statements. Perceived in this way, the share of blankets is no less than 60 percent of all disclosure events (Figure 16b). Most of the analyses in the remaining part of this chapter are based on disclosure events, as we believe this is the most appropriate unit of analysis.

Figure 16. Occurrence of blanket disclosures at the eight SSOs that allow them

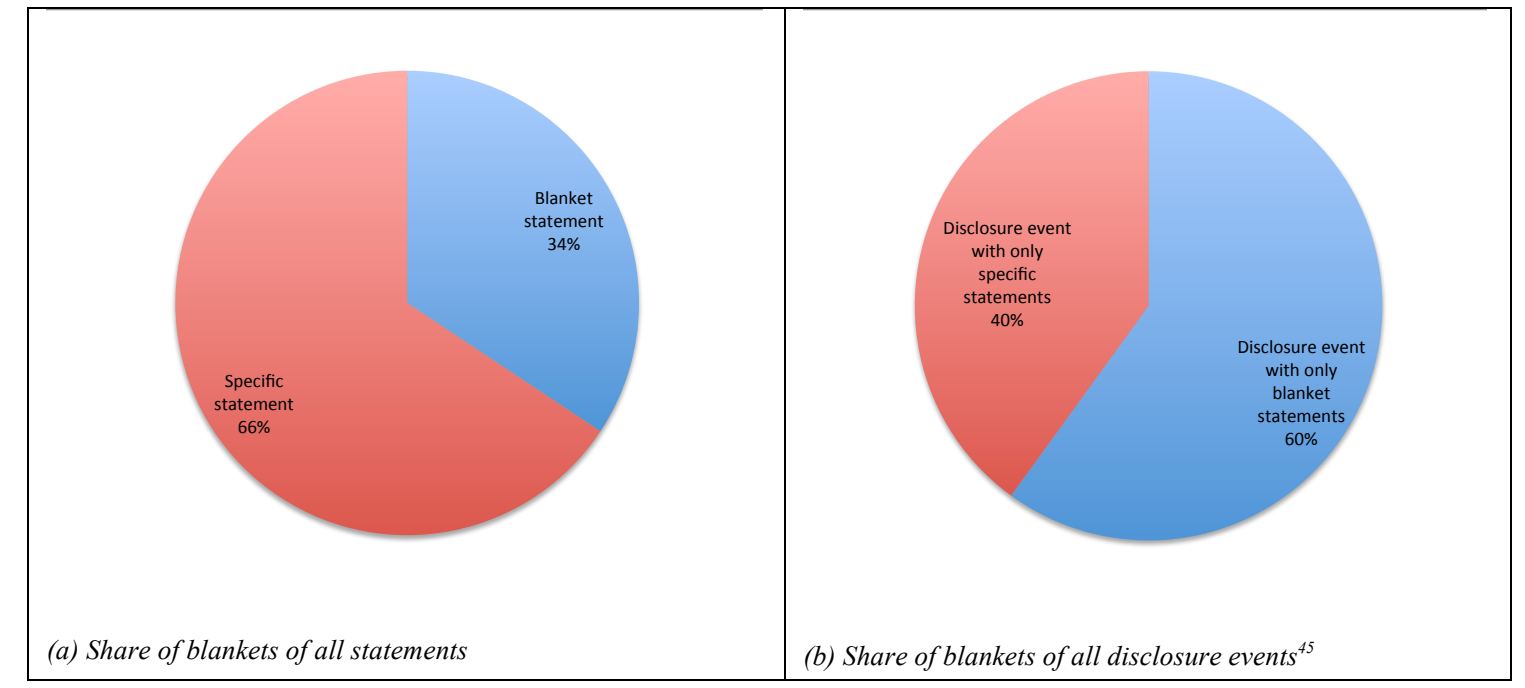

\footnotetext{
${ }^{45}$ Theoretically, a disclosure event could also be a mix of blanket and specific statements (which is strange, but a firm could on a single day at a single SSO make a blanket statement for standard A and three specific statements for standard B). But such cases do not occur in our data set.
} 


\subsection{Categories of firms regarding blanket disclosures}

It is conceivable that some firms will submit blanket disclosures whenever they are allowed to do so, and others will perhaps always make specific disclosures. To gain some understanding on this, we have compiled three categories of firms:

1. Firms that predominantly make specific disclosures - These are the firms that make specific declarations at more than 80 percent of all their disclosure events

2. Firms that predominantly make blanket disclosures - These are the firms that make blanket declarations at more than 80 percent of all their disclosure events

3. Hybrid firms - These are firms that are in between the two categories above.

Table 13 presents these three types of firms. While the differences are not great, the group of firms that predominantly makes blanket disclosures is the largest.

Table 13. Three categories of firms pertaining to blanket disclosure (only for selected SSOs)

\begin{tabular}{lll}
\hline Type of firms & Number & Percentage \\
\hline Firms that predominantly make specific disclosures & 75 & $28.4 \%$ \\
Firms that predominantly make blankets disclosures & 96 & $36.4 \%$ \\
Hybrid firms & 93 & $35.2 \%$ \\
\hline Total & 264 & $100 \%$ \\
\hline
\end{tabular}

Looking at firms' behavior, we can distinguish three types of companies: 'Blanket firms', 'Specific Declaration firms' and 'Hybrid firms'. The first group includes all the companies whose declarations are mostly blanket (blanket declarations account for more than 80 percent of the total); the second group includes companies whose declarations are mostly specific (blanket declarations are less than 20 percent the total); and the third group is the remaining companies. Each group is, roughly speaking, equally large.

We now considered how these three types of firms are represented at different various SSOs (Table 14), where we selected only SSOs that do allow for blanket disclosures. On the whole, the hybrid firms have the greatest presence: 66 percent of all disclosure events. We do see some differences across SSOs but these are not terribly large; so we conclude that firm behavior is relatively independent of SSO aspects. 
Table 14. Disclosure events at the eight selected SSOs by three types of firm events (only for selected SSOs)

\begin{tabular}{lccccccc}
\hline SSO & $\begin{array}{c}\text { Firms that predominantly make } \\
\text { specific disclosures }\end{array}$ & \multicolumn{2}{c}{$\begin{array}{c}\text { Firms that predominantly make } \\
\text { blanket disclosures }\end{array}$} & \multicolumn{2}{c}{ Hybrid firms } & Total \\
& Freq. & $\%$ & Freq. & $\%$ & Freq. & $\%$ & Total \\
\hline ATIS & 7 & $11.3 \%$ & 14 & $22.6 \%$ & 41 & $66.1 \%$ & 62 \\
IEC & 14 & $14.4 \%$ & 28 & $28.9 \%$ & 55 & $56.7 \%$ & 97 \\
IEC-JTC1 & 27 & $16.1 \%$ & 53 & $31.5 \%$ & 88 & $52.4 \%$ & 168 \\
IEEE & 23 & $4.9 \%$ & 139 & $29.6 \%$ & 307 & $65.5 \%$ & 469 \\
IETF & 20 & $10.4 \%$ & 18 & $9.3 \%$ & 155 & $80.3 \%$ & 193 \\
ISO & 10 & $20.4 \%$ & 17 & $34.7 \%$ & 22 & $44.9 \%$ & 49 \\
ISO-JTC1 & 32 & $14.2 \%$ & 64 & $28.3 \%$ & 130 & $57.5 \%$ & 226 \\
ITU & 48 & $5.5 \%$ & 212 & $24.5 \%$ & 606 & $70.0 \%$ & 866 \\
TIA & 0 & $0.0 \%$ & 78 & $34.2 \%$ & 150 & $65.8 \%$ & 228 \\
\hline Total & 181 & $7.7 \%$ & 623 & $26.4 \%$ & 1,554 & $65.9 \%$ & 2,358 \\
\hline
\end{tabular}

\subsection{Blanket declaration occurrences for technology areas and individual standards}

Are there significant differences between technology areas when it comes to the phenomenon of blanket disclosures? That question is addressed in Table 15. Indeed, some differences are worth noting. Focusing firstly on technology areas with a high number of disclosures, we see that blanket disclosure occurrence is highest in the areas of telecommunications, LAN and Audiovisual. The technology area of IT is an outlier here, where specific disclosures are clearly more common. The 'smaller' technology areas give a mixed picture, but bearing in mind that the total number of reservations in these areas is often quite low, we are hesitant to draw any conclusions here.

Table 15. Blanket and specific disclosure events for top standards in terms of disclosure events (only for selected SSOs)

\begin{tabular}{|c|c|c|c|c|c|}
\hline & \multicolumn{2}{|c|}{ Specific disclosure events } & \multicolumn{2}{|c|}{ Blankets disclosure event } & \multirow[t]{2}{*}{ Total } \\
\hline & Freq. & $\%$ & Freq. & $\%$ & \\
\hline 1 Tele & 359 & $31.7 \%$ & 773 & $68.3 \%$ & 1,132 \\
\hline 2 LAN & 82 & $29.0 \%$ & 201 & $71.0 \%$ & 283 \\
\hline 3 IT & 165 & $65.5 \%$ & 87 & $34.5 \%$ & 252 \\
\hline $4 \mathrm{AV}$ & 137 & $33.9 \%$ & 267 & $66.1 \%$ & 404 \\
\hline $5 \mathrm{Secu}$ & 88 & $56.1 \%$ & 69 & $43.9 \%$ & 157 \\
\hline 6 Trans & 4 & $33.3 \%$ & 8 & $66.7 \%$ & 12 \\
\hline 7 Energ & 5 & $55.6 \%$ & 4 & $44.4 \%$ & 9 \\
\hline 8 Ind & 29 & $54.7 \%$ & 24 & $45.3 \%$ & 53 \\
\hline 9 MTS & 11 & $78.6 \%$ & 3 & $21.4 \%$ & 14 \\
\hline Other & 22 & $53.7 \%$ & 19 & $46.3 \%$ & 41 \\
\hline Total & 902 & $38.3 \%$ & 1,456 & $61.7 \%$ & 2,358 \\
\hline
\end{tabular}

Turning now to specific standards, we investigated how often blanket disclosure events occur. As can be seen in Table 16, which shows the top standards in terms of disclosure events, 
blankets are (again) very common. With the exception of the JTC1 ISO/IEC 18000 standard, all top standards have considerably more blanket disclosure events than specific disclosure events. As a result, there is a great lack of transparency in the actual IPR ownership for these standards.

Table 16. Blanket and specific disclosure events for top standards in terms of disclosure events (only for selected SSOs)

\begin{tabular}{|c|c|c|c|c|c|}
\hline & \multicolumn{2}{|c|}{ Specific disclosure events } & \multicolumn{2}{|c|}{ Blankets disclosure events } & \multirow[t]{2}{*}{ Total } \\
\hline & Freq. & $\%$ & Freq. & $\%$ & \\
\hline JTC1 ISO/IEC 14496 incl. ITU H.264 & 66 & $37.7 \%$ & 109 & $62.3 \%$ & 175 \\
\hline IEEE 802.11 & 30 & $23.4 \%$ & 98 & $76.6 \%$ & 128 \\
\hline JTC1 ISO/IEC 18000 & 65 & $73.0 \%$ & 24 & $27.0 \%$ & 89 \\
\hline JTC1 ISO/IEC 13818 and H.222 and H.626 & 24 & $36.9 \%$ & 41 & $63.1 \%$ & 65 \\
\hline IEEE 802.16 & 28 & $45.2 \%$ & 34 & $54.8 \%$ & 62 \\
\hline IEEE 802.3 & 27 & $43.5 \%$ & 35 & $56.5 \%$ & 62 \\
\hline IEEE 802.1 & 19 & $39.6 \%$ & 29 & $60.4 \%$ & 48 \\
\hline ITU G.992 & 15 & $37.5 \%$ & 25 & $62.5 \%$ & 40 \\
\hline ITU G.729 & 13 & $34.2 \%$ & 25 & $65.8 \%$ & 38 \\
\hline ITU M.1225 & 9 & $28.1 \%$ & 23 & $71.9 \%$ & 32 \\
\hline
\end{tabular}

\subsection{Blanket declaration occurrence in relation to business models}

There could be reasons to assume that firms' business model (interpreted here as the position firms occupy in the value chain) has an impact on their likelihood to submit blanket disclosures. The results are shown in Table 17. A number of distinct business models is grouped as 'upstream', and another group as 'downstream'. As can be seen, the upstream companies made relatively more blanket disclosures than the downstream companies. While this is an interesting observation, we would like to caution against a too simplistic conclusion that upstream companies are more likely to make blanket disclosures because they are upstream; there could be other explanatory factors that are in some way related to this group of firms. For this reason, we present a regression analysis on the determinants of blanket disclosure behavior in Section 5.6, where we properly control for all possibly relevant aspects. 
Table 17. Blanket and specific disclosure events for different business models (only selected SSOs)

\begin{tabular}{|c|c|c|c|c|c|}
\hline & \multicolumn{2}{|c|}{ Specific disclosure events } & \multicolumn{2}{|c|}{ Blankets disclosure event } & \multirow[t]{2}{*}{ Total } \\
\hline & Freq. & $\%$ & Freq. & $\%$ & \\
\hline UPSTREAM BUSINESS MODELS & 209 & $29.5 \%$ & 500 & $70.5 \%$ & 709 \\
\hline \multicolumn{6}{|l|}{ Of which... } \\
\hline $\begin{array}{l}\text { Pure upstream knowledge developer or } \\
\text { patent holding companies (excl. } \\
\text { universities) }\end{array}$ & 27 & $29.3 \%$ & 65 & $70.7 \%$ & 92 \\
\hline $\begin{array}{l}\text { Universities / public research institutes / } \\
\text { states }\end{array}$ & 46 & $35.7 \%$ & 83 & $64.3 \%$ & 129 \\
\hline Components (incl. semiconductors) & 76 & $21.8 \%$ & 272 & $78.2 \%$ & 348 \\
\hline Software and software-based services & 50 & $41.3 \%$ & 71 & $58.7 \%$ & 121 \\
\hline Individual patent owner & 10 & $52.6 \%$ & 9 & $47.4 \%$ & 19 \\
\hline DOWNSTREAM BUSINESS MODELS & 682 & $42.2 \%$ & 934 & $57.8 \%$ & 1616 \\
\hline \multicolumn{6}{|l|}{ of which... } \\
\hline $\begin{array}{l}\text { Equipment suppliers, product vendors, } \\
\text { system integrators }\end{array}$ & 535 & $40.0 \%$ & 802 & $60.0 \%$ & 1,337 \\
\hline $\begin{array}{l}\text { Measurement and instrument, test } \\
\text { system }\end{array}$ & 5 & $83.3 \%$ & 1 & $16.7 \%$ & 6 \\
\hline $\begin{array}{l}\text { Service providers (telecommunications, } \\
\text { radio, television, etc.) }\end{array}$ & 142 & $52.0 \%$ & 131 & $48.0 \%$ & 273 \\
\hline OTHER BUSINESS MODELS & 11 & $33.3 \%$ & 22 & $66.7 \%$ & 33 \\
\hline TOTAL & 902 & $38.3 \%$ & 1,456 & $61.7 \%$ & 2,358 \\
\hline
\end{tabular}

\subsection{Determinants of blanket disclosure behavior}

In the previous sections we saw a variety of tables that showed differences in the occurrence of blanket disclosure events across SSOs, technology areas, 'top' standards, and business models. But what makes a company adopt this behavior? Picking out just one aspect of these summary tables may lead to false results, if not properly corrected for other (possibly related) potential causes. For instance: one might find a particular result for a specific business model, but perhaps the blanket behavior is not caused by this business model but merely due to the fact that all the firms in that business model category happen to be large, and being large is the actual cause (this is a fictional example).

The final section aims to find the determinants of blanket disclosure behavior. We did so by using a series of regression analyses that consider all (observable) aspects that can be a possible explanation, and all aspects that need to be controlled. 
Underlying our approach are two propositions:

(1) Companies with extensive patent portfolios would have high search costs in order to identify SEPs, and prefer to make blanket disclosures to avoid such costs.

(2) Companies participating in many various standardizations would have high search costs in order to identify SEPs for all these different standards, and prefer to make blanket disclosures to avoid such costs.

In addition, there is the notion that different business models have different strategic implications for firms' incentives to make blanket disclosures (however we will not postulate specific hypotheses here).

In order to perform our analyses, we prepared a number of variables (see Table 18 for an overview). Several of these come from the OEIDD database and were already introduced above, or are self-explanatory. We will not explain them further here.

Table 18. Explanation of variables in regression analysis

\begin{tabular}{|c|c|}
\hline Variable & Explanation \\
\hline Blanket & $\begin{array}{l}\text { Dependent variable. Dummy variable that takes value } 1 \text { if the declaration is missing a patent } \\
\text { identity (i.e. blanket declaration) }\end{array}$ \\
\hline LnKnowledgeStock & $\begin{array}{l}\text { The logarithm of a company's total patent stock. This is calculated using the inventory method } \\
\text { and a depreciation rate of } 0.15\end{array}$ \\
\hline LnSpecificKnowledgeStock & The logarithm of the specific to the standard patent portfolio \\
\hline Number of standards & Number of standards in which a company is involved per year \\
\hline HHI standards-activity & $\begin{array}{l}\text { The Herfindahl-Hirschman Index measures the concentration of a company's standardization } \\
\text { efforts. It takes values between } 0 \text { and } 1 \text {. When it is close to } 0 \text {, this means a company makes } \\
\text { declarations in several standards, whereas when it is close to } 1 \text {, a company makes most of its } \\
\text { declarations to a single standard }\end{array}$ \\
\hline Business model & Dummy variables indicating a company's business model \\
\hline Licensing commitment & Dummy variable indicating the licensing commitment \\
\hline SSO & Dummy for the SSO \\
\hline Telecom dummy & Dummy for controlling whether a standard is in the telecommunication area \\
\hline
\end{tabular}

New are the variables with respect to the size of firms' patent portfolios, to enable us to test our propositions. Firstly, we calculated the overall patent portfolio of all companies that submitted patent disclosures. This is not a trivial task; despite no great variety of patent databases, they all differ in their functionality, their approach, and (in particular) the ways they have or have not harmonized applicant names. ${ }^{46}$ In order to determine this portfolio, we started with data from the CESPRI database, which cleans and groups assignee names of companies that patent in Europe. Since the CESPRI database only aims to cover certain

\footnotetext{
${ }^{46}$ As illustration: a staff member of a large multinational once shared with us that his firm appeared under more than 800 (!) different names in the various national patent offices. While some of these names are typos, and others are variants that could be traced using text processing algorithms, a considerable amount of applicant names cannot easily be traced without additional knowledge (for instance on acquired subsidiaries).
} 
sectors, numerous organizations featured in our database had not yet been cleaned. That is why we performed a manual search of all the relevant remaining companies in PATSTAT. We double-checked the overall result for many firms with the Derwent DII database (which has integral assignee-name cleaning), to ensure there were no firms with a significant undercounting. Secondly, we considered that firms might be very diverse in terms of business activities. A company that is active in, say, telecommunications, nuclear power stations, and shipbuilding, does not necessarily need to investigate its full patent portfolio when searching potential SEPS for specific standardization activities. It only needs to consider its portfolio in the knowledge area that is relevant for the standard in question. In order to determine that relevant knowledge portfolio (which is different for each firm-standards pair), we created what we call a 'knowledge profile' for each standard. This knowledge profile is broader than a single standard: for instance, IEEE 802.11 and HIPERLAN are certainly distinct standards, but share the same knowledge profile. In total, we created 70 distinct knowledge profiles. Of the 939 distinct standards appearing at the eight selected SSOs, 799 ( 85 percent) could be matched to one of these knowledge profiles. For each knowledge profile, we created an 'IPC class' profile representing the relevant knowledge in terms of the technology classes as they are used by patent offices. ${ }^{47}$ Then, for each particular company, in combination with each particular standard, we could determine the relevant patent portfolio by counting all the patents that company owns in the IPC classes belonging to the relevant knowledge profile.

We now turn to the results of our regression analysis, shown in Table 19. We started by performing a standard OLS regression. Model 1 is the version we used to consider firms' total patent portfolio. Controlling for all the other variables, we see that this knowledge stock has a positive, significant impact on the likelihood of making blanket declarations. While these effects are interesting, there is an important caveat here: these estimates do not control for unobserved heterogeneity at firm level. The usual way to address this is to add fixed effects, which do control such heterogeneity (in fact, this is like adding a dummy variable for each individual firm to the regression). This addition reveals that the actual effect is negative. (The mere change already signaled that the simple OLS was biased.) Checking the robustness of our finding, we did a similar analysis, only considering the patent portfolio relevant to the standard in question, and it also had a positive and significant effect (Model 2). The findings remained stable. For both models, we also ran a regression where we not only controlled firm fixed effects, but also SSO fixed effects. Even then, the result was stable. We also found that companies willing to make a royalty-free commitment (variable 'FREE' in the table) are more likely to make a blanket disclosure than companies that reserve the right to demand royaltybearing licenses (regular FRAND). This finding is quite understandable. Since these companies do not reap any financial benefits from their patents in the first place, they might not want to incur search costs; also implementers should have little concern not knowing the patent identities, because they get free access to them anyway.

\footnotetext{
${ }^{47}$ To do so, we first took all the patents disclosed in the standards belonging to that knowledge profile. Then we created a set of all 4-character IPC classes that represent the top-25 percentile of the distribution of frequencies.
} 
Table 19. Regression analysis of the determinants of blanket disclosures (selected SSOs only; dependent variable is blanket disclosure)

\begin{tabular}{|c|c|c|c|c|c|c|}
\hline & & Model 1 & & & Model 1 & \\
\hline Variable & OLS & $\begin{array}{c}\text { FIRM FIXED } \\
\text { EFFECT }\end{array}$ & $\begin{array}{c}\text { FIRM_SSO } \\
\text { FIXED } \\
\text { EFFECT }\end{array}$ & OLS & $\begin{array}{c}\text { FIRM FIXED } \\
\text { EFFECT }\end{array}$ & $\begin{array}{c}\text { FIRM_SSO } \\
\text { FIXED } \\
\text { EFFECT }\end{array}$ \\
\hline LnKnowledgeStock & $0.0108 * * *$ & $-0.0313^{* *}$ & $-0.0291^{*}$ & & & \\
\hline LnSpecificKnowledgeStock & & & & $0.0063^{*}$ & $-0.0223 * * *$ & $-0.0229 * *$ \\
\hline \multicolumn{7}{|l|}{ Licensing Commitment } \\
\hline FREE & $0.1498^{* * *}$ & $0.1479 * * *$ & $0.1752^{* * *}$ & $0.1471 * * *$ & $0.1240 * * *$ & $0.1795^{* * *}$ \\
\hline OTHER & $0.1718^{* * *}$ & $0.1958^{* * *}$ & $0.1730 * * *$ & $0.0912 * *$ & $0.0856 * *$ & $0.0747 *$ \\
\hline \multicolumn{7}{|l|}{ sSO } \\
\hline IEC & $-0.2293 * * *$ & $-0.1886 * *$ & & $-0.1510^{*}$ & $-0.2216^{* *}$ & \\
\hline IEC - JTC1 & $-0.1924 * *$ & -0.1353 & & -0.1191 & -0.0464 & \\
\hline IEEE & 0.0761 & 0.0698 & & 0.0757 & 0.053 & \\
\hline IETF & $-0.3472 * * *$ & $-0.3302 * * *$ & & & & \\
\hline ISO & -0.0621 & -0.0521 & & -0.0238 & -0.1167 & \\
\hline ISO - JTC1 & -0.0712 & 0.0144 & & -0.0663 & 0.0037 & \\
\hline ITU & 0.0325 & 0.0394 & & 0.0354 & 0.0213 & \\
\hline TIA & $0.3950 * * *$ & $0.4147^{* * *}$ & & $0.3861^{* * *}$ & $0.3888 * * *$ & \\
\hline \multicolumn{7}{|l|}{ Business Model } \\
\hline Upstream & $0.1555^{* * *}$ & & & $0.1699 * * *$ & & \\
\hline Other & $0.1866^{* *}$ & & & $0.1874 * *$ & & \\
\hline Number of standards & -0.0074 & & -0.002 & -0.0016 & 0.0008 & -0.0018 \\
\hline HHI standards-activity & -0.0443 & 0.0407 & 0.0649 & -0.0417 & 0.0744 & $0.0840^{*}$ \\
\hline Telecom dummy & -0.0399 & -0.0308 & -0.0433 & -0.045 & -0.0308 & -0.0351 \\
\hline Constant & $0.4891^{* * *}$ & $0.8036 * * *$ & $0.7882^{* * *}$ & $0.5226 * * *$ & $0.6987^{* * *}$ & $0.7474 * * *$ \\
\hline $\mathrm{N}$ & 2358 & 2247 & 2358 & 2143 & 2044 & 2143 \\
\hline Group & & 229 & 599 & & 217 & 540 \\
\hline R-Square & 0.1368 & 0.3353 & 0.5073 & 0.103 & 0.3188 & 0.4836 \\
\hline
\end{tabular}

Our conclusion on the above is that the larger a firm's patent portfolio, the less likely it is to make blanket disclosures, all other things being equal. On the basis of this finding, we conclude that the size of patent portfolio is not the reason firms revert to blanket disclosures (in contrast to what is often argued). They might have other reasons, but it is not the search costs argument.

So can we determine these other reasons? Unfortunately, that is harder with the data at our disposal. In the OLS regression we added business model (upstream versus downstream) as one of the controls. The results there suggest that firms with an upstream business model are more likely to submit blanket claims. But given the observed bias of OLS in this context, we do not want to attach too much importance to this finding. Regrettably, the business model variable cannot be used in the firm fixed effect analysis: since each firm in the data set has been assigned one business model, there will be no variation at all in this analysis. 


\subsection{Summary}

This chapter looked into the phenomenon of blanket declarations - this is a declaration by a firm that it believes to own essential patents, but does not specify the identity of these patents. We can summarize the main findings of this section as follows:

Eight of the thirteen large SSOs we investigated allow organizations to submit blanket declarations. In those organizations, such blanket declarations are a very common phenomenon, representing 60 percent of all disclosures. There are significant industry differences, though. For telecommunications, LAN and audiovisual standards, the proportion of blanket disclosures varies from 66 to 71 percent, whereas for IT standards it is much lower, namely 34 percent.

In discussions, larger firms have often indicated that they prefer to be allowed to submit blanket claims, because searching their large portfolios of relevant patents for essential patents incurs considerable search costs. They also claim that they prefer to submit blanket claims if they are involved in many standardization activities at the same time. In our analyses, however, we found no substantiation for large companies' search costs claims. In fact, we found the opposite: the larger a firm's patent portfolio, the less likely it is to make blanket disclosures, all other things being equal. So there must be other (strategic?) reasons why, given the choice, certain firms submit blanket claims, and others do not.

We also found that companies willing to make a royalty-free commitment are more likely to make a blanket disclosure. This finding is quite understandable though. Since these companies gain no financial benefit from their patents, they might not want to make search costs, and also implementers should have little concern not knowing the patent identities, because they get free access to them anyway. 


\title{
6 Transferring ownership of SEPs
}

\author{
This chapter was prepared by Yann Ménière and Tim Pohlmann
}

Recent studies conclude that about 13 percent and 5 percent of all patents granted respectively in the USA and in Europe are traded at least once. ${ }^{48,49}$ Such transfers of patent rights are usually perceived as a means to enable a more efficient division of labor (e.g. among upstream technology specialists and downstream manufacturing companies). Recent cases also suggest that companies may acquire SEPs as strategic weapons to prevent or wage patent disputes in complex technology fields where firms' patent portfolios tend to overlap.

The transfer of SEPs constitutes a special case; unlike other patents, their value is derived extensively from the market success of the related standard. Since SEPs are widely infringed, they can indeed generate licensing revenues relatively easily. The larger the number of SEP holding entities, the more licenses the standard implementers have to obtain, and the more transaction costs and royalty stacking hinder the adoption of the standard.

SEP transfers can thus change market conditions with regard to market power, infringement claims and licensing. They may contribute to lowering enforcement costs, transaction costs and royalty stacking if they reduce the number of SEP holders. ${ }^{50}$ Conversely, they may generate market inefficiency if they induce more fragmentation of SEP ownership around a standard. SEP acquisitions by non-practicing entities (of which the most aggressive category is known as patent assertion entities or patent "trolls") also generate a risk of "hold-up" through aggressive enforcement strategies. ${ }^{51}$ While standard setting organizations require owners of SEPs to commit themselves to FRAND licenses or sometimes even royalty-free licenses, it is not fully clear whether such commitments are passed on to the new owner when the SEP is transferred.

In this chapter, we analyze the type and volume of SEP transfers from 1997 to 2009, transfer channels, and characteristics of the related standards. We studied as a second step the timing of transfers with regards to standardization processes and SEP declarations, and finally highlighted the impact of SEPs transfers on the extent of SEP concentration at the standard level.

\footnotetext{
48 Serrano, C. (2010) “The Dynamics of the Transfer and Renewal of Patents", RAND Journal of Economics, Vol. 41.

${ }^{49}$ Ménière, Y., Dechezleprêtre, A., Delcamp, H. (2012) “Le marché des brevets français, 1997-2009” Rapport d'étude pour l'INPI.

${ }^{50}$ Shapiro, C. (2001) "Navigating the Patent Thicket: Cross Licenses, Patent Pools, and Standard-Setting". In Jaffe, Adam B. et al. Innovation Policy and the Economy. I. Cambridge: MIT Press, 119-150.

${ }^{51}$ Pohlmann, T.; Opitz, M. (2013): Typology of the Patent Troll Business, R\&D Management, Volume 43, Issue 2, 103-120, March 2013.
} 


\subsection{Data and methodology}

The SEP transfers database is compiled from the registers of reassignments at the European (EPO) and French (INPI) patent offices, which cover all changes of ownership respectively for European patents transferred during the examination phase (EPO register) and for French patents filed through the national route and granted European patents validated in France ${ }^{52}$ (INPI register) from 1998 to 2009. For each reassigned patent, this dataset provides information on the name of the new owner (the assignee) and the date of ownership transfer registration. Information on the initial applicant of patents was collected from the OECD EPPAT database (for patents filed at EPO) and the INPI F-PAT database (for patents filed at INPI).

To construct our sample we merged the database of European patent reassignments with a second dataset of 11,476 declared SEPs (distinct patent families) from 1992 until 2010. Declared SEPs were retrieved from public patent declaration databases of ISO ${ }^{53}$ IEC,${ }^{54}$ ETSI, ITU-T, ITU-R, and IEEE. The data merge resulted in 617 observations as to the transaction of a distinct patent family. ${ }^{55}$ Overall only 13 patents have changed ownership twice during the period. Out of 1,400 standards where we identified declared SEPs, 153 standards were subject to traded SEPs. We further identified 58 distinct SEP sellers and 51 distinct SEP buyers.

We checked the identity of the applicant and new owner of each transferred SEP in order to sort these transfers into three separate categories. In some cases, the former and new owners were subsidiaries of the same mother corporation. Such reassignments are likely to proceed from fiscal optimization and strategic motives at the group level. We label them as "Internal" SEP transfers if they take place between established entities of the same group, and as "Acquisition" if they immediately follow the acquisition of the initial SEP-owning entity by the group. Finally, SEP reassignments that are not identified as "Internal" or "Acquisition" correspond to bare SEP transfers between two legally independent entities, and are labeled accordingly as "Bare" transfers. Consequently, "Bare" and "Acquisition" transfers are especially interesting, since they imply a market-mediated transfer. We identified 253 "Bare" transfers (41 percent of all transfers), 92 "Acquisition" transfers (15 percent), and 274 "Internal" transfers (44 percent). We further categorized each patent transfer in connection with the standard where the transferred SEP has been declared. These standards were then differentiated by SSO and technology area.

\footnotetext{
${ }^{52}$ About 98 percent of European patents are designated in France. Hence the INPI register covers nearly all granted European patents.

${ }^{53}$ We present the results for the JTC1 activity of ISO and IEC separately, in order not to mask the other activities at these two bodies.

${ }^{54}$ Ibid.

${ }^{55}$ By proxying SEPs, looking at those patents that are declared essential, we are obviously prone to some bias, because not all actual SEPs might be disclosed properly, and companies might have disclosed non-SEPs (e.g. under and over disclosure). We also cannot observe SEPs that are part of blanket disclosures. It is not possible, however, to overcome such bias.
} 


\subsection{Distribution of SEP transfers over time, SSO and technology area}

Using the year of reassignment as a proxy for the year of SEP transfer, we present in Figure 17 the evolution of annual volume of SEP transfers from 1997 to 2009. We can see that SEP transfers, having been almost non-existent until 2005, started to increase sharply afterwards and most actually took place at the end of the period. Although this trend applies to all categories of transfers, it is stronger in the case of "Bare" and "Acquisition" transfers, with a peak in $2009^{56}$.

Figure 17. SEP transfer over time regarding type of transfer

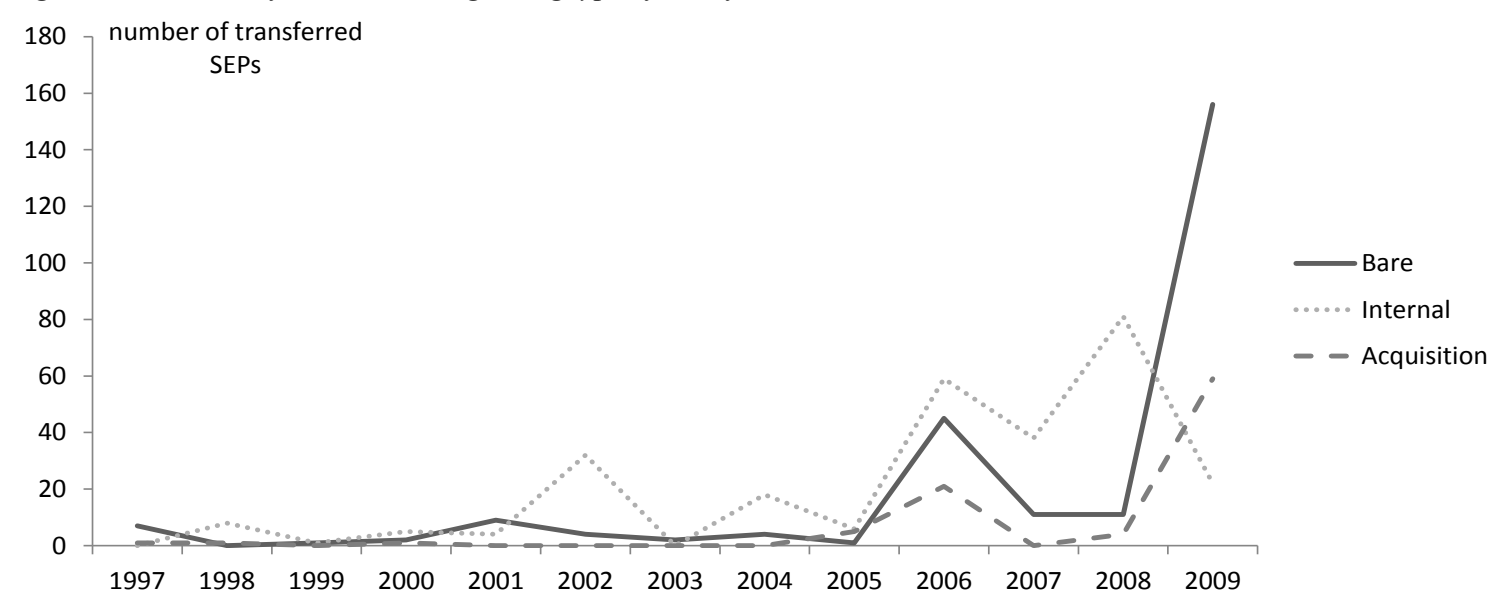

Figure 18 shows in turn that most of the transferred SEPs are related to ETSI and the telecommunication technology area. Other SSOs and technology areas only show very low numbers of transfers. While JTC1 accounts for about 50 SEP transfers, ITU-T, IEEE and ISO have very few. ITU-R, CEN or IEC standards were not subject to a transfer of declared SEPs. Although it is particularly strong in the case of "Internal" transfers, the domination of ETSI and telecommunication (Tele) standards remains true for each category of SEP transfer.

Figure 18. Number of SEP transfers and type of transfer subject to standards in SSO and technology categories
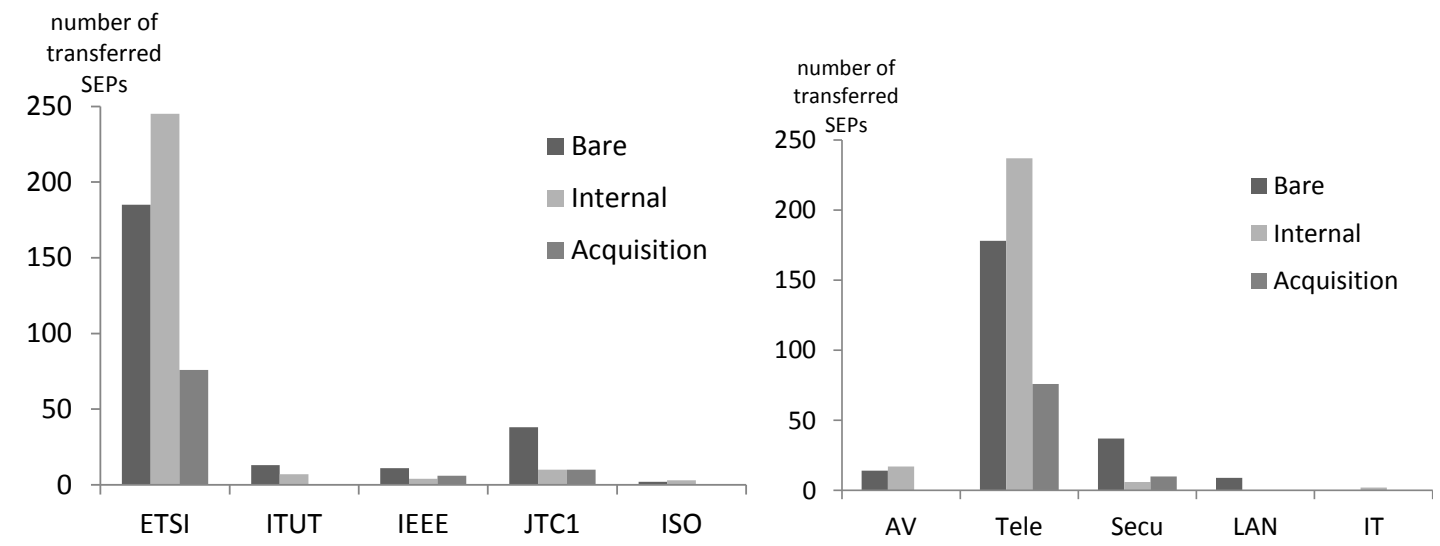

\footnotetext{
${ }^{56}$ A closer analysis shows that the peak observed in 2009 is not due to one particular event. We aggregated "Bare" and "Acquisition" transfers into larger transactions (defined as a set of patents reassigned the same day with the same applicant and new assignee" and found that most of them consist of two or three patents although a few transactions also consist of more than 50 patents. The two largest transactions take place in 2009 but the peak would still be observed without them.
} 
The fact that a large majority of SEP transfers is related to ETSI could be misleading, given the particularly high number of SEP declarations at ETSI during the same period. Indeed, Figure 19 (right hand side) shows that only 6 percent of all patents declared at ETSI have been reassigned - a proportion roughly equivalent to what was observed at ISO or JTC1. We therefore developed alternative indicators of SEP transfer activity by computing the number and share of standards (level of specification) ${ }^{57}$ issued by each SSO, where at least one declared SEP has been reassigned. As illustrated in Figure 19, ETSI and JTC1 are again the SSOs with the highest number and share of standards subject to SEP transfers. We could identify at least one SEP transfer for almost 70 percent of all ETSI standards where SEPs have been declared. JTC1 has a share of 60 percent, IEEE around 30 percent, ITU-T 8 percent and ISO 6 percent.

Figure 19. Number and share of transferred SEPs and of standards subject to SEP transfers per SSO

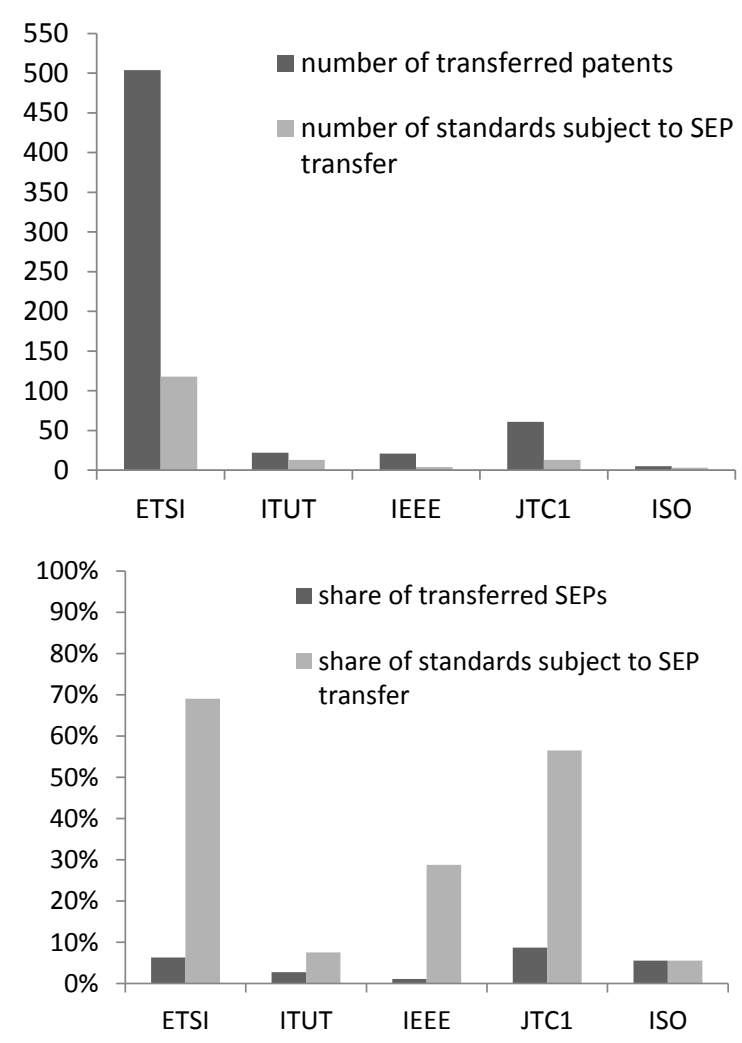

\subsection{Timing of SEP transfers}

Matching patent reassignments and standards data makes it possible to track the timing of patent trade over the years. Using the year of reassignment as a proxy for the year of SEP transfer, we compared this with the years of patent priority and events in standard setting such as standard release and the year of SEP declaration to the issuing SSO.

\footnotetext{
${ }^{57}$ To enable comparisons across SSOs, we disaggregated large ETSI projects such as GSM, UMTS and DVB into smaller technical standards at a lower level of specification. This explains the large number of standards observed for ETSI in Figure 3. This approach, however implies that some SEP declarations at ETSI not pointing to one particular standard are excluded from the sample.
} 
Figure 20.Transferred SEP as to year of inscription, priority year, patent declaration and standard release

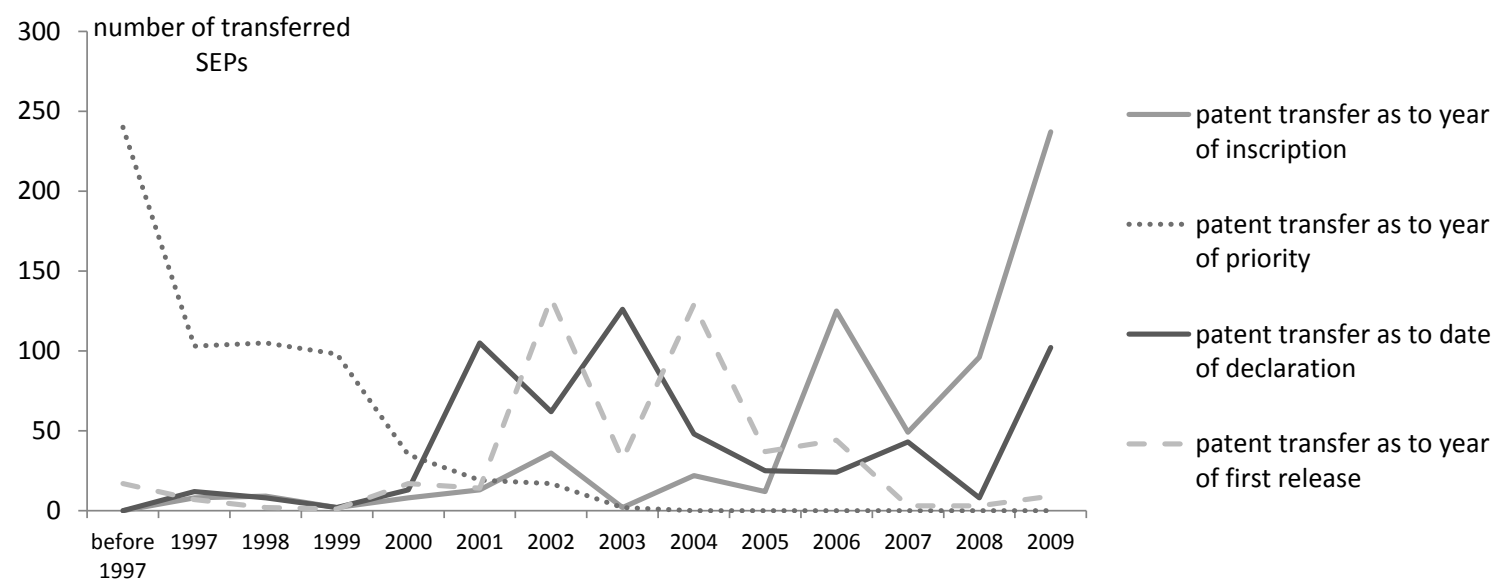

Figure 20 counts reassignments from 1997 to 2009, regarding the year of patent priority, the year of SEP trade, the year of SEP declaration and the year of first standard release. ${ }^{58}$ It shows firstly that most SEPs in the sample were applied for at the beginning of the period, on average about 6 years before the standard release and their declaration as SEP at the SSO. In contrast, SEP transfers mostly took place after the standard release ( 83.5 percent of cases) and after the declaration (69.9 percent). On average they occurred 3 years after standard release and 2.8 years after SEP declaration. This suggests that declarations and standard releases enable or facilitate the transfer of SEP ownership, by making public the existence of the SEP and clarifying its technical linkage with the standard.

Figure 21. Mean share of transferred SEPs regarding timing, by technology area ${ }^{59}$

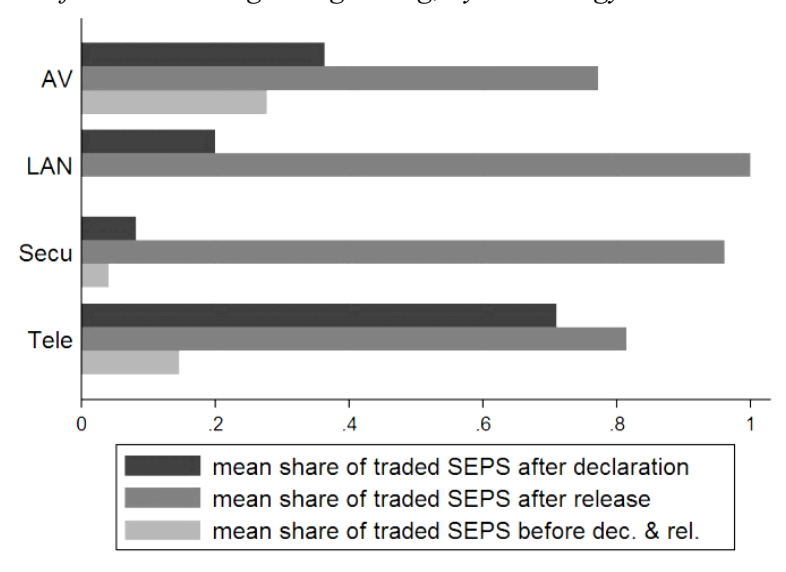

Comparing the timing of SEP transfers by technology area, however, reveals some noticeable differences (Figure 21). While most of the SEP transfers take place after standard release, the sequence between declaration and transfer is not uniform across all technology areas. The Telecommunications technology area (Tele) is the only one where a majority (about

\footnotetext{
${ }^{58}$ Note that standards may still evolve after their first release. In particular, some patented technologies can be added to new versions of the standard.

${ }^{59}$ For IT standardization, the timing could not be determined.
} 
70 percent) of SEP transfers follows the declaration. In contrast, the share of SEP transfers following declaration is about 40 percent in the audiovisual technology area (AV), and only about 20 percent and 10 percent in the short range communication (LAN) and Security (Secu) technology area.

\subsection{SEP transfers impact the distribution of SEP ownership at standard level}

We now analyze how SEP transfers affect the distribution of SEP ownership at the standard level. Since the "Internal" transfers actually take place within different entities of the same group, we do not take them into account in this subsection and rather focus our analysis on "Bare" and "Acquisition" transfers. Moreover we focus only on standards where at least one declared SEP has been transferred.

We used the total numbers of declared SEPs per standard to create 6 categories of standard size (from standards with less than 10 declared SEPs to standards with more than 500 declared SEPs). Each category consists of 15 standards, where at least one SEP has been traded. As Figure 22 shows, the average share of transferred SEPs per standard is lower the higher the number of declared SEPs for the same standard. This firstly implies that although most traded SEPs cover very large standards, their reassignment does not have a significant impact on the distribution of SEP ownership for these standards. Yet this also means that a minority of SEP transfers may have a strong impact on the number of SEP owners (and licensors) for about 45 standards with fewer than 60 declared patents each.

Figure 22. How the observed traded SEPs are distributed over 15categories (15 standards per category)

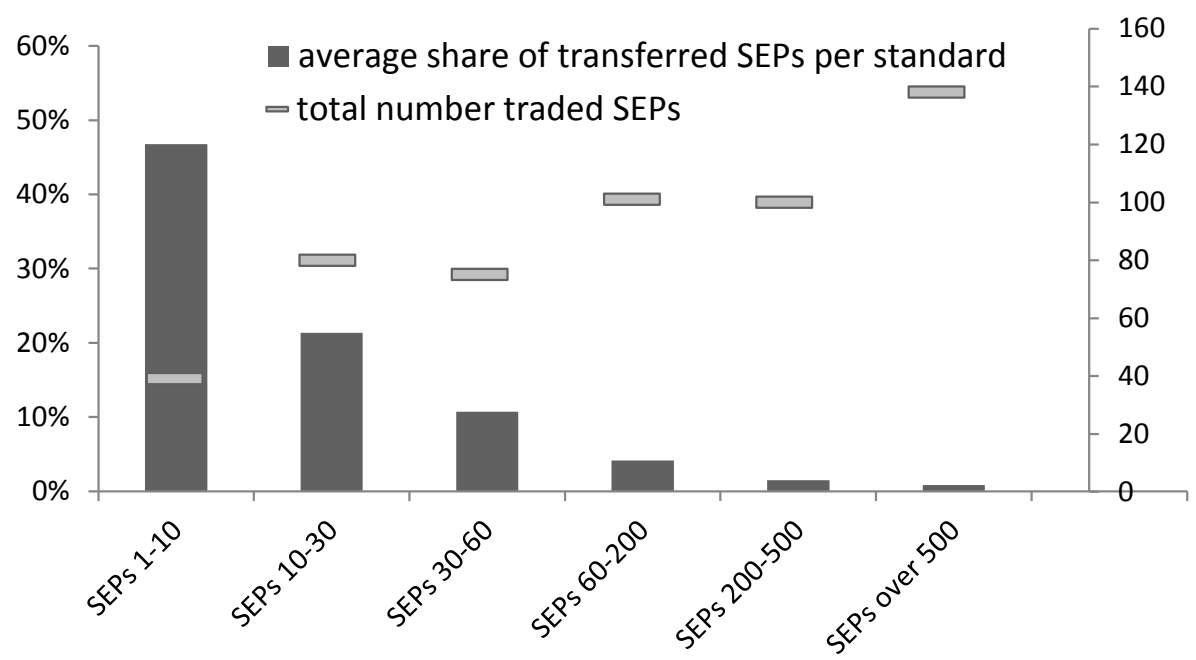

Figure 23 displays the mean share of traded SEPs per standard at the technology area level. This average share ranges from 20 and 40 percent in Telecommunications (Tele), Audiovisual $(\mathrm{AV})$ and Security (Secu) technology areas. The rather high rates ${ }^{60}$ suggest that SEP transfers significantly impact a large number of small standards. The LAN and IT technology areas are

\footnotetext{
${ }^{60}$ Note that the shares of traded SEPs are calculated only for standards where at least one SEP has been traded. Averages shares would be much lower if they were calculated over all standards.
} 
two exceptions, with respectively a very low mean share of traded SEPs, and a very high but insignificant (given the small number of observations) 100 percent share.

Figure 23. Mean share of SEPs transferred per standard as to technology area

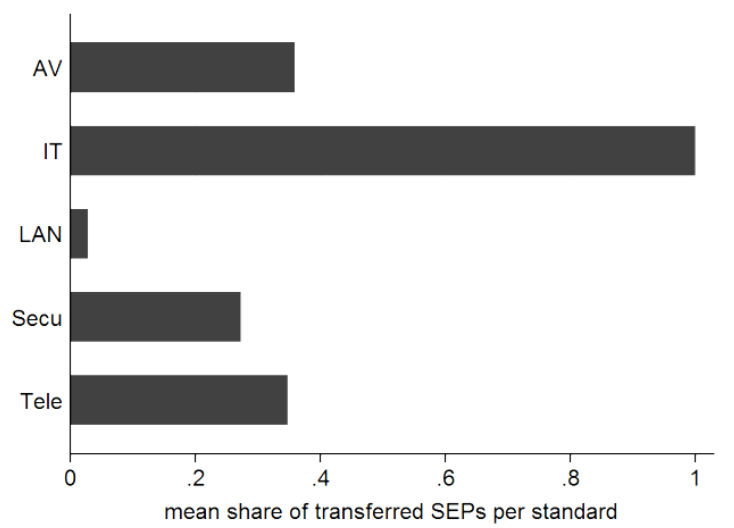

The reallocation of a large share of SEPs may affect the market for SEP licenses if it changes the number of SEP owners for a given standard. Since SEPs are complements and not substitutes, each of them confers in principle equal market power to its owner, and the dispersion of SEPs among different owners does not create competition but simply more transactions costs and royalty stacking ${ }^{61}$. Against this background, SEPs transfers may reduce (increase) transaction costs and royalty stacking if they result in a smaller (larger) number of licensors.

In order to study the impact of SEP transfers on the extent of SEP concentration, we thus calculated for each standard the share of declared SEPs held by each declaring company before and after the SEP transfers. We then derived the HHI value of each standard before and after transfers to measure the change in market concentration (Figure 24).

Figure 24. HHI index of SEP concentration per standard before and after the SEP transfer ${ }^{62}$

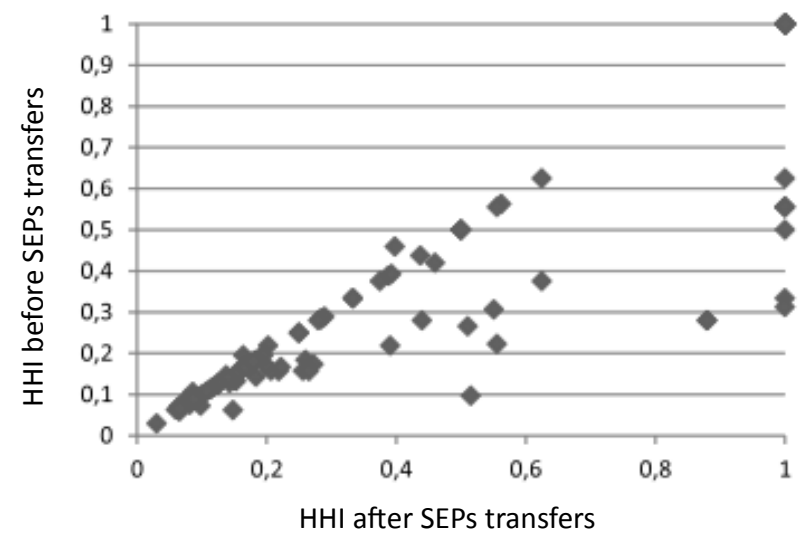

\footnotetext{
${ }^{61}$ See e.g. Shapiro, Carl (2001) "Navigating the Patent Thicket: Cross Licenses, Patent Pools, and Standard-Setting". In Jaffe, Adam B.; et al.. Innovation Policy and the Economy I. Cambridge: MIT Press. pp. 119-150.

${ }^{62}$ Dark grey bars refer to the left scale and light grey bars to the right scale.
} 
Overall we found transfers increased SEP concentration in around 80 percent of the cases and almost 100 percent in the Telecommunication technology area. The negative effects of trade on concentration are both scarce and very modest. In contrast, SEP concentration can significantly increase after trade for some standards where SEP ownership was already initially concentrated. For some small standards, we observe in particular that SEP transfers result in the full concentration of all declared SEPs in the hands of a single patent holder.

\subsection{Summary}

SEP transfers were almost non-existent before 2005 and thereafter increased rapidly. A large majority of the transferred SEPs has been declared at ETSI for Telecommunications standards, JTC1 coming next. Yet, in both cases this represents less than 10 percent of all SEPs declared to the SSO. ETSI has also by far the largest number of standards that are subject to SEP transfers.

A large majority of SEP transfers took place after their declaration to the SSO (69.9 percent of cases) and the official release of the standard ( 83.5 percent), which suggests that both events may facilitate transfers. However, this sequence mainly reflects the timing of transfers for SEPs declared at ETSI. In other SSOs, most transfers took place after the standard release, but not after the declaration.

Although most traded SEPs cover very large standards (with more than 60 declared SEPs), this does not significantly change the distribution of SEP ownership for such standards. In contrast, SEP transfers have a significant impact (from 10 to 50 percent of all declared SEPs) on the distribution of SEP ownership for smaller standards in Telecommunications, Audiovisual and Security areas. Overall transfers increase SEP concentration in around 80 percent of cases, thereby reducing transactions costs and royalty stacking in the market for SEP licenses. About 80 percent of the standards where concentration increases belong to the Telecommunication technology area, and the average increase of concentration is also highest in this sector. 


\section{Patent pools}

\section{This chapter was prepared by Justus Baron and Yann Ménière}

Patent pools provide a one-stop solution for licensing a bundle of standard essential patents owned by different entities, thereby aiming to mitigate transaction costs and royalty stacking. ${ }^{63}$ Competition law concerns limited the practice of pooling patents in the second half of the $20^{\text {th }}$ century. However, since the late 1990 s, a new type of patent pool has emerged, closely linked to technological standards and providing several safeguards against anticompetitive effects. Over forty patent pools have been created, which have granted more than 8,000 licensing contracts. Nevertheless, patent pooling is still not widely practiced in most areas where standard-essential patents play an important role. Furthermore, while some well-known patent pools have gathered a large number of members and patents, not all pools are successful in quickly attracting a large share of the relevant patent holders. Several attempts at pooling patents have not even resulted in a pool being created. Against this background, this section presents descriptive statistics on patent pools for standard-essential patents as well as failed attempts at creating pools, the size and coverage of these pools, and the patterns of entry and exit of pool members.

\subsection{Data and methodology}

The data presented in this section is mostly based on information provided by licensing administrators. Based upon an extensive desk research, we attempted to gather comprehensive information on all recent patent pooling efforts related to technological standards. Many of these pools are administered by a limited number of licensing administrators. We completed the list of pools by searching the websites of these pool licensing administrators, including the archives of news releases on past activities and projects for attempted and effective pool creations (an attempted pool creation is defined as any serious effort to create a pool, such as a call for patents). The data covers 60 attempted or effective pool creations since 1992, which have resulted in 45 pools and 11 failures, 4 calls for patents still being open ${ }^{64}$. For all the existing pools, we additionally sought to systematically obtain information on pool members (licensors), licensees, and included patents from the pool administrators' websites. The information on pool members and licensing administrators was available for all 45 pools, whereas information on licensees was available for 25 of these pools. Using the Internet Archive (www.archive.org), we could compare the current lists of members, patents and licensees with previous lists, providing information about the patterns of entry and exit of members and growth and decline in the number of licensees. This information was tracked as far back in time as possible (in most cases to the start of the licensing program).

\footnotetext{
${ }^{63}$ Shapiro, C. (2001) "Navigating the Patent Thicket". Jaffe, Adam B. et al. Innovation Policy, 119-150.

${ }^{64}$ This list is meant to include all patent pools related to technological standards, and we asked several practitioners to bring to our knowledge patent pools that should be included. It is however possible that less well-known pools and failed attempts at creating pools were not included in spite of our extensive search. In this case, the data underlying our study is likely to be biased towards large and successful pools, as well as pools administrated by one of the large licensing administrators.
} 


\subsection{Descriptive overview}

Pools are launched and administered by a licensing administrator (for distribution see Figure 25). In some of the oldest pools (DVD6C, DAB, mp3), this administrator is a patent holding company picked from the pool members. However, more recent pools are usually administered by independent third parties. Currently, five companies specializing in the administration of patent pools indeed account for the large majority of pools and attempted pool launches: MPEGLA, ViaLicensing, Sisvel, SiproLab, and VoiceAge. In other cases (e.g. One-Blue, One-Red), the pool members have created an ad hoc entity to administer a particular pool.

Figure 25. Number of pools by licensing administrator

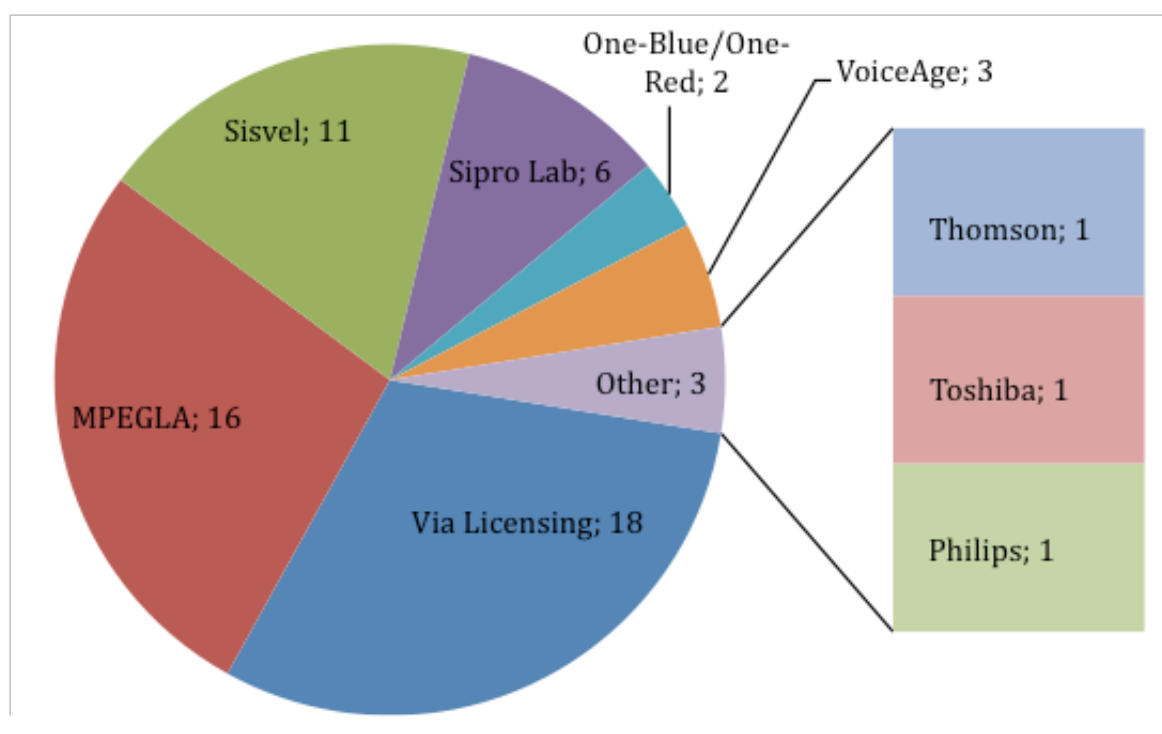

Patent pools are not evenly distributed across technological fields in which standard-essential patents are relevant (see Table 20). They are more frequently found in coding and compression, broadcasting and Audio/Video home systems - all of which are related to consumer electronics. The remaining pools are associated with short-range communication standards and the telecommunication sector. Half of the latter 14 pools are related to large telecommunication and (wireless) network standards, while the other half cover speech compression technologies and codecs. 
Table 20. Pools by technological sector and subsector

\begin{tabular}{|c|c|c|c|c|}
\hline \multirow[t]{2}{*}{ Technological area } & \multicolumn{2}{|c|}{ Aggregated standards } & \multicolumn{2}{|c|}{ Disaggregated standards } \\
\hline & Subsector & Pools or launches & Subsector & Pools or launches \\
\hline $\begin{array}{l}\text { Telecommunications } \\
\text { (1 Tele) }\end{array}$ & Telecom standards & $\begin{array}{c}2^{\text {nd }} \text { Generation Wireless; CDMA2000; } \\
\text { IEEE802.16 (WiMax); LTE (Sisvel); LTE } \\
\text { (Via); Spectral Band Replication; W- } \\
\text { CDMA }\end{array}$ & Speech codecs & $\begin{array}{c}\text { AMR; AMR-WB/G.722.2; AMR- } \\
\text { WB+; G711.1; G723.1; G729; } \\
\text { G729.1 }\end{array}$ \\
\hline $\begin{array}{l}\text { Local wireless and wired } \\
\text { communication ( } 2 \text { LAN) }\end{array}$ & $\begin{array}{l}\text { Short range wireless } \\
\text { communication }\end{array}$ & $\begin{array}{l}\text { IEEE802.11; IEEE 802.11n; NFC; Power } \\
\text { over Ethernet; Wireless Mesh }\end{array}$ & & \\
\hline \multirow[t]{2}{*}{ Audio-visual (4 AV) } & Broadcasting & $\begin{array}{c}\text { ATSC; DAB; DMB; Digital Radio } \\
\text { Mondiale; DVB-C2; DVB-H; DVB-MHP; } \\
\text { DVB-T; DVB-T2; GEM-MHP; OCAP; TOP } \\
\text { Teletext; TV Anytime; WSS }\end{array}$ & \multirow{2}{*}{$\begin{array}{l}\text { AV Coding and } \\
\text { Compression } \\
\text { (except speech } \\
\text { codec) }\end{array}$} & $\begin{array}{l}\text { AVC H.264; Digital Media Project; } \\
\text { H.264 SVC; HEVC; MPEG Audio; } \\
\text { mp3; MPEG2; MPEG2 AAC; } \\
\text { MPEG4 AAC; MPEG4 Systems; }\end{array}$ \\
\hline & Home Systems & $\begin{array}{l}\text { Agora-C; One Blue; Premier BD; } \\
\text { DVD3C; DVD6C; HD-DVD; IEEE1394 }\end{array}$ & & $\begin{array}{l}\text { MPEG7; MPEG Surround; MVC; } \\
\text { OMA-DRM; VC1; VP8 }\end{array}$ \\
\hline Security (5 Secu) & $\begin{array}{l}\text { Radio Frequency } \\
\text { Identification }\end{array}$ & UHF RFID & & \\
\hline
\end{tabular}

It is useful to differentiate between standards according to their level of aggregation as shown in Figure 26. Disaggregated standards such as codecs or compression technologies are typically used in many different applications. Pools on such standards often achieve high coverage and a very large number of licensees, especially in consumer electronics. In contrast, highly aggregated standards such as telecommunication standards (e.g. LTE), broadcasting technologies (DVB-T, ATSC) or home systems (Blu-Ray), incorporate and combine a large number of disaggregated technology standards for a particular technological purpose. Pools on these standards often achieve lower coverage of essential patent owners and have a limited number of licensees. We wish to note, though, that these are dynamic markets. A standard that results in a stand-alone product at one point in time (e.g. 802.11, for which initially specific products were made) may thus be combined with other standards later in its life.

Figure 26. Average number of (known) licensees and licensors

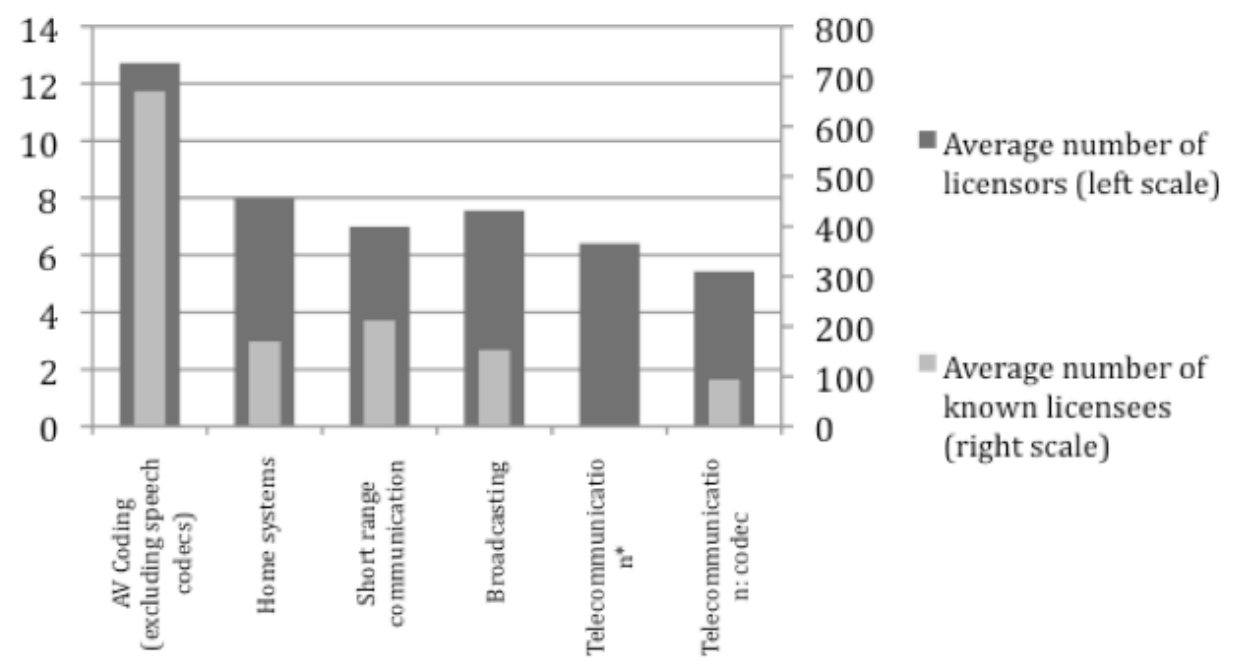


Figure 27 provides the details of the number of licensors and known ${ }^{65}$ licensees at the pool level. The various technological fields are characterized by significant differences in the average number of licensees (varying between 250 and almost 700), ${ }^{66}$ but the number of licensees varies even more strongly between individual pools, with only seven pools disclosing more than 500 licensees, and several pools having a very limited number of licensees. There is a similar, though less extreme skew in the number of licensors: three pools have more than 20 pool members, but most pools achieve only between four to ten members at the time of their greatest expansion.

Figure 27. Number of (known) licensees and licensors

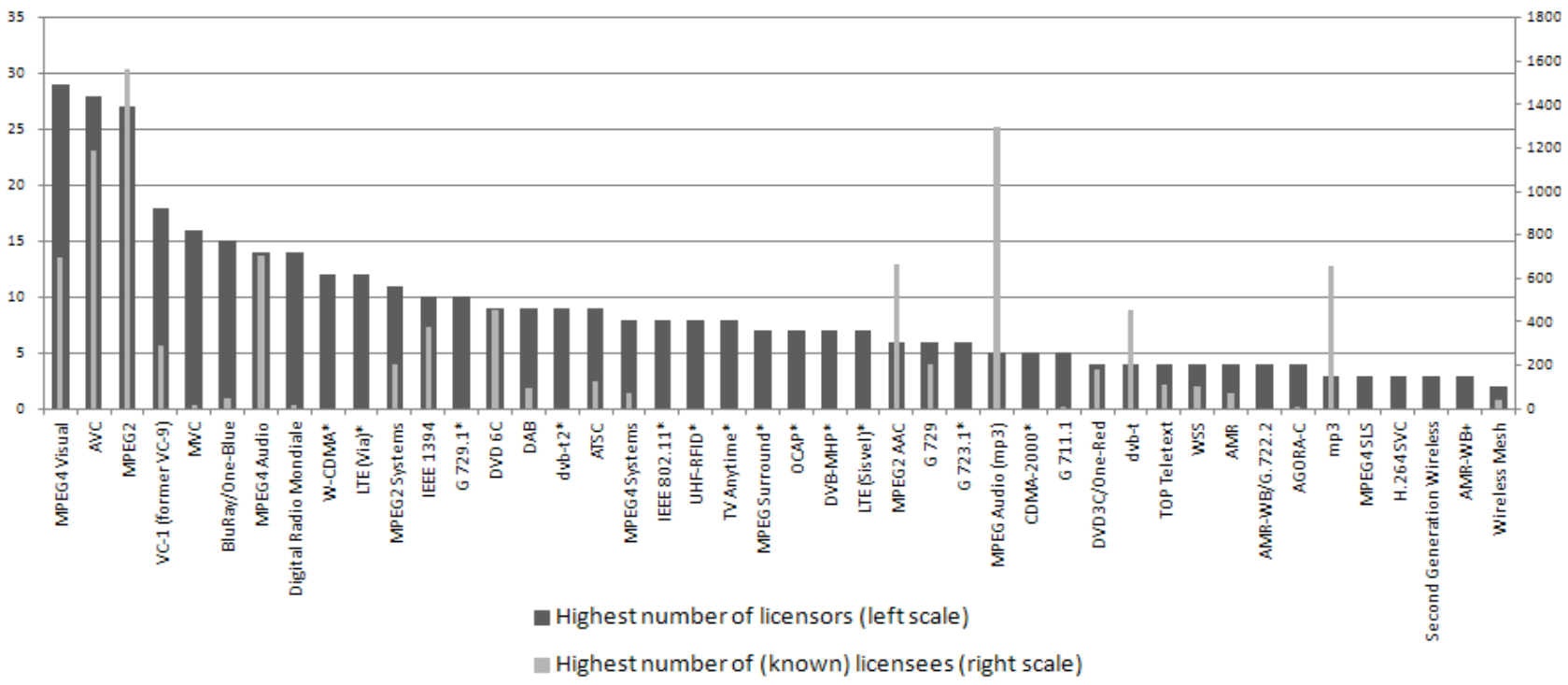

\subsection{Success and failure to create pools}

The main topic in the public discussion on patent pools concerns a small number of clearly successful pools. However, over the past 15 years, there have also been several unsuccessful attempts to launch pools.

In Table 21, we identify a "failed launch" if there is evidence of a significant effort to create a pool (e.g. a call for patent), which is not followed by a pool being created. We label it "effective" if: (a) a pool has been created within 3 years after standard release, (b) there is a single pool, the pool achieves good or very good coverage ${ }^{67}$, and (c) the pool remains stable or

\footnotetext{
${ }^{65}$ Most pools provide lists of licensees in good standing. These lists are, however, not available for all pools, and may not necessarily be complete. It is possible that a licensee in good standing asks not to disclose the existence of the licensing contract.

${ }^{66}$ Since several pools are already in a phase of substantial decline, all figures provided refer to the highest value observed.

${ }^{67}$ Coverage is very good if all declaring companies are pool members, and there is no information regarding significant patent holders staying outside the pool. Coverage is good if more than 60 percent of the declaring companies, including the majority of the most relevant patent holders in the field, or more than 40 percent of the declaring companies, including all the most patent holders, are pool members. Coverage is $o k$ if more than 60 percent of the declaring companies, but none of the most significant patent holders, or more than 40 percent of the declaring companies and some but not all of the most relevant holders are pool members. Coverage is incomplete if less than 60 percent of the declaring companies and none of the most relevant patent holders, or less than $40 \%$ of the declaring companies are pool members ("small, but includes major players" if all the
} 
grows through inclusion of other members over time. A "rather effective" pool creation refers to a case where either there are multiple pools (failure to achieve a single pool for one standard, like in the case of DVD or LTE ${ }^{68}$ ), the pool fails to achieve good coverage, or is created after a significant delay. If a pool is abandoned after a short time, or the pool includes only fringes of the relevant patents, we speak of a "rather ineffective" pool creation.

most relevant patent holders are pool members). Coverage is very incomplete if less than 40 percent of the declaring companies and none of the relevant patent holders, or less than 10 percent of the declaring companies are members of the pool.

${ }^{68} \mathrm{We}$ analyzed the effectiveness of pool creation by standard, not by pool. If several pools were created for one standard, the two pools were combined for the coverage analysis, but the failure to achieve a single pool was taken into account for the categorization. 
Table 21. Pool launches, categorized by the effectiveness of pool creation

\begin{tabular}{|c|c|c|c|c|c|c|}
\hline Category & Standard & $\begin{array}{l}\text { Pool Licensing } \\
\text { administrator(s) }\end{array}$ & $\begin{array}{l}\text { Time to } \\
\text { build }^{69}\end{array}$ & Single pool & Coverage $^{70}$ & Post-launch evolution \\
\hline Effective pool & AVC H.264 & MPEGLA & $<2$ years & $\begin{array}{c}\text { After } 2 \\
\text { years }\end{array}$ & Good & Dynamic growth \\
\hline Effective pool & DAB & Philips & 1 year & Yes & Good & Stable \\
\hline Effective pool & DVB-T2 & Sisvel & 1 year & Yes & Likely good & Growth \\
\hline Effective pool & G711.1 & Sipro Lab & 1 year & Yes & Very good & Stable \\
\hline Effective pool & MPEG2 & MPEGLA & 3 years & Yes & Good & Dynamic growth \\
\hline Effective pool & MPEG4 Visual & MPEGLA & 3 years & Yes & Good & Dynamic growth \\
\hline Rather effective & AMR & VoiceAge & $>6$ years & Yes & Incomplete & Stable \\
\hline Rather effective & AMR-WB/G.722.2 & VoiceAge & 7 years & Yes & Incomplete & Stable \\
\hline Rather effective & AMR-WB+ & VoiceAge & $<1$ year & Yes & Incomplete & Stable \\
\hline Rather effective & Blu-Ray & One Blue; Premier BD & 10 years & No & Good* & \\
\hline Rather effective & DVB-T & $\begin{array}{l}\text { DVBLA, MPEGLA, then } \\
\text { Sisvel }\end{array}$ & 4 years & Yes & $\begin{array}{l}\text { Incomplete over } \\
\text { time }\end{array}$ & Exits and late entries \\
\hline Rather effective & DVD & Philips; Toshiba & 4 years & No & Good* & Stable \\
\hline Rather effective & G729.1 & Sipro Lab & $<3$ years & Yes & Ok & Significant exits \\
\hline Rather effective & IEEE1394 & MPEGLA & 5 years & Yes & $\begin{array}{c}\text { Incomplete, but } \\
\text { includes major } \\
\text { players }\end{array}$ & Stable and then decline \\
\hline Rather effective & MPEG Audio & Thomson; Sisvel & $<3$ years & No & $\begin{array}{l}\text { Incomplete but } \\
\text { includes major } \\
\text { players }\end{array}$ & Stable \\
\hline Rather effective & MPEG2 AAC & Dolby, Via Licensing & $3-4$ years & Yes & Good & Growth \\
\hline Rather effective & MPEG4 Audio / AAC & Dolby, Via Licensing & $<3$ years & Yes & Incomplete & Dynamic growth \\
\hline Rather effective & MPEG4 Systems & MPEGLA & $<4$ years & Yes & Incomplete & $\begin{array}{l}\text { Licenses no longer } \\
\text { offered }\end{array}$ \\
\hline Rather effective & MPEG4SLS & Via Licensing & 4 years & Yes & Incomplete & Stable \\
\hline Rather effective & MPEG Surround & Via Licensing & $<5$ years & Yes & Good & Stable \\
\hline Rather ineffective & CDMA 2000 & Sisvel & 9 years & Yes & Incomplete & Significant exits \\
\hline Rather ineffective & DVB MHP & Via Licensing & 8 years & Yes & Ok & Disappears after 6 years \\
\hline Rather ineffective & G 723.1 & Sipro Lab & 5 years & Yes & Incomplete & Significant exits \\
\hline Rather ineffective & G 729 & Sipro Lab & 3 years & Yes & Very incomplete & Significant exits \\
\hline Rather ineffective & IEEE802.11 & Via Licensing & 8 years & Yes & Very incomplete & Significant exits \\
\hline Rather ineffective & LTE & Sisvel; Via Licensing & 3 years & No & Incomplete & \\
\hline Rather ineffective & NFC & Via Licensing & 3.5 years & Yes & Very incomplete & Abandoned after 5 years \\
\hline Rather ineffective & $\begin{array}{c}2^{\text {nd }} \text { Generation } \\
\text { Wireless }^{71}\end{array}$ & Sipro Lab & 9 years & Yes & $\begin{array}{c}\text { Very } \\
\text { incomplete* }\end{array}$ & Disappears after 9 years \\
\hline Rather ineffective & TV Anytime & Via Licensing & 2 years & Yes & Good & Disappears after 6 years \\
\hline Rather ineffective & UHF RFID & $\begin{array}{l}\text { MPEGLA; Sisvel (now } \\
\text { only Sisvel) }\end{array}$ & 1 year & $\begin{array}{l}\text { After } 2 \\
\text { years }\end{array}$ & Very incomplete & $\begin{array}{c}\text { Significant exits and } \\
\text { entries }\end{array}$ \\
\hline Rather ineffective & W-CDMA & $\begin{array}{c}\text { PlatformWCDMA, now } \\
\text { Sipro Lab }\end{array}$ & 3 years & Yes & Incomplete* & Growth \\
\hline
\end{tabular}

${ }^{69}$ Time lapse from standard release to availability of the first license in the pool.

${ }^{70}$ Coverage was estimated comparing the list of pool members to the list of companies declaring ownership of essential patents.

We checked whether the pool members are the largest patent holders in the field using Patstat as well as the IPC classes of the declared essential patents. This information was complemented with evidence from public reports and practitioner feedback.

${ }^{71}$ This pool, run by Sipro Lab until 2008, included 2G patents by Nokia, Sipro and Université de Sherbrooke. We could not discover which $2 \mathrm{G}$ standards were exactly covered by the licensing program. 
Table 21, continued

\begin{tabular}{|c|c|c|c|c|c|c|}
\hline Failed launch & Digital Media Project & Sisvel & Failed & & & \\
\hline Failed launch & DMB & MPEGLA & Failed & & & \\
\hline Failed launch & DVB-C2 & Sisvel & Failed & & & \\
\hline Failed launch & DVB-H & MPEGLA; Sisvel & Failed & & & \\
\hline Failed launch & GEM MHP & Via Licensing & Failed & & & \\
\hline Failed launch & HD DVD & MPEGLA & Failed & & & \\
\hline Failed launch & IEEE 802.16 & Via Licensing & Failed & & & \\
\hline Failed launch & MPEG7 & Via Licensing & Failed & & & \\
\hline Failed launch & OMA-DRM & MPEGLA & Failed & & & \\
\hline Failed launch & Power over Ethernet & Via Licensing & Failed & & & \\
\hline Failed launch & $\begin{array}{l}\text { Spectral Band } \\
\text { Replication }\end{array}$ & Via Licensing & Failed & & & \\
\hline Unknown success & AGORA-C & Via Licensing & 1.5 years & Yes & Unknown & Stable \\
\hline Unknown success & ATSC & MPEGLA & 12 years & Yes & Unknown & Stable \\
\hline Unknown success & Digital Radio Mondiale & Via Licensing & 4 years & Yes & Unknown & Stable \\
\hline Unknown success & H.264 SVC & Sisvel & 5 years & Yes & Unknown & Stable \\
\hline Unknown success & MVC & MPEGLA & $<3$ years & Yes & $\begin{array}{c}\text { Currently very } \\
\text { small }\end{array}$ & Stable \\
\hline Unknown success & OCAP & Via Licensing & unknown & Yes & Unknown & Stable \\
\hline Unknown success & TOP Teletext & Sisvel & $>10$ years & Yes & Unknown (small) & Stable \\
\hline Unknown success & VC1 (former VC8) & MPEGLA & 1 year & Yes & Unknown & Some growth \\
\hline Unknown success & Wireless Mesh & MPEGLA & unknown & Yes & Unknown & \\
\hline Unknown success & WSS & Sisvel & 15 years & Yes & Unknown (small) & Stable \\
\hline Open call & HEVC & MPEGLA & call open & & & \\
\hline Open call & IEEE802.11n & Via Licensing & call open & & & \\
\hline Open call & VP8 & MPEGLA & call open & & & \\
\hline
\end{tabular}

* For these observations we used other sources than the declaration database to assess coverage.

Failed attempts at pool launches can be for various reasons: in many cases, the underlying standard or technology fails in the market. The pool project is abandoned as a reaction to insufficient potential demand. In other cases, the failure of the pool launch is attributable to a failure in the coalition building for the pool itself. The two scenarios are not always clearly distinguishable, and can be interrelated. The failure of a pool launch can undermine the chances of a standard in the market, or the coalition building for a pool can fail for the same reasons, thus weakening the support for the standard (such as strong rivalry between significant players). The present classification does therefore not attempt to distinguish these different cases.

We can nevertheless use this classification to illustrate the evolution of the patent pool landscape over the past twenty years. Figure 28 represents the annual number of pool launches. The year of pool launch is defined as the first time the attempt at pool creation is made public. In recent years, this date typically corresponds to a public call for patents. 


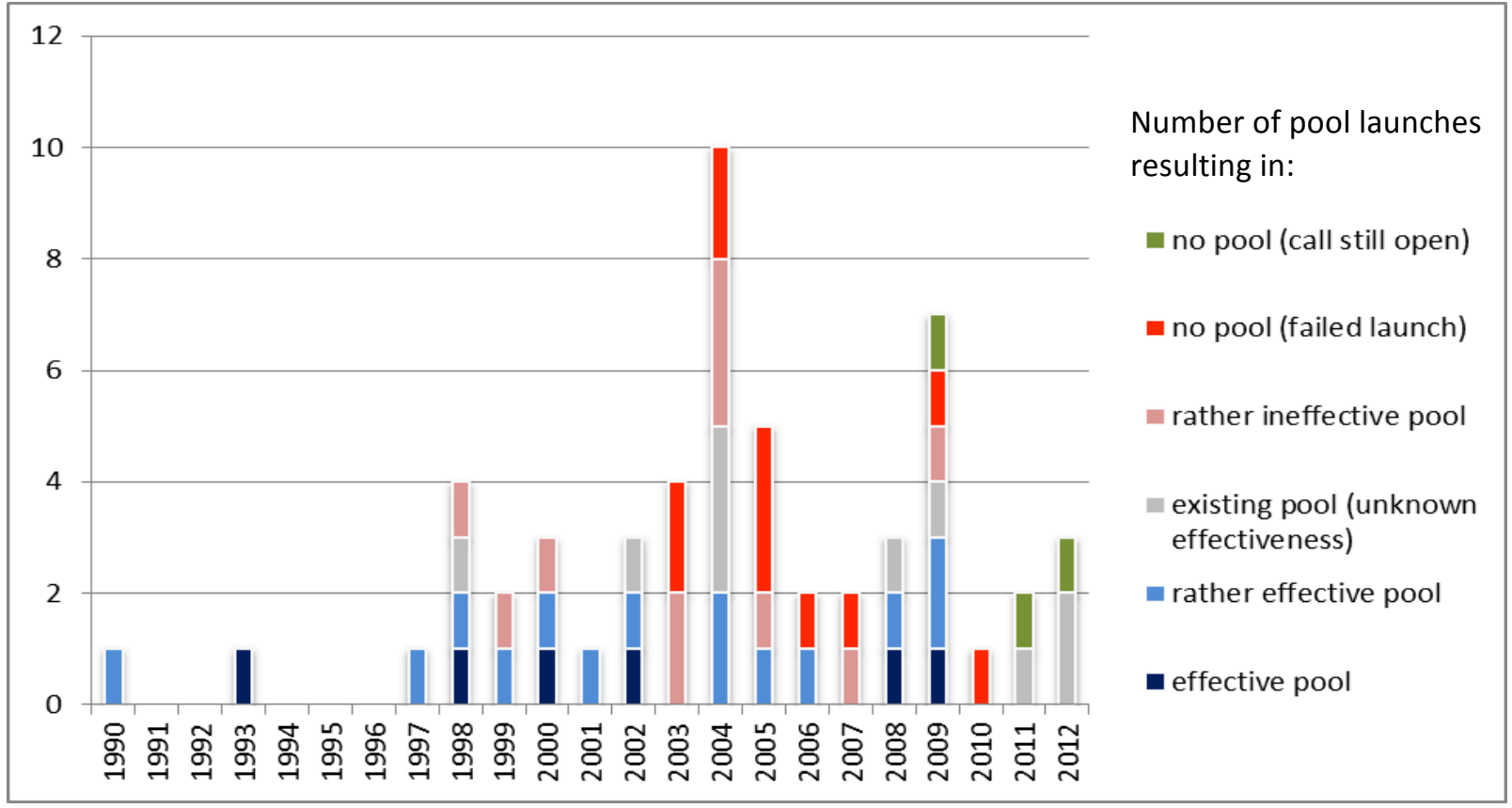

The resulting timeline evokes some interesting comments. Firstly, we can clearly see the effect of the change to a more positive stance in the application of competition law to patent pools, which occurred from 1997 to 1999 . While only a limited amount of standard-related patent pools was launched before 1997, several very significant and successful patent pools were launched in the following five years. The regulatory framework regarding patent pooling was progressively clarified in this period. Furthermore, a number of specialized pool licensing administrators were established, acquiring increasing experience in the creation and administration of pools. These factors should have made it easier to create pools. However we can see that the intermediary phase from 2003 to 2006 typically had a high number of launches, but also a relatively high rate of failure and relative failure. New waves of relatively successful pools have subsequently occurred from 2008-2009 and 2011-2012.

\subsection{Pool membership and dynamics}

One of the most important dimensions of pool success is the pool's ability to attract a large share of the holders of standard-essential patents. Comparing the list of pool members to the list of companies declaring ownership of essential patents to the relevant SSO provides an initial indication of pool coverage. We performed this analysis in the 29 pools for which both the list of licensors and data on the declared essential patents were available. The aggregate numbers of pool members, declaring companies and companies featured on both lists are represented in Figure 29. For the purpose of this analysis, companies making blanket declarations are included in the group of declaring companies. The 29 pools have 283 pool members, whereas 489 companies have declared essential patents or provided blanket 
declarations to the relevant SDOs. Only 145 companies feature on both lists. ${ }^{72}$ This means that approximately half of the pool members have declared their essential patents or made a blanket declaration to the corresponding SSO, and the pools include less than a third of the corresponding declaring companies.

Figure 29. Pool members, declaring companies and overlap - aggregated for 29 patent pools and standards

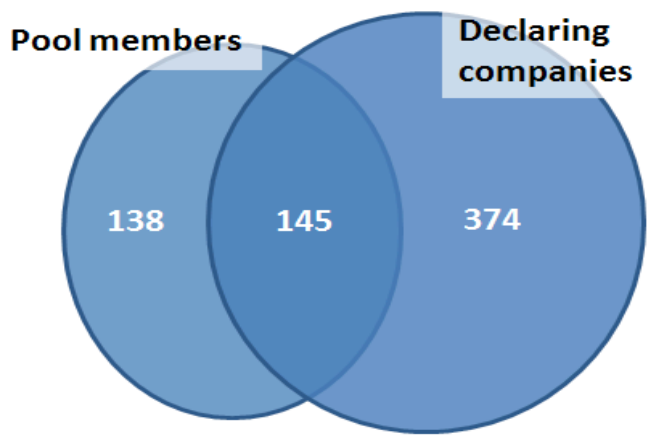

The number of identified pool members and the number of companies declaring essential patents or making blanket declarations are in turn reported in Figure 30 at the disaggregated pool level. The graph also displays the overlap between these lists, i.e. the number of companies featured on both the list of pool members and the list of declaring companies.

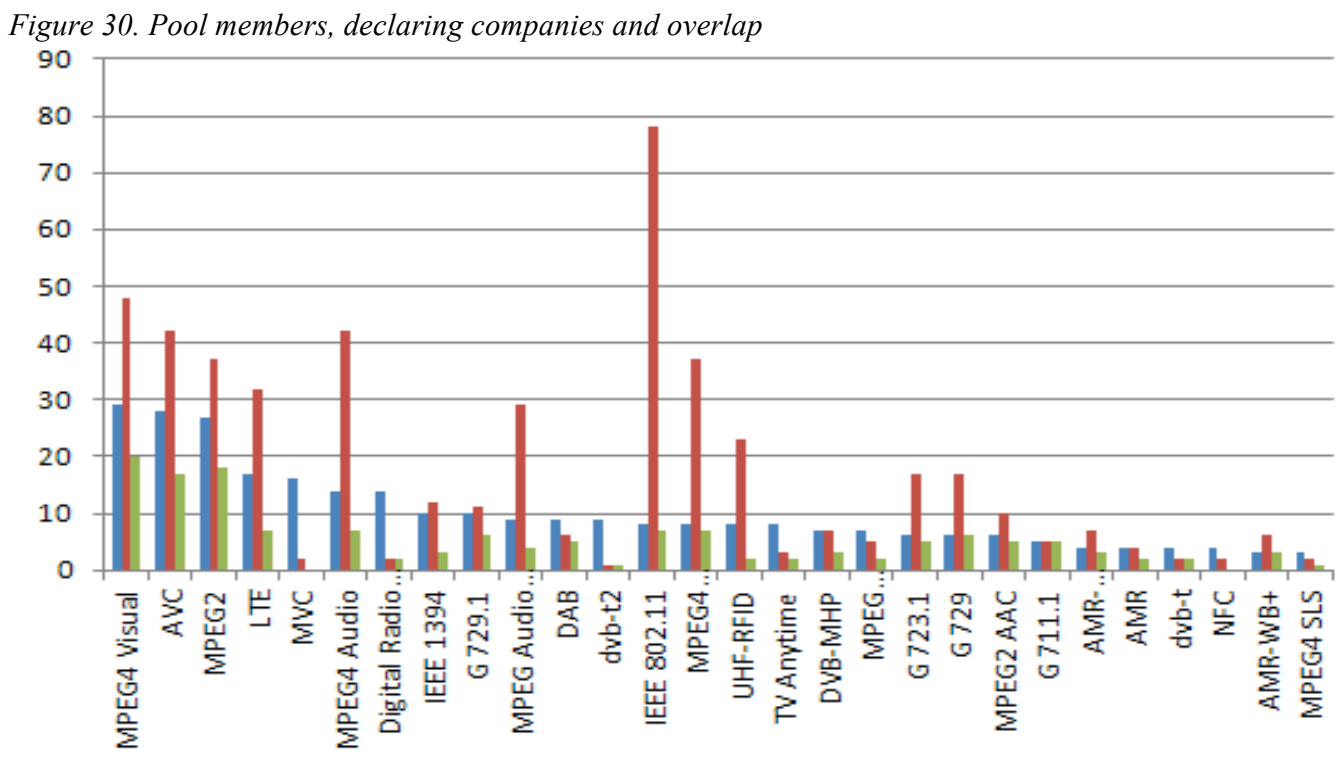

There are only few cases where the number of companies that overlap equals the number of declaring companies. This implies that in almost all cases, there are declaring companies that do not appear as a member of the pool, either because the firm did not choose to participate in the pool, or because the pool administrator did not agree with the essentiality claim made by the patent holder. In almost all cases, the overlap is also smaller than the number of pool

\footnotetext{
${ }^{72}$ We have tried to include all cases where the patent declaring company is affiliated to the same corporation as a company that is a pool member, but we cannot exclude that the measured overlap is biased downwards because of companies providing different names.
} 
members. This implies that almost every pool includes companies that have neither declared ownership of these essential patents to the relevant SSO nor provided a blanket declaration.

This can for instance be the case if the respective company has not participated in the standard development, or has acquired the essential patent after it was declared by its previous assignee.

We can further investigate this issue by considering the dynamics of firms' entry in the pools. Comparing the lists of pool members at various dates from pool launch until the present day, we can identify initial members (who typically include the initiators of the pool), later entrants and members that eventually left the pool (Figure 31). We see that approximately three fourths of the current pool members were initial members of the pool. There is, however, also a significant turnover in pool membership, a large number of entries after pool launch and a more limited number of exits.

Figure 31. Initial members, entries, and exits (cumulative for all pools)

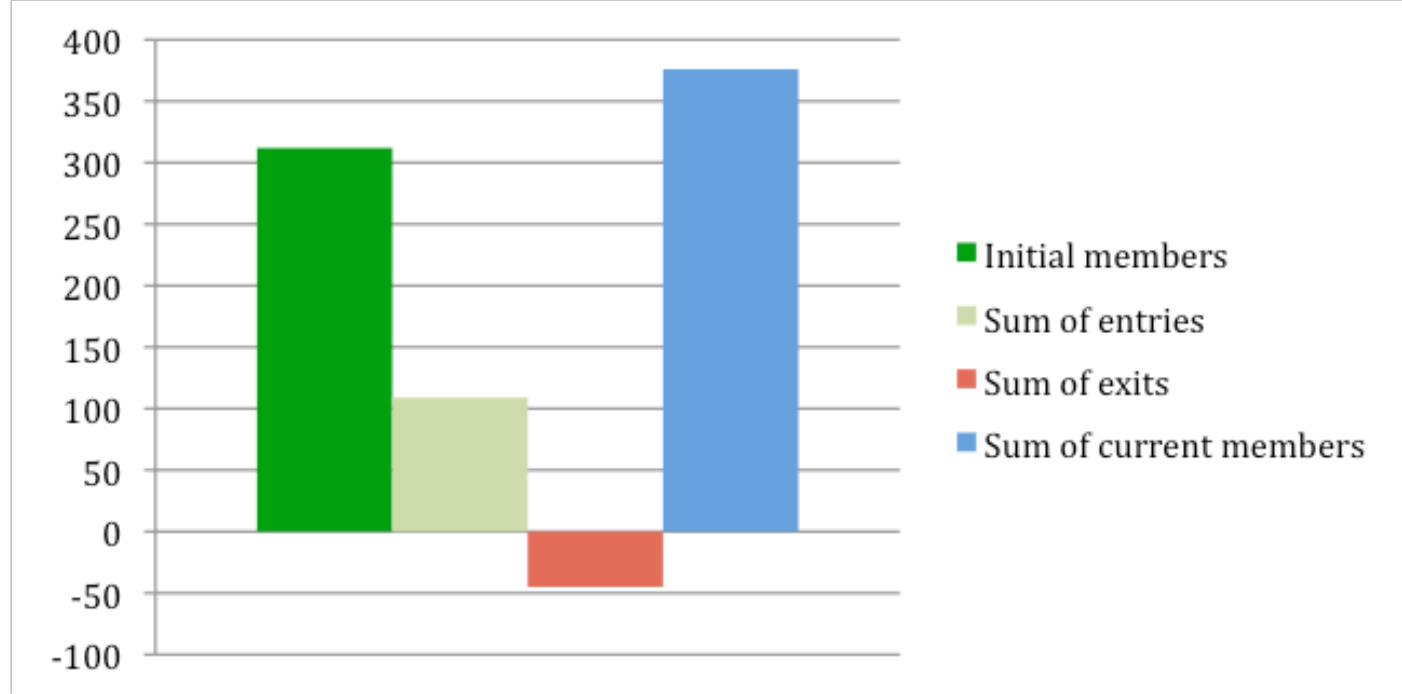

One fourth of the eventual pool members have joined the pool after its initial launch. These companies forego the possibility to shape the institutional setup of the pool. One reason for such a delayed entry is that the respective company was granted its first essential patents after the launch of the pool ${ }^{73}$. Late entries can also result from patent reassignments. In still other cases, companies that initially stayed out of the pool eventually find it profitable to join, for instance depending upon the stage of the technological life cycle of the standard. Exits from existing pools can take place when the last essential patent of a company expires, but also when a company decides to leave a pool. ${ }^{74}$ Yet another possibility is the sale of the essential

\footnotetext{
${ }^{73}$ Baron, J., Delcamp, H. (2012) "The strategies of patent introduction into patent pools", Working paper. This study reveals that most of the companies joining patent pools after launch obtained their essential patents significantly later than the founding members, which could explain why these companies joined late. This study also confirms that late entrants into patent pools find it more difficult to introduce a large number of patents into the pools than the founding members.

${ }^{74}$ In this case, existing pool licensees usually keep their license to the patents of this company, but new licensees must negotiate a license bilaterally. In many cases however, licenses are for a limited term (pools frequently offer licenses for an initial 5 year period) and pool members can leave the pool at the end of this term. Pool administrators have also reviewed the licensing conditions of existing pools, and offer more favourable conditions such as lower royalty rates, for instance after expiry of
} 
patents, leading to the exit of the former and entry of the new owner (e.g. in the case of the sale of essential patents by Daewoo to ZTE).

Figure 32 in turn describes the patterns of entry and exit by year following the pool creation, ignoring the companies joining at pool launch or in the first couple of months thereafter. It reveals that most entries and exits occur during the first year after pools are created. There are however, also several cases of very late entry into patent pools, and exits apparently related to patent expiry also occurring very late in the life cycle of the pool.

Figure 32. Entries to and exits from existing patent pools over time (years after pool creation)

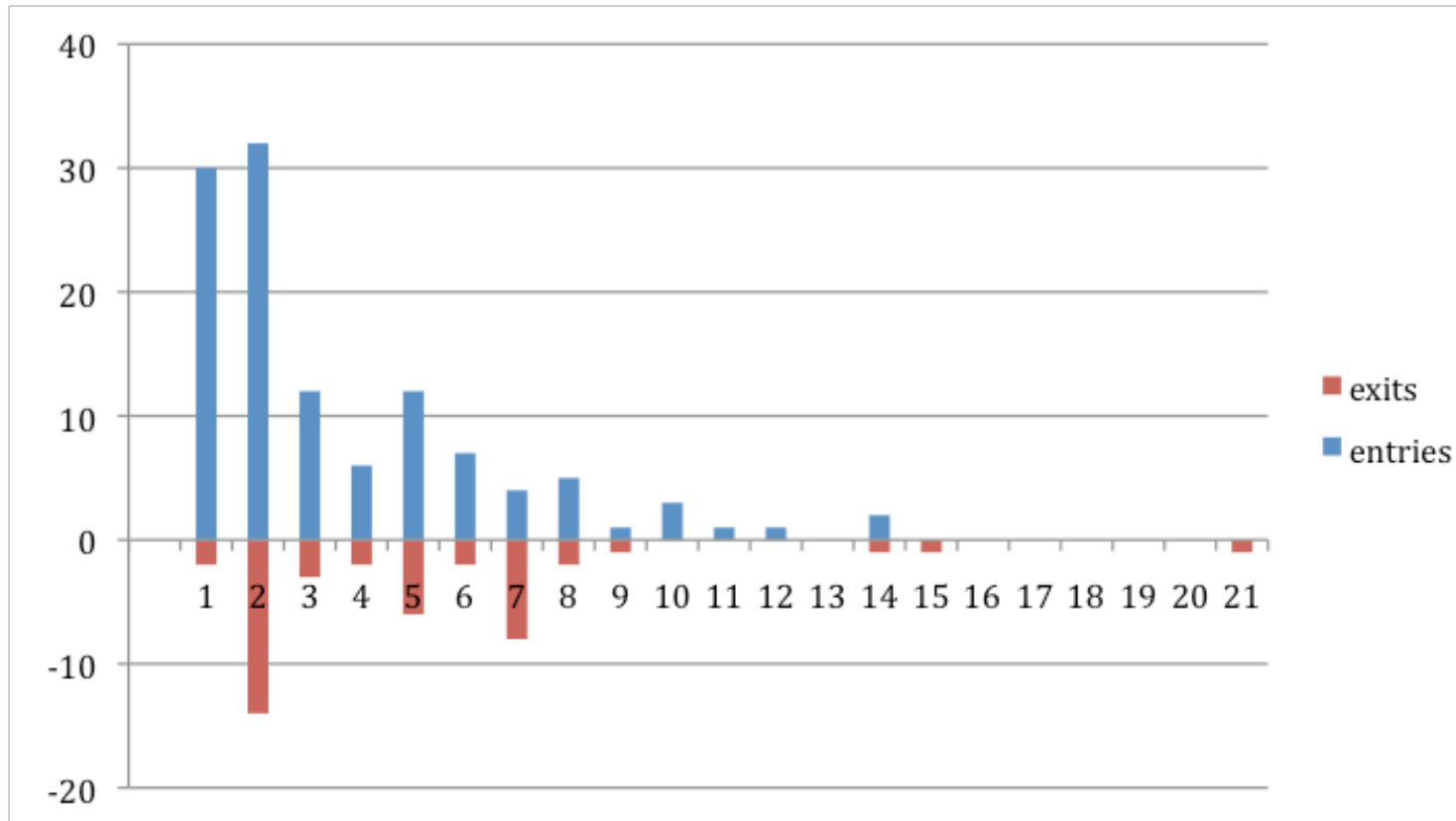

In order to understand the nature of this turnover, we concentrated the analysis on a subset of eleven pools with a relatively long history since pool launch, and compared the composition of these pools at the first and most recent observations. In particular we analyzed the share of pool members having declared ownership of essential patents to the relative SSO, and the share of pool members (licensors) also figuring on the list of licensees of the same pool. Just like any other company, a pool member (licensor) can choose to take a license from the pool for its own use of the technology, or to negotiate bilaterally with the other owners of essential patents. By comparing the lists of licensees and licensors, it appears that a majority, but not all pool members (licensors) also figure on the list of licensees. We can see that the share of licensees among pool members increases over time from approximately 75 percent to approximately 85 percent, whereas the share of declaring companies drops from almost 70 percent to approximately 60 percent. Entry into the pool seems to have been driven overproportionally by licensees of the pool, and by companies that were not initially involved in standard setting as declaring companies.

important patents, or when a new generation of a technology becomes available. In this situation, existing licensees have an incentive to replace the existing license with a new license, giving an opportunity to incumbent members to leave the pool. 
Figure 33. Composition of patent pools at launch and at the most recent observation

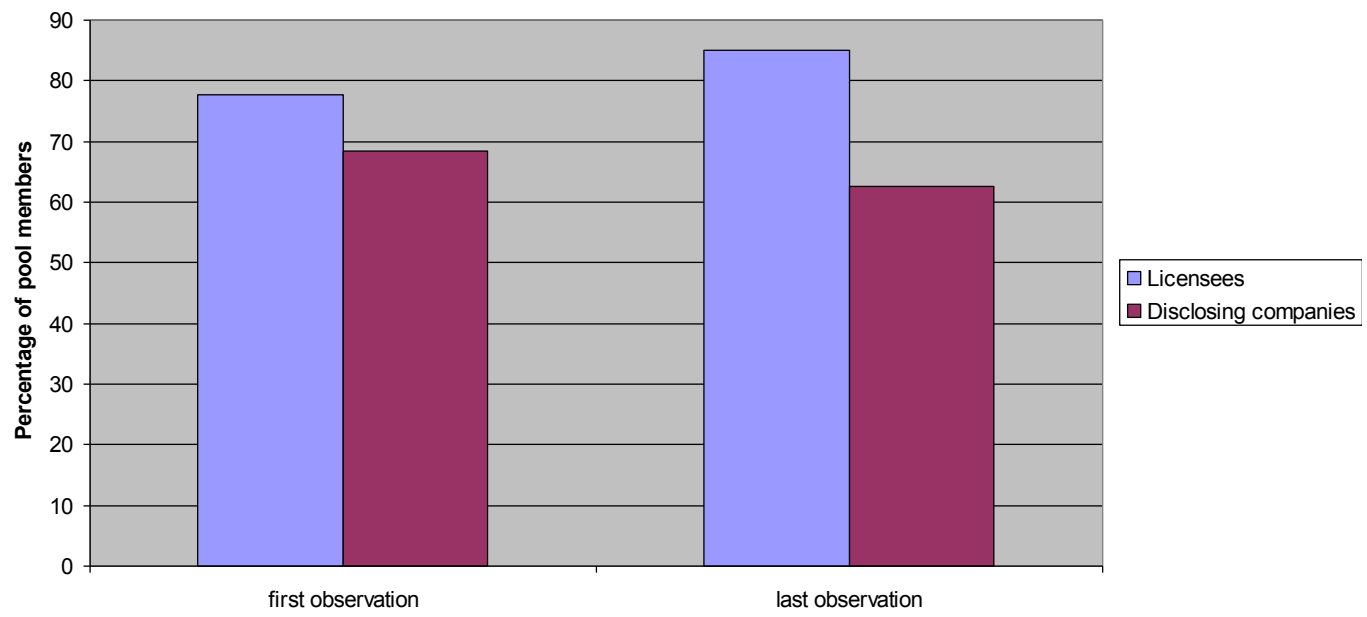

\subsection{Summary}

More than forty patent pools related to technological standards have been created over the past twenty years. Patent pools are however concentrated in relatively narrow technological fields: they are particularly present for coding and compression technologies, as well as for broadcasting and audio / video home systems.

Over time, the rate of pool launches per year has increased after 1997 and reached its highest level in 2004, with ten launches. Since 2006, the number of pools created every year varies between one and three, with the exception of 2009, when seven pool launches were observed. These pool launches have had unequal success in quickly attracting patent holders and licensees. Only a minority of patent pools gathers a large share of the companies declaring essential patents for the relevant standard.

Less than one third of the companies declaring essential patents for the respective standards were identified as members (licensors) of the pools in our sample. Most of the pool members joined the respective patent pool with its creation, but more than one fourth of the pool members joined the respective pool later than one year after launch. Those patent holders also taking a license from the pool are more likely to be among the late entrants to the group of pool members (licensors), whereas companies having declared standard essential patents to the relevant SSO are more likely to be among the initial members. 


\title{
8 SEPs and litigation
}

\author{
This chapter was prepared by Arianna Martinelli and Rudi Bekkers
}

Recently, litigation cases that included standard-essential patents have attracted considerable attention. But are they really a recent phenomenon, or just getting more publicity in the past few years? And are essential patents more likely to be litigated than comparable non-essential patents? These are the types of questions this chapter addresses. We begin with an analysis of the likelihood of litigation, comparing disclosed SEPs with patents that are otherwise comparable, but not disclosed to be a SEP. We then continue by looking at differences between technology areas, and differences between owners with different business models. Finally, a regression analysis seeks to explore the relationship between litigation and a variety of aspects relevant for SEPs.

\subsection{Data and methodology}

The data used in this section are derived from the OEIDD dataset introduced in Section 2.1. We linked the essential patents in this database with litigation data originating from Derwent LIT/Alert. ${ }^{75}$ Since we only had access to the litigation data of US patents, we created a subset that consisted of all granted USPTO patents in our disclosed essential patent data set, plus a USPTO DOCDB family member of any disclosed EPO patent (in so far as no USPTO family member of that patent was already in the set). This resulted in a final sample of 5,768 granted US patents. Considering patents covered by one single piece of legislation made the data more consistent and allowed us to ignore possible institutional differences at different patent offices.

In order to investigate the effect of being essential on litigation, we built a one-to-one matching control sample (referred to as 'baseline') by randomly choosing undeclared USPTO patents with the same technological class, ${ }^{76}$ the same application year, and the same grant year. Consequently, the two samples have identical joint distribution of technological classes and pendency years. The final set includes 11,535 patents: 5,768 SEPs plus 5,768 control patents. The patents were applied for between 1948 and 2009.

One caveat of our data is that we only observe 'official' litigated cases. Settlements or arbitrage processes are typically not made public and so cannot be viewed.

\footnotetext{
${ }^{75}$ Derwent LitAlert includes records of IP lawsuits filed in the 94 US District Courts since 1973, as reported to the Commissioner of the US Patent and Trademark Office. Also included are records for thousands of lawsuits filed since the early 1970s that have never been reported in the Official Gazette.

${ }^{76}$ Since we are considering USPTO patents, we used the USPC technology class, matching at the 3-digit level.
} 


\subsection{SEPs and litigation}

Academic literature on patent value suggests that litigation can be used as a proxy for patent value. In fact, as litigation suits can be rather expensive, we expect the value of the technology protected by a patent will at least exceed the costs of an eventual lawsuit. As SEPs generally have strategic value (even if not always coupled with real technological value), it would not be surprising if they are litigated more often than other patents (non-SEPs, or 'baseline'). Indeed, this is what we see in our data (Figure 34). There it is shown that 6.7 percent (393 of 5,768 ) of all essential patents in our data set were part of litigation (to date), whereas this was only 1.5 percent $(89$ of 5,768$)$ for other patents.

Here, it should be emphasized that there seems to be a industry practice that even when the value of the whole portfolio is in dispute, this is tested by litigating of only a very small sample of patents within the portfolio (namely those patents of which the patent owner believes has the best chances in litigation).

Figure 34: Litigation of SEPs compared to baseline patents (i.e. non-SEPS)

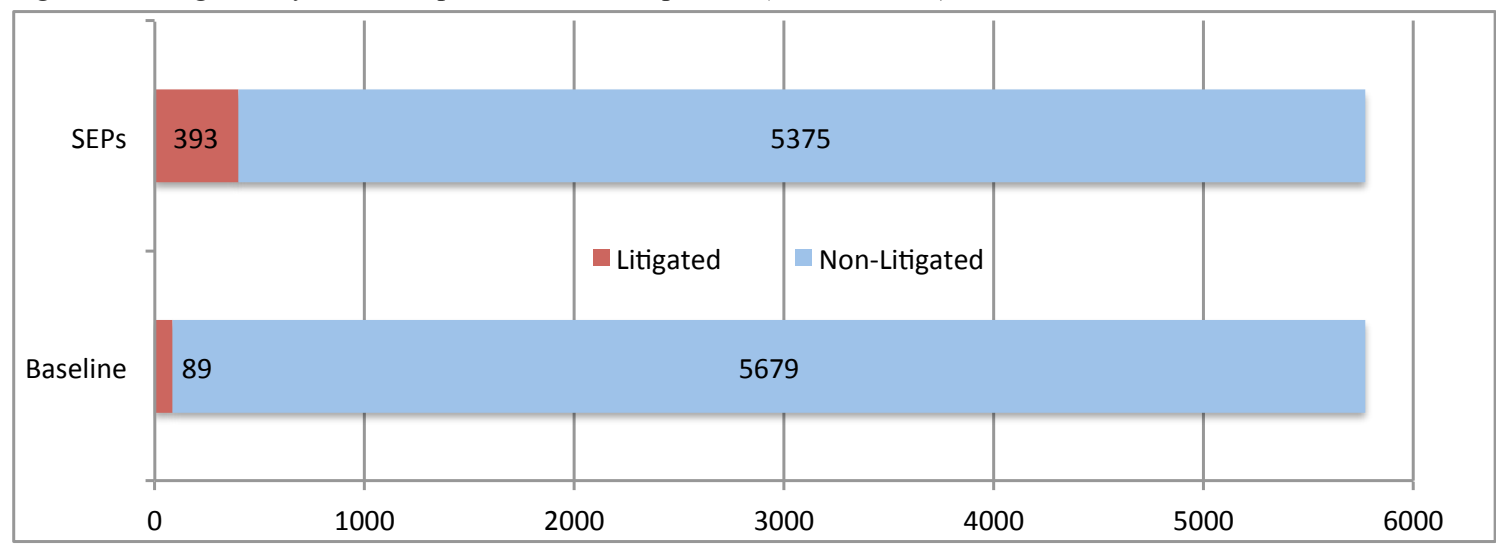

The likelihood of a patent being litigated may change over the patent lifetime. Duration analysis allowed us to compute such probability and to compare it to the control sample. Figure 35 shows the cumulative litigation hazard over the 20 -year life of both essential and control patents. The yearly increment of the line represents the increase in the likelihood of a patent to be litigated at a certain age, given the fact it had not been previously litigated.

The large distance shows that the two groups have a rather different probability of litigation profile. ${ }^{77}$ Essential patents are more likely to be litigated than the control patents, and the associated estimated likelihood of litigation over the entire lifetime is around 16 percent compared to 3 percent for a matched set of patents with otherwise similar characteristics. In other words, their likelihood to be litigated is over five times as high. This is consistent with our earlier observation that SEPs were more often part of litigation than comparable nonSEPs.

\footnotetext{
${ }^{77}$ Indeed we reject the null hypothesis for equality of survivor functions with 1 percent significance.
} 
Figure 35: Lifetime Litigation Probability (20-Year Cumulative Litigation Hazard) ${ }^{78}$

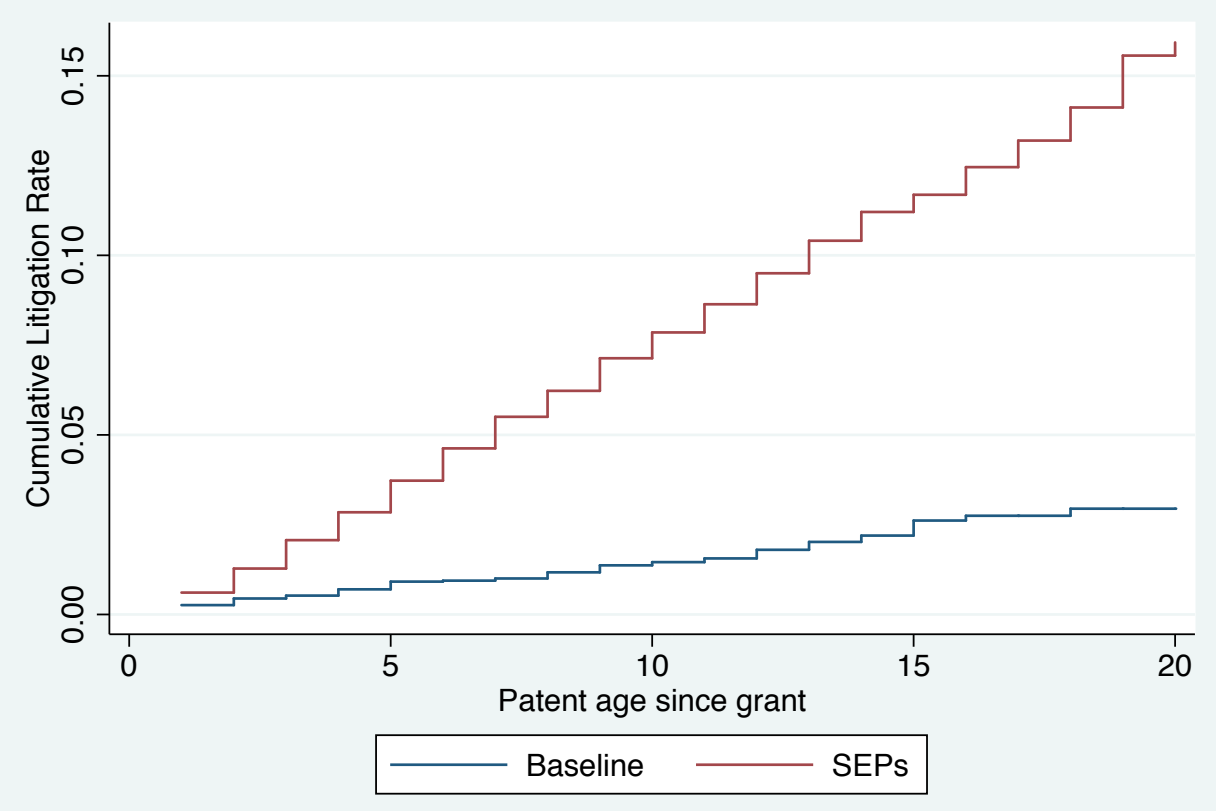

Figure 36: Number of litigation cases of SEPS and control group patents by litigation years

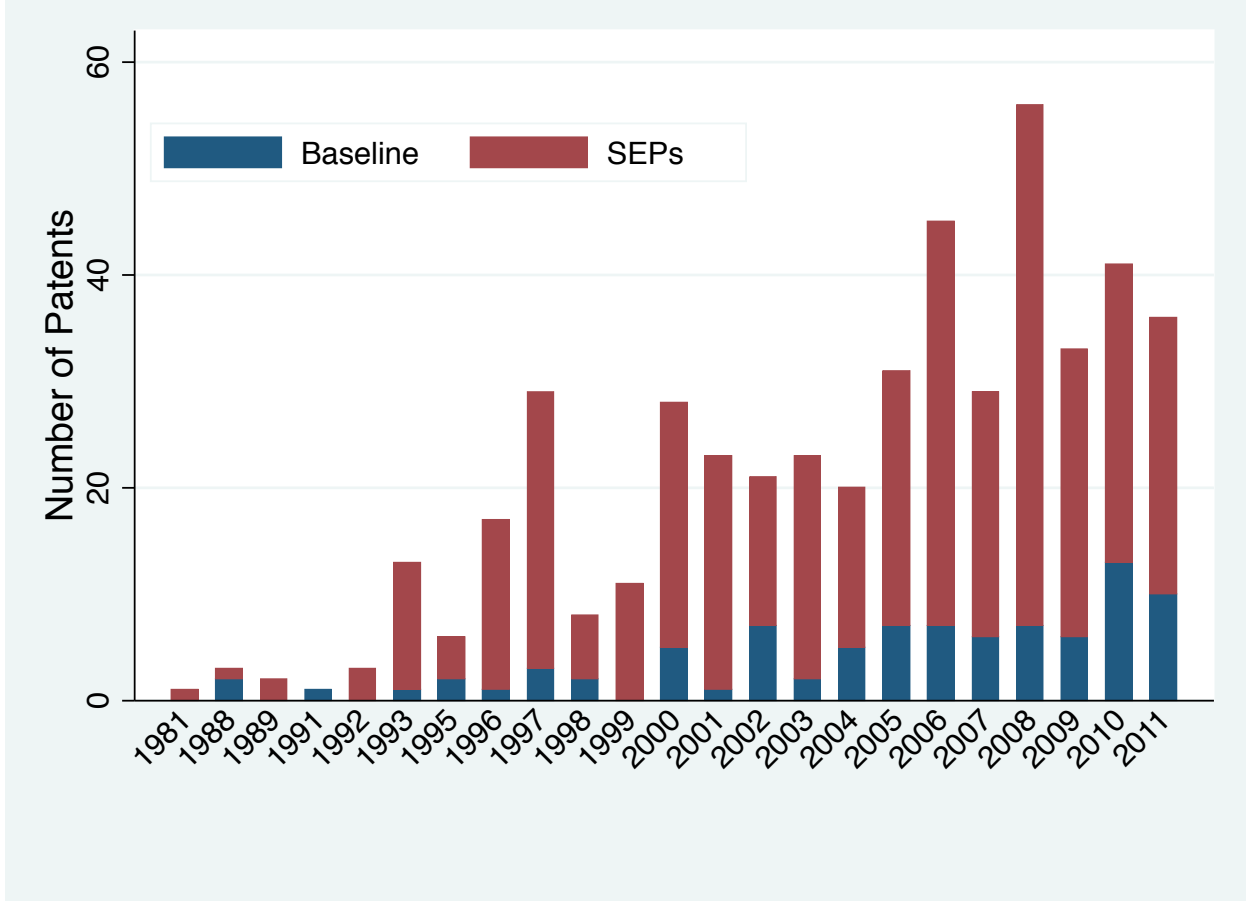

We can also investigate how the litigation date compares to the disclosure date. In principle, litigation can take place before a patent is disclosed as a SEP. This applies particularly for patents that are only disclosed later in their life (for instance when a new standard

\footnotetext{
${ }^{78}$ The graph plots the Nelson-Aalen cumulative hazard function.
} 
incorporates a technology that has already been patented a long time ago). Litigation can also take place after the patent has been disclosed as an SEP, and such litigation could also be triggered by that very fact (but not necessarily).

The data enabled us to explore the relationship in time between disclosure and starting the litigation procedure. It is interesting to see whether litigations tend to occur before or after the disclosure of a patent. Figure 37 shows the distribution of the time difference (in year) between disclosure and litigation. Positive values mean that litigation started after the disclosure, whereas negative values mean that litigation has started before the disclosure. We see that litigation has a bell-shape type of distribution around the disclosure data, with a slight emphasis on litigation after disclosure. ${ }^{79}$

Figure 37: Litigation year compared to disclosure year (positive value means litigation is after disclosure)

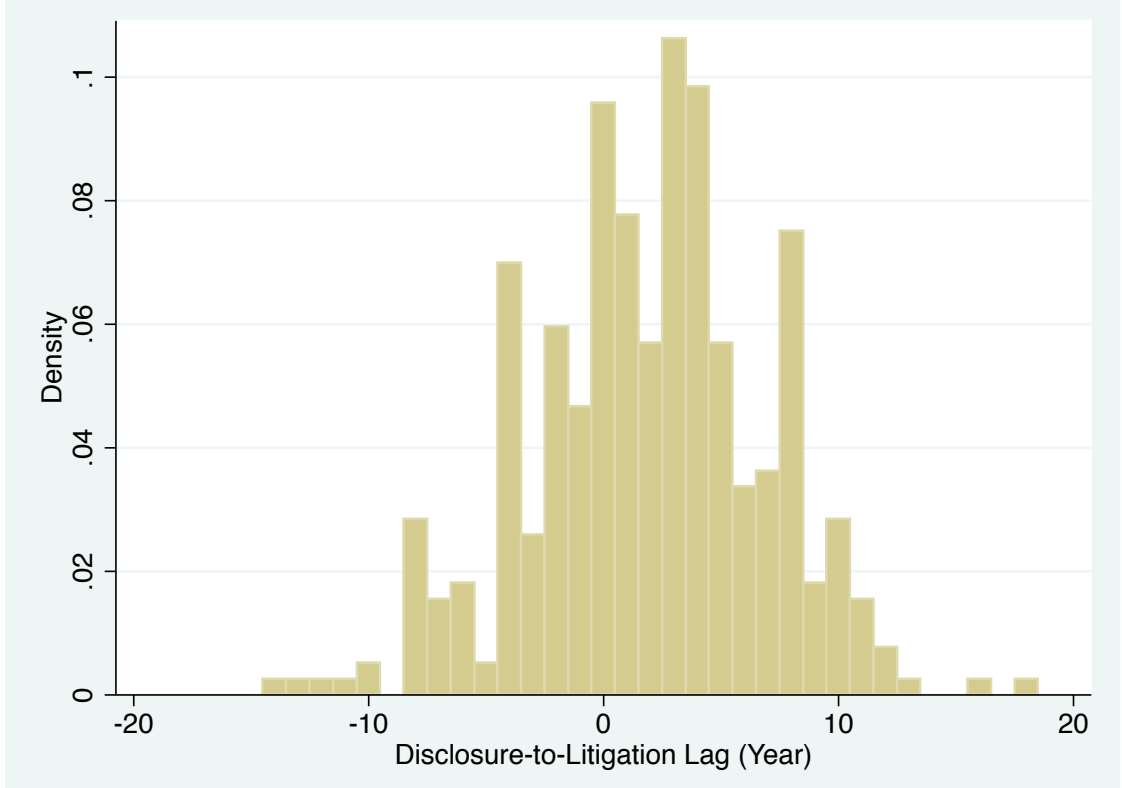

\subsection{Litigation and technology area}

Our data reveals that there are significant differences in litigation frequency between technologies areas. Although the telecommunications area is leading in terms of total numbers, its relative litigation rate (6 percent) is lower than that in LAN technology (14 percent), AV (also 14 percent) and security technologies (12 percent). Table 22 shows the results.

\footnotetext{
${ }^{79}$ We note that having this data still does not tell us whether the disclosure is also the cause of litigation. It is also possible that the patent in question was simply disclosed right after it was granted. In such cases, litigation is by definition after disclosure.
} 
Table 22. Litigation cases by technology area

\begin{tabular}{|c|c|c|c|c|}
\hline Category & Technology area & SEPS & Litigated SEPS & Percentage \\
\hline 1 Tele & Telecommunications via public networks & 4,284 & 244 & $6 \%$ \\
\hline 2 LAN & LAN/PAN/BAN networks, wired and wireless & 236 & 32 & $14 \%$ \\
\hline 3 IT & Information technology and Internet & 534 & 23 & $4 \%$ \\
\hline $4 \mathrm{AV}$ & $\begin{array}{l}\text { Audio/video systems, coding and compression, } \\
\text { broadcasting, home systems, home entertainment }\end{array}$ & 221 & 32 & $14 \%$ \\
\hline $5 \mathrm{Secu}$ & Security, identification, cryptography, biometrics & 182 & 21 & $12 \%$ \\
\hline 6 Trans & $\begin{array}{l}\text { Transport, logistics, aerospace, intelligent transport } \\
\text { systems }\end{array}$ & 3 & 0 & $0 \%$ \\
\hline 7 Energ & $\begin{array}{l}\text { Energy generation and distribution and storage, fuel } \\
\text { cells, power electronics }\end{array}$ & 6 & 0 & $0 \%$ \\
\hline 8 Ind & Industrial equipment, manufacturing, production & 41 & 2 & $5 \%$ \\
\hline 9 MTS & $\begin{array}{l}\text { Measurement, testing, safety standards, language } \\
\text { standards }\end{array}$ & 22 & 1 & $5 \%$ \\
\hline Total & & 5,529 & 355 & \\
\hline
\end{tabular}

We also investigated how the likelihood of litigation developed over the lifetime of the patent. Figure 38 summarizes the results for all the technology areas in which we observed 20 or more litigation cases. Security patents are only litigated in the first 12 years of their life. Also IT patents are not litigated any more once they are near the end of their life cycle. For LAN patents, in contrast, the litigation likelihood soars when they are 15 years old or more. Telecommunication and AV patents have an in-between pattern: their litigation likelihood grows steadily over the years, with no particular highs or lows.

Figure 38: Lifetime litigation probability by selected technology area (SEPS only)

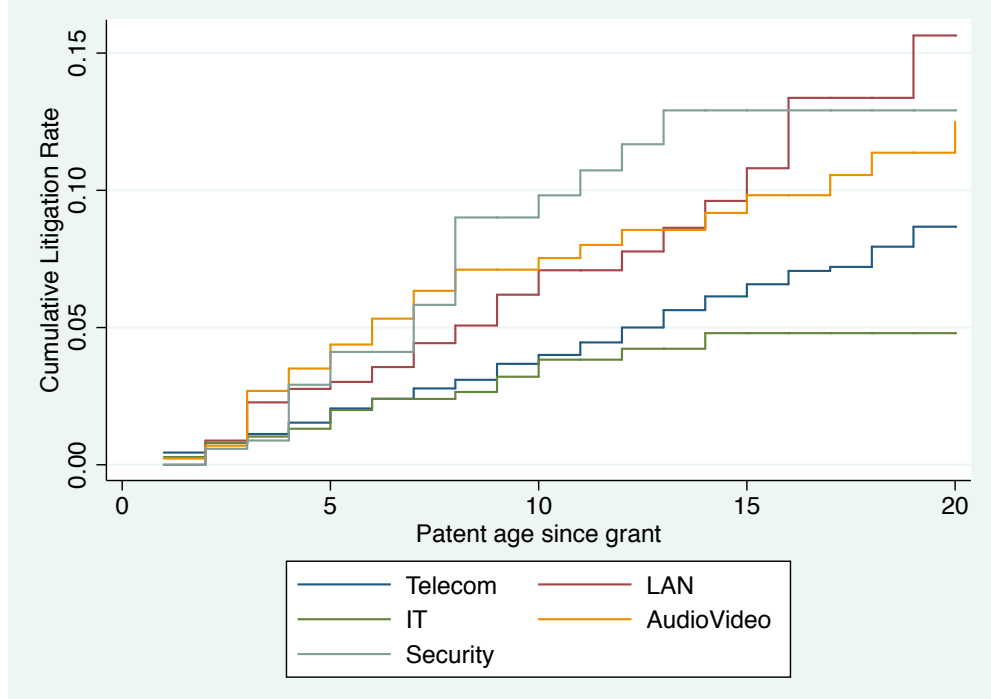

A similar analysis can be carried out to examine the difference across SEPs and the control sample within technology areas (Figure 39). Control patents do not belong to any standards (as they are not essential), therefore they are assigned to a standard area according to their one-to-one matching. 
Figure 39: Lifetime litigation probability: SEPs and control sample by technology area (selected)
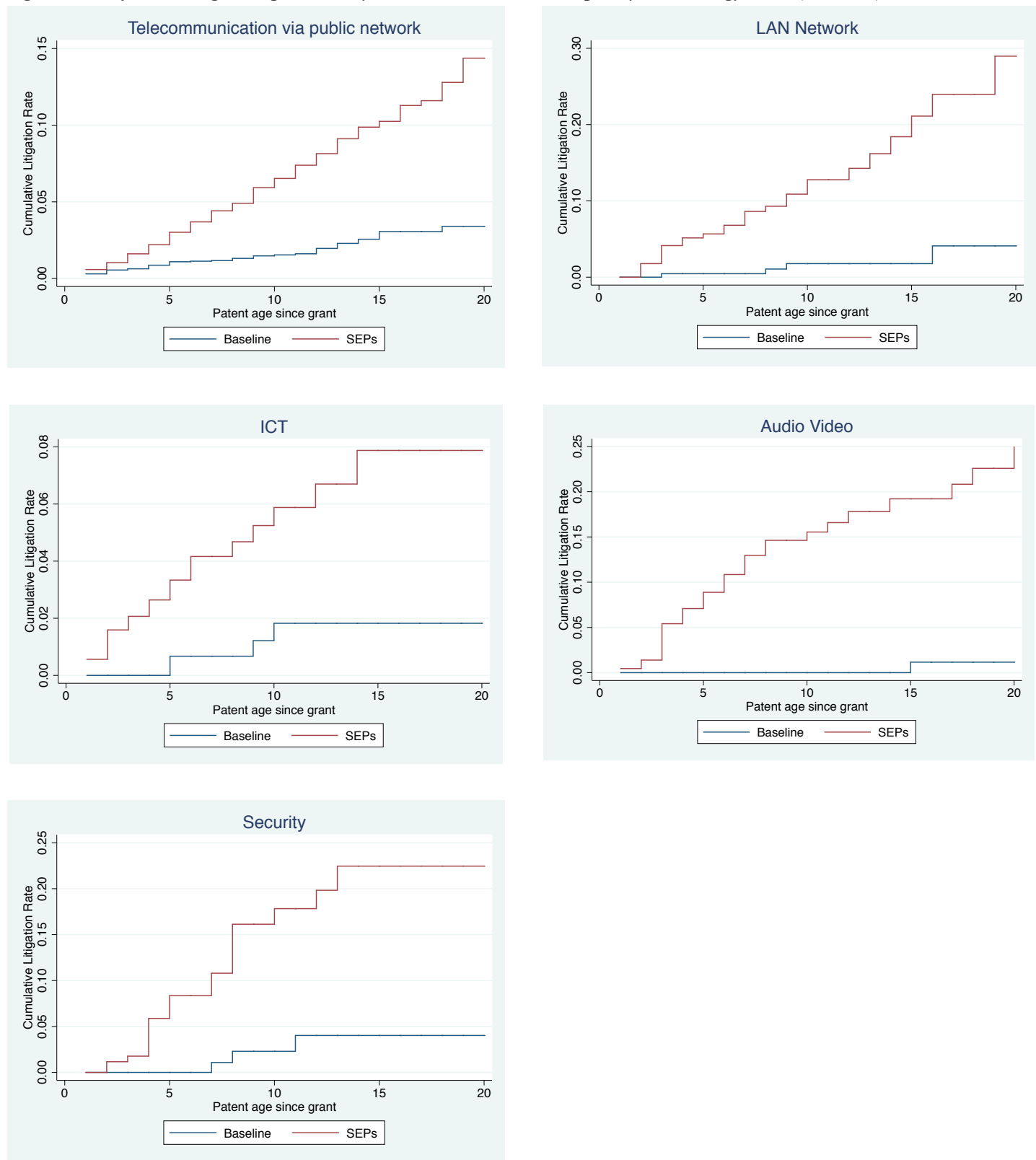

\subsection{Relationship between litigation and the patent owner's business model}

Another interesting aspect is whether firms with different business models have a different likelihood of asserting their essential patents. We investigated this by considering the business models of the companies that disclosed these essential patents. (In Section 3.4 we already introduced the way these business models are coded for this study.)

It is important to note here that ownership changes may affect our results. While our data considers the disclosing party's business model and thus does 'correct' for patent transfers 
that take place between the moment of the original patent assignment and the moment the patent is disclosed as SEP by its new owner, we cannot see whether a patent changed ownership after this disclosure, ${ }^{80}$ and subsequently gets litigated. As there is no obligatory register for such transfers for US patents, we cannot observe such ownership changes.

Table 23 shows SEP litigation cases divided into the disclosing party's business model. First of all, we observe that for all business models, the average is considerably above the average level for non-SEPs, which was found to be 1.5 percent (see above). Exceptions are the small categories of 'individual patent owners' and 'other business models', where there are simply no litigation cases at all. We also see some interesting differences. Downstream players are less 'ligitative' than upstream players. This is particularly true if we compare some of the larger categories in those two groups: Equipment suppliers (average 5.3 percent) and pure upstream companies (average 8.5).

Table 23. Litigation cases showing the disclosing party's business model

\begin{tabular}{llcc}
\hline \multicolumn{1}{c}{ Business Model } & SEPS & Litigated SEPS & $\%$ \\
\hline $\begin{array}{l}\text { UPSTREAM BUSINESS MODELS } \\
\text { Of which... }\end{array}$ & 1847 & 139 & $7.5 \%$ \\
$\quad \begin{array}{l}\text { Pure upstream knowledge developer or patent } \\
\text { holding companies (excl. universities) }\end{array}$ & 638 & 54 & $8.5 \%$ \\
$\quad \begin{array}{l}\text { Universities / public research institutes / states } \\
\quad \text { Components (incl. semiconductors) }\end{array}$ & 42 & 10 & $23.8 \%$ \\
$\quad$ Software and software-based services & 885 & 66 & $7.5 \%$ \\
$\quad$ Individual patent owner & 230 & 9 & $3.9 \%$ \\
\hline $\begin{array}{l}\text { DOWNSTREAM BUSINESS MODELS } \\
\text { Of which... }\end{array}$ & 52 & 0 & $0.0 \%$ \\
$\quad \begin{array}{l}\text { Equipment suppliers, product vendors, system } \\
\text { integrators }\end{array}$ & 3575 & 194 & $5.4 \%$ \\
$\quad$ Measurement and instrument, test system & 3,235 & 170 & $5.3 \%$ \\
$\quad \begin{array}{l}\text { Service providers (telecommunications, radio, } \\
\text { television, etc.) }\end{array}$ & 10 & 1 & $10.0 \%$ \\
\hline OTHER BUSINESS MODELS & 330 & 23 & $6.9 \%$ \\
\hline TOTAL & 24 & 0 & $0.0 \%$ \\
\hline
\end{tabular}

Note: “OTHER BUSINESS MODELS” include SSOs, fora and consortia (which are patent owners in some cases), technology promotion associations, and a few entities too diverse to be categorized as upstream or downstream.

Intrigued by the high percentage of litigated patents that were disclosed by universities, public research institutes and states (an average of 24 percent), we examined these 10 cases in more detail. Three of them are owned by a Korean government-funded research institute, and disclosed to SSOs as such. While the INPADOC Legal Status file does not reveal an ownership change, they are later used by a commercial firm in a US litigation case. Two other patents were originally held by a Canadian university. Again we traced no ownership change in the INPADOC Legal Status file, but it was a European vendor that subsequently disclosed owning these patents to an SSO. Later, this vendor litigated the patents. An interesting case is

\footnotetext{
${ }^{80}$ Unless the new owner also submitted a disclosure.
} 
that of a patent developed by a Canadian inventor and initially assigned to a Canadian entity. Later ownership was formally transferred to the inventor, who was then reported to be living in California. The University of California then disclosed these as SEPs, and later a Californian firm litigated them against another firm. In yet another patent, the US Secretary of the Navy was the original assignee, and also the party that disclosed the patent. No ownership change was reported, but the patent was later used in litigations against a European and an American bank, and a financial consultant. While each case is a story in itself, they often involve ownership changes before they become part of litigation.

We also investigated whether there are changes in litigation likelihood over time if we distinguish different business models. As can be seen in Figure 40, these differences are quite small. As shown above, upstream owners have a higher tendency to litigate, but this pattern is equal over time. ${ }^{81}$

Figure 40: Lifetime Litigation Probability by Business Model (SEPS only)

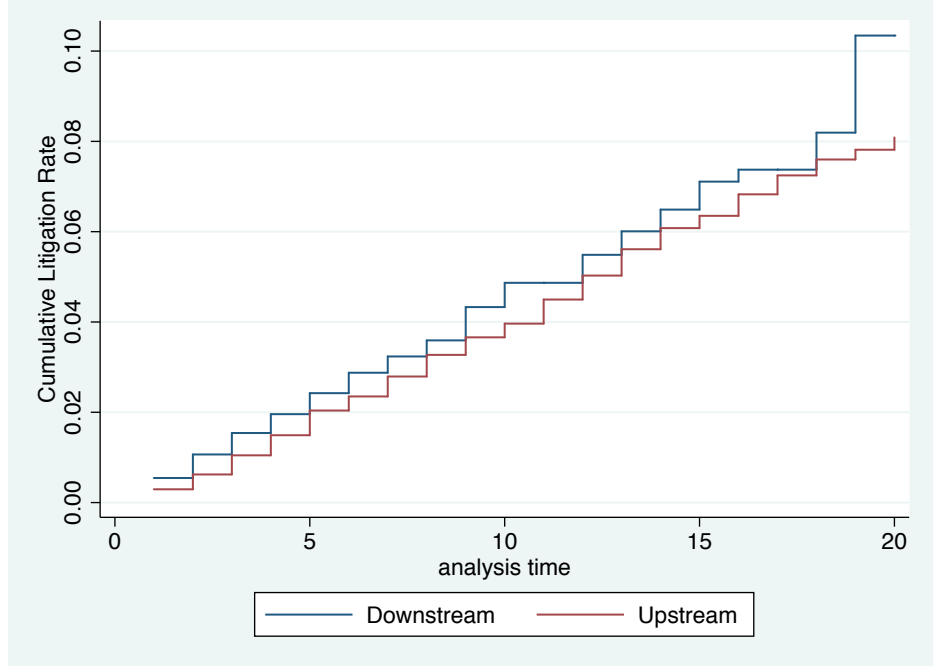

\subsection{Litigation and other relevant factors in standardization}

In this final section we exploit the rich OEIDD dataset to investigate the relationship between litigation and other relevant aspects of the standardization procedure such as possible institutional differences at the SSO, the licensing commitment made by the patent owner, and the disclosure lag. The use of the full sample (i.e. the set of SEPs and the matched control sample) allowed us to adjust for differences at patent level (such as age and technological class).

Table 24 shows the results of the patent level regression analysis ${ }^{82}$ where Models 1,2 , and 3 estimate how litigation varies across SSOs, licensing commitments, and disclosure timing,

\footnotetext{
${ }^{81}$ We cannot reject the null hypothesis of the two estimated functions being the same: The rank test for equality of survivor functions has a chi(2) value equal to 2.28 .

${ }^{82}$ The equation estimated is: $Y_{i, j}=\alpha+\beta$ DECLARED $_{i}+\Sigma_{j} \gamma_{j}$ GROUP $_{j}+\Sigma_{j} \delta_{j}$ DECLARED $_{i}$ GROUP $_{j}+\lambda_{\text {year }}+v_{\text {tech }}+\varepsilon_{i, j}$ where:

$\mathrm{Y}_{\mathrm{i}, \mathrm{j}}$ is a dummy variable that takes value 1 if the patent $\mathrm{i}$ in group $\mathrm{j}$ is litigated and 0 otherwise, DECLARED is a variable equal

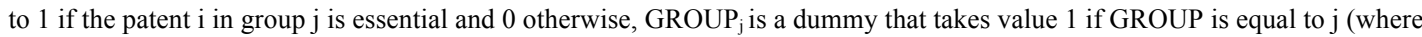


respectively. As we estimated a linear probability model, each coefficient could be interpreted as the difference in the probability (expressed in percentage points) of litigation between patents declared to an SSO and the relevant set of matched controls. There are two sets of variables for each model; in our interpretation we focused on the first set because the latter set is just a control of the group average effect.

Table 24. Litigation likelihood in relation to SSOs, licensing commitments, and disclosure timing

\begin{tabular}{|c|c|c|c|c|c|c|c|c|c|c|c|c|}
\hline & \multicolumn{4}{|c|}{ Model 1} & \multicolumn{4}{|c|}{ Model 2} & \multicolumn{4}{|c|}{ Model 3} \\
\hline & & $\mathrm{SE}$ & $\mathrm{t}$ & $P>|t|$ & & SE & $\mathrm{t}$ & $P>|t|$ & & SE & $\mathrm{t}$ & $\mathrm{P}>|\mathrm{t}|$ \\
\hline \multicolumn{13}{|l|}{$\beta+\gamma_{j}+\delta_{j}$} \\
\hline ANSI & 0.133 & 0.026 & 5.050 & 0.000 & & & & & & & & \\
\hline ATIS & 0.123 & 0.032 & 3.840 & 0.000 & & & & & & & & \\
\hline ETSI & 0.075 & 0.011 & 6.770 & 0.000 & & & & & & & & \\
\hline IEEE & 0.100 & 0.016 & 6.280 & 0.000 & & & & & & & & \\
\hline IETF & 0.071 & 0.014 & 5.050 & 0.000 & & & & & & & & \\
\hline ISO/IEC/JTC1 & 0.122 & 0.019 & 6.450 & 0.000 & & & & & & & & \\
\hline ITU & 0.075 & 0.015 & 5.050 & 0.000 & & & & & & & & \\
\hline OMA & 0.124 & 0.022 & 5.760 & 0.000 & & & & & & & & \\
\hline OTHER & 0.061 & 0.030 & 2.030 & 0.043 & & & & & & & & \\
\hline \multicolumn{13}{|l|}{$\gamma_{j}$} \\
\hline ANSI & 0.000 & NA & NA & NA & & & & & & & & \\
\hline ATIS & 0.028 & 0.015 & 1.930 & 0.054 & & & & & & & & \\
\hline ETSI & 0.038 & 0.010 & 3.700 & 0.000 & & & & & & & & \\
\hline IEEE & 0.031 & 0.011 & 2.730 & 0.006 & & & & & & & & \\
\hline IETF & 0.038 & 0.011 & 3.440 & 0.001 & & & & & & & & \\
\hline ISO/IEC/JTC1 & 0.022 & 0.011 & 2.010 & 0.045 & & & & & & & & \\
\hline ITU & 0.009 & 0.011 & 0.810 & 0.418 & & & & & & & & \\
\hline OMA & 0.027 & 0.011 & 2.450 & 0.014 & & & & & & & & \\
\hline OTHER & 0.029 & 0.019 & 1.520 & 0.129 & & & & & & & & \\
\hline \multicolumn{13}{|l|}{$\beta+\gamma_{j}+\delta_{j}$} \\
\hline FRAND & & & & & 0.053 & 0.004 & 14.060 & 0.000 & & & & \\
\hline $\mathrm{RF}$ & & & & & 0.023 & 0.013 & 1.820 & 0.069 & & & & \\
\hline OTHER & & & & & 0.046 & 0.020 & 2.290 & 0.022 & & & & \\
\hline$\gamma_{j}$ & & & & & & & & & & & & \\
\hline FRAND & & & & & 0.000 & NA & NA & NA & & & & \\
\hline $\mathrm{RF}$ & & & & & -0.002 & 0.003 & -0.630 & 0.527 & & & & \\
\hline OTHER & & & & & -0.010 & 0.008 & -1.250 & 0.210 & & & & \\
\hline \multicolumn{13}{|l|}{$\beta+\gamma_{j}+\delta_{j}$} \\
\hline Lag $<2.8$ yrs & & & & & & & & & 0.038 & 0.006 & 5.910 & 0.000 \\
\hline$(2.8,4.9]$ & & & & & & & & & 0.038 & 0.007 & 5.610 & 0.000 \\
\hline $94.9,7.7]$ & & & & & & & & & 0.028 & 0.006 & 4.320 & 0.000 \\
\hline Lag $>7.7$ yrs & & & & & & & & & 0.062 & 0.008 & 7.550 & 0.000 \\
\hline$\gamma_{j}$ & & & & & & & & & & & & \\
\hline Lag $<2.8$ yrs & & & & & & & & & 0.000 & NA & NA & NA \\
\hline$(2.8,4.9]$ & & & & & & & & & -0.010 & 0.004 & -2.390 & 0.017 \\
\hline $94.9,7.7]$ & & & & & & & & & -0.013 & 0.004 & -2.840 & 0.004 \\
\hline Lag $>7.7$ yrs & & & & & & & & & -0.020 & 0.006 & -3.280 & 0.001 \\
\hline Year dummies & \multicolumn{4}{|c|}{ Yes } & \multicolumn{4}{|c|}{ Yes } & \multicolumn{4}{|c|}{ Yes } \\
\hline Tech dummies & \multicolumn{4}{|c|}{ Yes } & \multicolumn{4}{|c|}{ Yes } & \multicolumn{4}{|c|}{ Yes } \\
\hline Observations & \multicolumn{4}{|c|}{11536} & \multicolumn{4}{|c|}{11536} & \multicolumn{4}{|c|}{11506} \\
\hline R-Squared & \multicolumn{4}{|c|}{0.0564} & \multicolumn{4}{|c|}{0.051} & \multicolumn{4}{|c|}{0.0476} \\
\hline
\end{tabular}

Note: See footnote 4 for the explanation of the coefficient.

The first panel of Table 24 shows that there is considerable variation across SSOs in the probability of an essential patent being litigated. The difference in litigation probabilities between baseline and SSO patents is largest at ANSI, ATIS, ISO/IEC and OMA, where there is a 12 percentage point or more increase in litigation. This gap is smaller at ETSI, IETF, ITU and the category OTHER. The second panel in Table 24 shows the results for a similar estimate where the characteristic examined was the licensing commitment. For this analysis

the groups are: SSOs, licensing commitment, and disclosure lag), and $\lambda_{\text {year }}$ and $v_{\text {tech }}$ are the year and technological class fixed effects. 
we considered three broad categories (FRAND, RF, and OTHER), ${ }^{83}$ based on the licensing commitment in the patent disclosure. The results show that patents declared under a RF commitment are litigated significantly less often than those in the royalty bearing categories. In particular, the 2.3 percentage point difference in litigation rates between SSO-RF patents and their matched controls is less significant $(\mathrm{p}=0.07)$, and the model rejects the hypothesis that the FRAND and RF patents have the same increase in litigation relative to their respective controls. The result that $\mathrm{RF}$ patents are less likely to be litigated is rather intuitive as there is little incentive to sue if a patent can be freely infringed (though defensive suspension provisions may explain why these patents are still more likely to be litigated than their matched controls).

The last panel in the table examines the correlation between disclosure timing and litigation rates. It emerges that patents with a long lag between patent application and declaration to an SSO have a higher litigation rate (relative to their matched controls) than patents with a shorter lag. If we take litigation as a proxy for patent value, this suggests that longer application-to-disclosure lags are correlated with better patents. An alternative, and perhaps more provocative, interpretation of this finding is that long lags are associated with hold-up, since delays allow time for a standard to diffuse and for implementers to make substantial technology-specific investments. Unfortunately, we cannot evaluate the hold-up hypothesis without better information on standardization dates, implementation and the true essentiality of declared essential patents.

\subsection{Summary}

In this chapter we investigated the litigation of essential patents. The main findings can be summarized as:

Essential patents are more likely to be litigated than non-essential patents: the estimated likelihood of litigation over their whole lifetime is around 16 percent compared to 3 percent for a matched set of patents with otherwise similar characteristics. In other words, their likelihood to get litigated is over five times as high. Most litigation takes place after the patent is disclosed as being essential.

Although in absolute numbers there are more litigation cases for telecommunications standards than any other technology area we studied, the relative litigation rate of telecommunications, 6 percent of all patents, is lower than in LAN technology (14 percent), audiovisual standards (also 14 percent) and security technologies (12 percent).

We also observe differences between companies with different business models. In short, downstream players are less 'ligitative' than upstream players. Essential patents disclosed by universities are very often litigated (as much as 23 percent). After investigating a number of

\footnotetext{
${ }^{83}$ The largest category (FRAND) contained 5,433 patents. The second category was "RF" which includes royalty free commitments and non-assertion covenants, and contains 318 patents. The final category (OTHER) contains all other types of declarations, e.g. licenses offered under specific terms or refusals to license, and contains 358 patents.
} 
actual cases, we saw that each has its own story, and that these patents were often transferred to others owners before they were litigated.

Patents declared under a Royalty Free commitment are litigated significantly less often than those in the royalty bearing categories. This is not unexpected: these owners do not require financial compensation for their patents anyway. ${ }^{84}$

\footnotetext{
${ }^{84}$ One might wonder why these patents are litigated at all. The answer is that we observed all litigations, not only those specifically related to the use of the patent in the context of a standard. It is highly likely that a patent owner makes a royaltyfree commitment for the use of the patent to implement the standard, but requires paid licenses for any other use.
} 